\title{
Remote sensing of land use and carbon losses following tropical deforestation
}

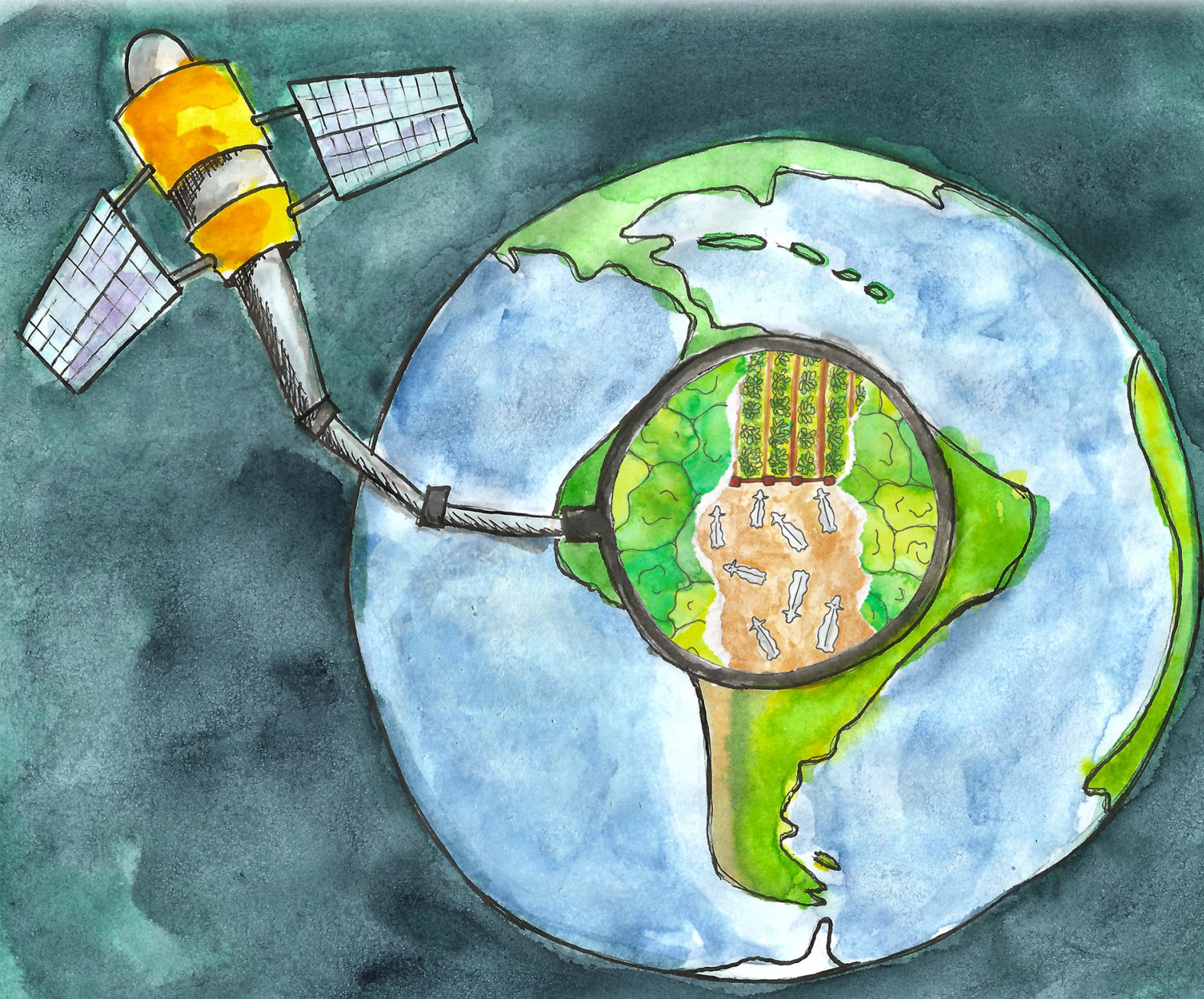

Veronique De Sy 


\section{Remote sensing of land use and carbon losses following tropical deforestation}




\section{Thesis committee}

\section{Promotor}

Prof. Dr M. Herold

Professor of Geo-information Science and Remote Sensing

Wageningen University

\section{Co-promotors}

Dr J.G.P.W. Clevers

Associate professor, Laboratory of Geo-information Science and Remote Sensing Wageningen University

Dr L. Verchot

Research Director, Forests and Environment

Center for International Forestry Research (CIFOR), Bogor, Indonesia

\section{Other members}

Prof. Dr M. van Noordwijk, Wageningen University \& ICRAF, Bogor, Indonesia Dr P. Meyfroidt, Université Catholique de Louvain, Belgium

Dr C. Sannier, SIRS, Villeneuve d'Ascq, France

Dr L. Wollenberg, CCAFS, Burlington, United States of America

This research was conducted under the auspices of the C.T. de Wit Graduate School of Production Ecology \& Resource Conservation (PE\&RC) 


\title{
Remote sensing of land use and carbon losses following tropical deforestation
}

\author{
Veronique De Sy
}

\section{Thesis}

submitted in fulfilment of the requirements for the degree of doctor at Wageningen University by the authority of the Rector Magnificus

Prof. Dr A.P.J. Mol,

in the presence of the Thesis Committee appointed by the Academic Board

to be defended in public

on Friday 17 June 2016

at 11 a.m. in the Aula. 
Veronique De Sy

Remote sensing of land use and carbon losses following tropical deforestation 158 pages.

$\mathrm{PhD}$ thesis, Wageningen University, Wageningen, NL (2016)

With references, with summary in English

ISBN 978-94-6257-803-6

DOI: $10.18174 / 380263$ 


\section{Contents}

Page

$\begin{array}{lll}\text { Chapter } 1 & \text { Introduction } & 3\end{array}$

Chapter 2 Synergies of multiple remote sensing data sources for REDD+ monitoring

Chapter 3 An assessment of deforestation and forest degradation drivers in developing countries

Chapter 4 Land use patterns and related carbon losses following deforestation in South America

Chapter 5 Estimation of carbon emission factors from tropical defor$\begin{array}{ll}\text { estation using remotely-sensed land use and biomass information } & 81\end{array}$

Chapter 6 Synthesis

References

Summary

Acknowledgements

List of publications

Short biography

PE\&RC Training and Education Statement 

Chapter 1

\section{Introduction}




\subsection{Tropical forest change}

Forests have played a major role as source of food, fuel and raw materials throughout human history. When cleared, forests provided land for agriculture and settlements. In addition, forests play an important role in the global carbon cycle, as sinks and storage of carbon, and provide a range of other ecosystem services (e.g. biodiversity, watershed protection). Currently, forests cover about $30.6 \%$ of the earth's land surface (FAO, 2015). Up to the early twentieth century, most deforestation occurred in the temperate forests in Europe, North America and Asia. During the twentieth century, however, deforestation practically came to a halt in these regions but rapidly increased in tropical forests (FAO, 2012). The growing demand for food, fibre and fuel has accelerated the pace of gross forest loss in the tropics and tropical forest change is estimated to have emitted approximately $1.4 \mathrm{Pg} \mathrm{C} \mathrm{yr}^{-1}$ to the atmosphere since the 1990s (Houghton, 2012). Not only does tropical deforestation contribute to greenhouse gas (GHG) emissions, it also destroys an important global carbon sink that is critical in future climate change mitigation.

\subsection{REDD+}

The new Paris Agreement, approved by 195 countries under the auspice of the United Nations Framework Convention on Climate Change (UNFCCC), calls for limiting global warming to "well below" $2^{\circ}$ Celsius. An important part of the climate agreement relates to reducing emissions from deforestation and forest degradation, and enhancing carbon stocks (REDD+) in non-Annex I (mostly developing) countries. In essence, REDD+ can be seen as a set of requirements and guidelines for financially rewarding developing countries for their efforts to reduce carbon emissions and enhance carbon removals related to deforestation and forest degradation.

Reducing emissions from deforestation in developing countries was first discussed in 2005 at the international UNFCCC Conference of Parties (COP), but only started receiving more attention two years later at the 13th $\mathrm{COP}$ in Bali as part of the 'Bali action plan'. At this time five eligible REDD+ activities were specified: (i) reducing emissions from deforestation; (ii) reducing emissions from forest degradation; (iii) conservation of forest carbon stocks; (iv) sustainable management of forests; and (v) enhancement of forest carbon stocks. In the following years more methodological guidance and decisions relating to REDD+ were negotiated at the COPs. An important step was reached at the 15th COP in Warsaw in 2013, where the Warsaw framework on REDD+ was adopted which provides an overall and near 
complete framework for REDD+ implementation.

Within the REDD+ framework, countries are encouraged to design and implement national REDD+ policies and measures. National capacity for implementing REDD+ should be built up in phases: (i) an initial 'readiness' phase to begin the development of national strategies or action plans, policies and measures, and capacity-building; (ii) followed by REDD+ implementation, further capacitybuilding, technology development and transfer, and the start of results-based demonstration activities; and (iii) evolving into results-based actions that should be fully measured, reported and verified (UNFCCC, 2010). The UNFCCC also calls on countries to identify and address drivers of deforestation and forest degradation in order to ensure effective REDD+ policies and measures (UNFCCC, 2009b).

Currently, more than 40 countries are developing national REDD+ strategies and policies, and hundreds of REDD+ projects have been initiated across the tropics (Angelsen and Brockhaus, 2009). A large part of the readiness efforts have focused on capacity building for national forest monitoring and MRV, since these systems are essential for the success of REDD+.

\subsection{Drivers of tropical forest change}

For decades the common view was that growing populations of shifting cultivators and smallholders were the main driver of forest changes. More recently, agricultural production for domestic urban growth and agricultural exports to other countries became the primary drivers of tropical deforestation, with the impact of smallholders decreasing (DeFries et al., 2010). In particular in the Amazon region and Southeast Asia, agribusinesses (cattle ranching, soybean farming and oil palm plantations) were identified as main drivers of post-1990 deforestation (Rudel et al., 2009; Boucher et al., 2011). However, tropical deforestation and degradation in Africa remains dominated by small-scale processes (DeFries et al., 2010; Fisher, 2010). Economic growth based on the export of primary commodities and increasing demand for timber and agricultural products in a globalizing economy are identified as main underlying drivers of deforestation and degradation across the pan-tropics (Rademaekers et al., 2010). Population growth and population density are closely interrelated with increased demand for agricultural land, pressures on fuel wood, easier access to remote forests due to infrastructure development, land tenure arrangements, agro-technological change and increased demand for forest products (Rademaekers et al., 2010). Poor governance, corruption, low capacity of public forestry agencies, land tenure uncertainties, and inadequate natural resource planning 
and monitoring can be important underlying factors of deforestation and degradation as well, especially regarding the enforcement of forest policies and combatting illegal logging (Rademaekers et al., 2010).

In the REDD+ debate the term 'driver' is used broadly, but for analysis, assessment and intervention strategies it is important to separate proximate/direct causes and underlying/indirect causes of deforestation and forest degradation (Geist and Lambin, 2001). Proximate causes are human activities or immediate actions that directly impact forest cover and loss of carbon. These causes can be grouped into categories such as agriculture expansion (both commercial and subsistence), infrastructure extension and wood extraction. Underlying causes are complex interactions of fundamental social, economic, political, cultural and technological processes that are often distant from their area of impact. These underpin the proximate causes and either operate at the local level or have an indirect impact from the national or global level. They are related to international (i.e. markets, commodity prices), national (i.e. population growth, domestic markets, national policies, governance) and local circumstances (i.e. change in household behaviour) (Geist and Lambin, 2001, 2002; Obersteiner et al., 2009).

Although agricultural expansion has been identified as the key driver of deforestation in the tropics (Kaimowitz and Angelsen, 1998; Chomitz, 2007; Gibbs et al., 2010), drivers vary regionally and change over time (Rudel et al., 2009; Boucher et al., 2011). Assessment of direct and indirect drivers and their interaction on the national level are just starting to emerge and are often generic and incomplete (Kissinger et al., 2012). Analyses of drivers have largely been based on local or regional case studies (Geist and Lambin, 2002) or on coarser assessments on the continental and global scales (DeFries et al., 2010; Rademaekers et al., 2010) with less focus on the national level.

\subsection{Monitoring of tropical forests and land use change}

\subsubsection{REDD+ MRV}

For REDD + activities to be effective, accurate and robust methodologies to estimate emissions from deforestation and forest degradation are crucial (UNFCCC, 2009b,a). Therefore, a national monitoring, reporting and verification (MRV) system is required which follows the international Good Practice Guidelines (GPG) of the 
intergovernmental Panel on Climate Change (IPCC) (Grassi et al., 2008; UNFCCC, 2009b; GOFC-GOLD, 2014). Measuring forest carbon emissions on the national level involves estimating and monitoring changes in two key variables: (i) area of deforestation and degradation (activity data); and (ii) terrestrial carbon stock densities per unit area (emission factors) (IPCC, 2006). Finally, national MRV should follow the reporting principles of the UNFCCC that include transparency, consistency, comparability, completeness and accuracy (Grassi et al., 2008).

The IPCC identifies three different approaches to estimate activity data (Penman et al., 2003). In Approach 1 the total area of forest area change is identified without accounting for conversions between forest and other land uses, while Approach 2 does involve tracking these forest-land use conversions in a non-spatially explicit manner. Approach 3 consists of sampling or wall-to-wall mapping techniques to derive spatially explicit land use conversion information (GOFC-GOLD, 2014). Carbon stock information on the various forest carbon pools can be obtained at different Tier levels according to the IPCC guidelines (Penman et al., 2003). Tier 1 uses default IPCC values (i.e. per ecological zone), while Tier 2 uses more country-specific carbon stock data. In Tier 3 more disaggregated data of carbon stocks in different pools are available from national inventories, through repeated measurements and supported by modelling. Spatially explicit data on carbon stock is valuable due to the large variation in forest biomass relating to environmental (slope, soil type, etc.) and anthropogenic factors (management practices, land use history, etc.) (Gibbs et al., 2007). Country or region specific carbon stock data are traditionally derived from forest field-inventories, which are valuable but often limited in geographic representativeness (Houghton, 2005; Gibbs et al., 2007; Asner, 2009; Saatchi et al., 2011a).

Remote sensing is commonly considered an essential REDD+ observation tool (Herold and Johns, 2007) and in combination with ground measurements it provides an objective, practical and cost-effective solution for developing and maintaining REDD+ MRV systems (Achard et al., 2007; DeFries et al., 2007; Herold and Johns, 2007; Hansen et al., 2008a; UNFCCC, 2010). Forest degradation is a more complex matter as it comprises a variety of degradation processes (fire, selective logging, etc.) with different effects on forest carbon and requiring different indicators to be monitored using field and remote sensing methods (Herold et al., 2011). The remote sensing monitoring objective for REDD+ is not only to map deforestation, but also to support policy formulation and implementation. The long-term viability of REDD+ depends on altering business-as-usual activities in sectors currently driving emissions from forests. Consequently, identifying land use, land-use change and forestry activities in REDD+ countries, in particular those that are linked to 
the drivers of deforestation and forest degradation, is an essential component of a REDD+ strategy.

\subsubsection{Monitoring drivers of tropical forest change}

Monitoring and provision of robust information on drivers and the related activities that lead to deforestation and forest degradation provide an essential data stream for countries in their REDD+ strategy and policy design and its implementation (Herold and Skutsch, 2011). Identifying forest change drivers (locally, nationally, internationally) is needed for several reasons: to help track their activities over time, to attribute emissions to specific causes, to design dedicated mitigation actions that address them, and to assess the impact of these.

Linking forest area changes to specific activities and follow-up land use is essential for assessing drivers and their impact for a particular location. Information useful for assessing which drivers are present in particular locations and to attribute land use change to specific activities and drivers can come from remote sensing analysis (GOFC-GOLD, 2011). The size of deforestation clearings, for example, is a strong indicator and discriminator between commercial vs. subsistence agricultural expansion as a deforestation driver. Size can be determined from analysis of deforestation polygons mapped with common satellite sensors (DeFries et al., 2007). In addition, the spatial context and location (such as shape, distance to settlements and previous forest change, location of concessions) and the presence or absence of other features such as new roads and infrastructure can help in the interpretation to better understand the causes of change. Remote sensing time series analysis can also provide information on land use following deforestation, for example row crops or pasture, which helps to assess the commodities driving deforestation. Spatial assessments are important to capture the space-time complexity of drivers to track their impacts over time and to support region-specific strategies to reduce emissions.

Besides assessing the role of drivers in terms of deforestation area it is also important for national REDD+ policy development to assess GHG emissions from different drivers. Attribution and estimation of GHG emissions associated with different drivers have commonly not been performed on the national level. The majority of countries have limited capacities for carbon stock assessment so data on carbon stocks and emission estimation are often not available (Romijn et al., 2012).

Underlying causes of forest change such as international markets, trade policies, technological change and population growth, are not readily detectable using 
remote sensing and ground data, and rely more on economic and social indicators, data sources and trend analysis (Kissinger et al., 2012). However, the link between data about deforestation patterns and underlying causes are important for developing reference (emission) levels where understanding of which drivers are important is essential in order to take national circumstances into account and construct plausible future scenarios that may deviate from historical trends (Herold et al., 2012). However, there are difficulties to establish clear links between underlying factors and deforestation/degradation patterns (Angelsen, 2008). Proximate causes of deforestation and forest degradation are often easier to monitor and to quantify, because they relate more to specific deforestation and degradation events on the ground.

\subsection{Problem statement and research objectives}

Most tropical developing countries have a limited capacity for monitoring forest area change and carbon stocks (Romijn et al., 2012). Currently not a single developing country has implemented a national MRV system for emissions from deforestation and forest degradation (Asner, 2011), although some non-annex I countries have forest area change monitoring systems (e.g. Brazil for the Amazon region ${ }^{1}$, India $^{2}$ ). Challenges and barriers for establishing a national forest monitoring system range from technical to scientific and from institutional to operational level (Asner, 2011).

In addition, the need for data on drivers and activities causing forest carbon change have been highlighted as central components in REDD+ readiness efforts (UNFCCC, 2010). Monitoring drivers (e.g. deforestation by agricultural expansion, fuelwood extraction, etc.) for REDD+ puts an emphasis on monitoring and tracking human activities, where remote sensing has an important role. Different activities and drivers will need different methods for monitoring (GOFC-GOLD, 2014). For example, large scale deforestation can be monitored by Landsat-type (30m resolution) satellite imagery, while selective logging will likely require finer resolution optical imagery or LiDAR (Light Detection and Ranging) data (DeFries et al., 2006; Herold et al., 2011). Thus, MRV design is dependent on the drivers and processes of deforestation and forest degradation within a country and as such is also linked to REDD + strategies and policies. Despite this important role, quantitative national-level information on these drivers and processes, and the related carbon emissions, is scarce.

\footnotetext{
${ }^{1}$ INPE 2010. Monitoramento da Floresta Amazônica basileira por Satelite, Projecto PRODES.

${ }^{2}$ FSI 2011. India state of forest report 2011 (www.fsi.nic.in).
} 
There is progress being made regarding several gaps (e.g. data, remote sensing methodologies, capacity building) and approaches are being put forward to manage the challenges associated with monitoring tropical forests for REDD+ (Maniatis and Mollicone, 2010; Grainger and Obersteiner, 2011; Herold and Skutsch, 2011; Bucki et al., 2012; Law et al., 2012). However, many gaps still remain (e.g. Romijn et al. 2012) and knowledge about and experience with the availability, potentials and limitations of various remote sensing data sources and methods for forest monitoring for REDD+ is scattered among researchers and practitioners.

The main objective of this thesis is to explore the role of remote sensing for monitoring tropical forests for REDD+ in general, and for assessing land use and related carbon emissions linked to drivers of tropical deforestation in particular. To achieve this, this thesis investigates the following research questions:

A What is the current role and potential of remote sensing technologies and methodologies for monitoring tropical forests for REDD+ and for assessing drivers of deforestation?

$\mathrm{B}$ What is the current state of knowledge on drivers of deforestation and degradation in REDD+ countries?

C What are land use patterns and related carbon emissions following deforestation, capitalising on available land use and biomass remote sensing data?

\subsection{Thesis outline}

This thesis consists of four main chapters, each addressing one or more of the research questions presented in Section 1.5.

Chapter 2 reviews the availability, potential and limitations of different remote sensing data sources for REDD+ forest monitoring with a focus on synergies among various approaches and it provides recommendations on how to improve the role of remote sensing for implementing REDD+.

Chapter 3 provides an assessment of proximate drivers of deforestation and forest degradation by synthesizing empirical data reported by countries as part of their REDD+ readiness activities, national communications and scientific literature. In addition, in this chapter the relative importance and patterns of different deforestation and forest degradation drivers are assessed to study driver variability in space and time. 
Chapter 4 presents an assessment of land use patterns following deforestation and related carbon losses in South America at continental and national scales using a comprehensive, systematic remote sensing analysis.

Chapter 5 capitalised on newly available remote sensing information on land use following deforestation (Chapter 4), above-ground live biomass density and tree cover at similar spatial resolutions. This chapter explores how to combine these datasets to improve carbon emission factor estimates by using spatially and temporally consistent high resolution remote sensing datasets, and by incorporating the carbon stock of the land use following deforestation.

Chapter 6 presents the main conclusions of this thesis and discusses the results with respect to the research questions. Chapter 6 further discusses the implication of these results and provides an outlook for the assessment of drivers of forest change, forest monitoring systems and the broader land use sector. 



\section{Chapter 2}

\section{Synergies of multiple remote sensing data sources for REDD+ monitoring}

This chapter is based on:

De Sy, V., Herold, M., Achard, F., Asner, G.P., Held, A., Kellndorfer, J., Verbesselt, J., 2012. Synergies of multiple remote sensing data sources for REDD+ monitoring. Current Opinion in Environmental Sustainability, 4, 696-706 


\section{Abstract}

Remote sensing technologies can provide objective, practical and cost-effective solutions for developing and maintaining REDD+ monitoring systems. This paper reviews the potential and status of available remote sensing data sources with a focus on different forest information products and synergies among various approaches and evolving technologies. There is significant technical capability of remote sensing technologies but operational usefulness is constrained by lack of consistent and continuous coverage, data availability in developing countries, appropriate methodologies for national-scale use and available capacities in developing countries. Coordinated international efforts, regional cooperation and continued research efforts are essential to further develop national approaches and capacities to fully explore and use the potential remote sensing has to offer for REDD+ forest monitoring. 


\section{$2.1 \quad$ Introduction}

Under the United Nations Framework Convention on Climate Change (UNFCCC), negotiations are in progress to develop a mechanism to reduce emissions from deforestation and forest degradation, and the role of conservation, sustainable management of forests and enhancement of forest carbon stocks in developing countries (REDD+) (Pistorius, 2012; Visseren-Hamakers et al., 2012). Robust data and methodologies for estimating greenhouse gas (GHG) emissions from and removals by forests are crucial for REDD+ (GOFC-GOLD, 2011; Herold and Skutsch, 2011). There is need for establishing national measurement, reporting and verification (MRV) systems in developing countries based on the IPCC Good Practice Guidelines (GPG) (GOFC-GOLD, 2011; Herold and Skutsch, 2011). Measuring forest carbon emissions on the national level involves estimating and monitoring changes in two key variables: (i) area of deforestation and degradation (activity data) and (ii) terrestrial carbon stock densities per unit area (emission factor) (Penman et al., 2003). In addition, the need for data on drivers and activities causing forest carbon change, and consideration of developing country capacities have been highlighted as central components in the development of REDD+ MRV systems (Herold and Skutsch, 2011).

Remote sensing is commonly considered an essential REDD+ observation tool (Herold and Johns, 2007) and in combination with ground measurements it provides an objective, practical and cost-effective solution for developing and maintaining REDD+ MRV systems (Achard et al., 2007; DeFries et al., 2007; Herold and Johns, 2007; Herold and Skutsch, 2011). Types of remote sensing data include optical and thermal, Synthetic Aperture Radar (SAR) and Light Detection And Ranging (LiDAR) data. Remote sensing can provide time-series data in many developing countries with historic forest monitoring gaps and can aid in comparing historic and future forest cover changes with the desired consistency. Given the REDD+ requirements, remote sensing can contribute to several relevant forest information products or services (see Section 'State of the art').

Despite the potential of remote sensing approaches, confusion remains among researchers and practitioners on the suitability of various remote sensing data sources and methods for forest monitoring. The aim of this paper is to review the availability, potential and limitations of different remote sensing data sources for REDD+ forest monitoring with a focus on synergies among various approaches; and to provide recommendations on how to improve the role of remote sensing for implementing REDD+. It is beyond the scope of this paper to discuss specific national REDD+ MRV systems. National REDD+ MRV systems are still in the design phase, and 
the suitability and cost-efficiency of the various remote sensing techniques and approaches will depend on specific national circumstances and capacities.

\subsection{State of the art}

\subsubsection{Monitoring of forest area change}

A remote sensing based national monitoring system of forest area change should measure gains and losses in forest area using the IPCC GPG (Penman et al., 2003). The use of time-series of observations in continuous and consistent manner to obtain accurate results and compare changes in the longer term is central (DeFries et al., 2007; Verbesselt et al., 2010; GOFC-GOLD, 2011). To date, the primary tool for monitoring national-scale forest area change in the tropics is optical medium spatial resolution (10-30 m) data (DeFries et al., 2007; GOFC-GOLD, 2011). Landsat TM and ETM+ satellite data are most commonly used owing to their observation continuity from the 1980s onward and their global free data access policy (Wulder et al., 2011; Hansen and Loveland, 2012), although recent problems with Landsat 5 and 7 create uncertainty about future use. Other relevant data sources are the Advanced Spaceborne Thermal Emission and Reflection Radiometer (ASTER), Système Pour l'Observation de la Terre (SPOT), Indian Remote Sensing Satellite (IRS), Disaster Monitoring Constellation (DMC) and the Chinese-Brazilian resource Satellite (CBERS) which are free for developing countries (Powell et al., 2007). Methodologies are well established (DeFries et al., 2007; Achard et al., 2010) and limitations are more related to long-term continuity of these systems and data availability (wall-to-wall or full coverage, persistent cloudiness and seasonality), country capacities and costs for processing and analysis (Herold and Skutsch, 2011). Operational wall-to-wall systems exist for the Brazil Amazon (PRODES) and India (NFI) (GOFC-GOLD, 2011). Alternatives for wall-to-wall mapping are systematic sampling (Eva et al., 2010; FAO, 2011b) and hotspot analysis (Hansen et al., 2008a; Romijn et al., 2012).

Using multiple sensors in synergy with different spectral, spatial and temporal resolutions can increase cost-efficiency and can resolve issues of limited optical coverage, cloudiness and seasonality. The suitability depends on national circumstances such as cost of data and technical capabilities, clearing size and patterns of deforestation, phenology of forests and overall size of country and forest area (DeFries et al., 2007; Romijn et al., 2012). 
Coarser resolution (250-1000 m) optical data (MODIS, MERIS) are commonly not suitable for determining forest area change in minimum mapping units ( $<1$ ha) required for REDD+ (Morton et al., 2005; Bontemps et al., 2012). However, owing to their higher temporal resolution (daily) and large coverage they have a function in sampling and stratification strategies, hotspot detection and pan-tropical monitoring for consistency among national efforts (Achard et al., 2007, 2010; Wulder et al., 2010; GOFC-GOLD, 2011).

Spaceborne SAR sensors (e.g. ERS1/2 SAR, JERS-1, ENVISAT-ASAR, ALOS PALSAR, Cosmo Skymed SAR) are ideal to compliment optical sensors because of all-weather availability and can provide multi-temporal datasets suitable for tropical forest monitoring at local to regional scales and for early detection of deforestation (Almeida-Filho et al., 2009; Achard et al., 2010; Rahman and Sumantyo, 2010; Walker et al., 2010; GOFC-GOLD, 2011). The combined processing or fusion of SAR and optical data for forest monitoring and land cover assessment has been applied in case studies with promising and accurate results (Erasmi and Twele, 2009; Lehmann et al., 2012).

The use of commercial spaceborne (RapidEye, IKONOS, Quickbird) and airborne fine resolution optical sensors and airborne LiDAR is limited for monitoring forest area change at national scale owing to relatively high costs and limited coverage but it can be useful in subnational hotspot monitoring (see Section 'Subnational hotspot monitoring').

\subsubsection{Near real-time deforestation detection}

The detection of active forest change (hotspots) is important for REDD+ implementation when tracking forest area change that requires immediate response or interventions. Coarse resolution optical sensors (MODIS, MERIS) currently make consistent and frequent measurements over large areas which makes them ideal for identifying locations of rapid change for further analysis with finer spatial resolution data or as an alert system for controlling deforestation (GOFC-GOLD, 2011). The Brazilian institute for Space research (INPE) has an operational near real-time warning system (DETER) to map large deforestation events (>25 ha) in the Amazon using MODIS and CBERS-2 data based on bi-temporal change analysis (Shimabukuro et al., 2006; GOFC-GOLD, 2011). Other near real-time change detection methods utilizing coarse optical satellite data are available in the research domain (Jiang et al., 2010; Verbesselt et al., 2012); including the use of both optical and SAR data (Almeida-Filho et al., 2009). However, further work is needed to evaluate and validate these methods for 
near real-time forest disturbance detection.

\subsubsection{Land use change patterns and tracking of human activities}

Information on land use change patterns and tracking of human activities can generate understanding about proximate causes and drivers of deforestation and forest degradation, which is fundamental for developing REDD+ policies and implementation strategies (Herold and Johns, 2007; Herold and Skutsch, 2011). Remote sensing can help to provide information on the type and intensity of land changes, shape and pattern of deforestation and degradation, and can track forest disturbances and dynamics using time-series. For example, the fate of the deforested land combined with available national datasets (e.g. distance to roads, market accessibility, ...) provides land use transitions and trajectories, corresponding to 'Approach 3' of the IPCC GPG (Penman et al., 2003). Approach 3 involves using spatially explicit land conversion information derived from sampling or wall-to-wall mapping techniques, for the assessment of activity data.

Mapping land use change is more challenging than mapping land cover. However, good results can be expected by using dense and long time-series to assess changes in rate, pattern and shape of deforestation (Hansen et al., 2009; Kennedy et al., 2010). Also, forest activity data obtained by community-based monitoring can be a valuable source of information (Fry, 2011; Larrazábal et al., 2012). The remote sensing survey of the FAO (FAORSS) (FAO, 2011b), a global forest remote sensing survey based on a systematic sampling design, provides information at global to regional scale on deforestation since 1990 and has improved knowledge of drivers and processes of deforestation, afforestation and natural expansion of forests (Gibbs et al., 2010). A number of studies have been done on local scale (Armenteras et al., 2010; Munsi et al., 2012) but national-scale quantitative, spatially explicit information on the drivers of deforestation remains scarce (Stach et al., 2009; Potapov et al., 2012), and thus emphasize a data gap that remote sensing can contribute in filling.

\subsubsection{Forest degradation monitoring}

Common human induced forest degradation activities in the tropics that reduce forest carbon stocks include extraction of forest products for subsistence and local markets, industrial/commercial extraction of forest products (for international markets) or uncontrolled anthropogenic wildfire (see Section 'Monitoring of wildfires and burnt area') (Herold et al., 2011). Many developing countries do not have the data and capacities to provide carbon emission estimates on forest degradation for 
historical periods (Herold et al., 2011). Robust approaches for the use of remote sensing data in degradation mapping are not yet available. The use of remote sensing data for monitoring forest degradation is more complicated and less efficient than for deforestation (Herold and Johns, 2007) and not all types of degradation can be monitored with high certainty (GOFC-GOLD, 2011; Herold et al., 2011).

Different methods are needed to derive activity data and emission factors for different degradation processes depending on the type of degradation, available data, capacities and resources, and the possibilities and limitations of various measurement and monitoring approaches (GOFC-GOLD, 2011; Herold et al., 2011). Commercial extraction is usually associated with substantial canopy damages and changes in infrastructure (roads, log landings), which makes it easier to observe with remote sensing. Wood extraction for local use is often more difficult to monitor with remote sensing as canopy changes tend to be subtle and gradual, and there is less infrastructural change. Local forest inventories and community-based monitoring are therefore valuable tools to monitor this type of degradation in terms of activity data and emission factors (Skutsch et al., 2011).

Activity data of forest degradation can be assessed with direct or indirect remote sensing approaches (GOFC-GOLD, 2011). Medium to fine spatial resolution optical, SAR or LiDAR sensors are needed (Asner et al., 2005; Matricardi et al., 2005; Souza et al., 2005a,b; Mollicone et al., 2007; Matricardi et al., 2010; Herold et al., 2011) to directly observe canopy damage, small clearings and structural forest changes. Often forest degradation is a more gradual process than deforestation and requires longer and dense time-series of observations (Huang et al., 2010; Kennedy et al., 2010). Frequent monitoring (annual to inter-annual) is necessary because the optical signature of the degradation (closing of canopy gaps) often disappears within 1-2 years (Souza et al., 2005a; Herold et al., 2011). The indirect approach focuses on observing human infrastructures associated with extraction of forest products. It has been successful in identifying degraded forest areas (Asner et al., 2005; Potapov et al., 2008) over longer periods with less frequent observations but lower quality than the direct approach.

Emission factors or changes in forest carbon stocks owing to degradation are usually measured through forest field sampling and forest inventories (Herold et al., 2011) but repeated in situ measurements of degradation emission factors are scarce. There is increasing evidence that spaceborne SAR and particularly airborne LiDAR can measure changes in forest carbon resulting from forest degradation (Asner et al., 2010; Trisasongko, 2010; Asner et al., 2011b; Mascaro et al., 2011; Ryan et al., 2012). Although progress has been made, current remote sensing methodologies are not 
considered mature enough for operational implementation at national scales (Hansen and Loveland, 2012), although subnational jurisdictional scales such as political states and departments are becoming increasingly tractable (Asner, 2011).

\subsubsection{Monitoring of wildfires and burnt area}

Biomass burning represents a direct and significant emission source of carbon and other trace gasses (e.g. methane) in tropical and subtropical regions. Monitoring carbon emissions from biomass burning entails 3 categories: detection of active fires, mapping post-fire burnt areas (fire scars and regeneration) and fire characterization (e.g. fire severity, energy released) (Lentile et al., 2006; Herold et al., 2011).

Active fire products are available in near real-time and multi-year global active fire data are generated using thermal infrared bands from coarse spatial resolution sensors such as AVHRR, Along Track Scanning Radiometer (ATSR), MODIS or from the Geostationary Satellite system (GOES) (Justice et al., 2002; Xu et al., 2010). Active fire data sets are useful for assessing fire history and effectiveness of REDD + related fire management activities (GOFC-GOLD, 2011) but are less relevant for estimating emissions.

Several satellite-derived multi-year global burnt area datasets have been developed from coarse resolution optical sensors such as AVHRR, MODIS, ATSR-2 and SPOT-VGT (Justice et al., 2002; Simon et al., 2004; Plummer et al., 2005; Giglio et al., 2009, 2010). These datasets can be used in combination with biogeochemical or fuel load models to estimate emissions (Schultz et al., 2008; van der Werf et al., 2009, 2010). The current burnt area products may not provide enough spatial resolution for compiling detailed emission inventories on national level but they can be integrated with finer resolution data (GOFC-GOLD, 2011).

An alternative to using burnt area models (indirect approach) is to directly measure the energy released by actively burning fires (fire characterization), using mid-infrared and thermal wavelengths, from which the total biomass consumed can be derived (Ichoku and Kaufman, 2005; Smith and Wooster, 2005). However, this approach requires fine spatial and temporal resolutions to get accurate results, consequently the method is still in the research phase and not yet operationally viable for REDD+ monitoring (GOFC-GOLD, 2011). 


\subsubsection{Biomass mapping}

Forest carbon densities are traditionally assessed using field-based inventories, which are valuable but expensive, time-consuming and inherently limited in geographic representativeness (Houghton, 2005; Gibbs et al., 2007; Asner, 2009; Saatchi et al., 2011b). Many developing countries do not have forest inventories of sufficient quality (DeFries et al., 2007; Romijn et al., 2012). It is possible to derive continuous and spatially detailed biomass estimates from remote sensing observations, which can be used in the stratification, analysis and quantitation of carbon stocks and emission factors (Goetz et al., 2009).

Recently two studies developed wall-to-wall pan-tropical benchmark maps from satellite data of forest carbon density at $500 \mathrm{~m}$ (Baccini et al., 2012) and $1 \mathrm{~km}$ resolution (Saatchi et al., 2011b). These coarse resolution data are an important step but cannot estimate carbon stocks of tropical forests for specific countries with the certainty required for REDD+ (Gibbs et al., 2007). Airborne, very fine resolution optical sensors however can measure forest carbon stocks with higher certainty (Gibbs et al., 2007). Airborne LiDAR sensor approaches have been successful in providing fine resolution estimates of forest carbon density for small areas (Asner et al., 2010; Saatchi et al., 2011a), and thus are gaining acceptance among government agencies willing and able to invest in airborne LiDAR systems. A satellite based LiDAR system would provide more global coverage and would greatly extend capabilities to estimate carbon stocks for all forest types (Baccini et al., 2012), but currently there is no satellite with vegetation LiDAR sensors operational (Gibbs et al., 2007). Until then, fine resolution cost-effective mapping of carbon stocks for project-scale and national-scale assessments will rely on an integration of optical satellite imagery and airborne LiDAR samples of forest carbon density (Asner, 2009; Asner et al., 2010). SAR sensors on board several satellites (ERS-1, JERS-1, Envisat, ALOS PALSAR) have been used to quantify forest carbon stocks in relatively young or degraded forests, but will be less useful for mature, higher biomass forests because of signal saturation (Gibbs et al., 2007; Böttcher et al., 2009). However, integration with optical satellite data and selected field measurements produces good results up to 400 tonnes of aboveground biomass per hectare (Lucas and Armston, 2007).

There are currently no standard practices or methods for measuring aboveground forest biomass through remote sensing or field inventory networks at national scales in REDD+ countries. The U.S.D.A. Forest Service Forest Inventory and Analysis (FIA) network enables national-scale biomass estimation following UNFCCC requirements and could be used as a model for implementation of standardized practices in tropical REDD+ countries. Furthermore, multi-sensor synergies among 
optical, radar and LiDAR technologies are rapidly overcoming the limitations of individual sensors, and the range of spatial, thematic and temporal information thus achieved can be used to augment and enhance plot-scale estimates of forest biomass and carbon stocks (Goetz et al., 2009). Moreover, new developments in compliance-ready REDD+ MRV at the lower jurisdictional scales of states, provinces, and departments show that a combination of tactical field plots and remote sensing can be implemented in a cost-effective manner to make carbon emissions monitoring a reality (Asner et al., 2011a, 2012). In any event, accurate biomass field data remain crucial to calibrate and improve the accuracy of biomass maps. Integrating remote sensing and in situ data for this purpose is an active and urgent research topic (Avitabile et al., 2011).

\subsubsection{Subnational hotspot monitoring}

The intensity of forest changes and REDD + implementation activities or projects varies within countries and not all areas need to be monitored with the same level of detail and accuracy. In fact, specific areas of active change or dedicated REDD+ implementation activities should be monitored with more precision and accuracy. For example, limitations of finer spatial resolution sensors are the high costs, technical complexity and relatively small coverage (Böttcher et al., 2009). Especially in countries where monitoring capacities are low it can be more efficient and pragmatic to dedicate major monitoring efforts on subnational hotspots, in particular to cover more challenging issues such as GHG emissions from forest degradation or GHG removals from sustainable management of forests (Herold and Skutsch, 2011). A national stratification by human activities affecting forest carbon can integrate the subnational monitoring into the national system, but a clear understanding of drivers and processes affecting carbon stock within a country is necessary (Herold and Skutsch, 2011). Stratification can be done by identifying locations of rapid and large deforestation using national monitoring of forest and land use change with coarse to medium resolution optical sensors or expert knowledge to be analysed with satellite (e.g. IKONOS, QUICKBIRD, TerraSAR-X, Cosmo Skymed) or airborne fine resolution optical, SAR or LiDAR sensors (Hansen et al., 2008a; Broich et al., 2011). Furthermore, fine resolution sensors and subnational hotspot analysis can provide verification and accuracy assessment of coarser resolution analysis, training data to calibrate algorithms and a link to ground based measurements (e.g. forest inventories) and national estimation approaches (DeFries et al., 2007; GOFC-GOLD, 2011). 


\subsubsection{Forest type mapping}

Forest type maps provide spatially explicit information on native, primary, secondary forests, plantations and tree species that can be useful for stratification purposes, estimating biomass, forest planning and biodiversity monitoring. The spectral and spatial resolution of most spaceborne optical sensors is not sufficient to differentiate consistently between forest types (GOFC-GOLD, 2011). However, fine resolution optical imagery can distinguish forest types based on spectral response or textural measures (e.g. regular spacing of plantation trees). Accuracies can be enhanced by using inter-annual multi-temporal data (seasonal dynamics) (Boyd and Danson, 2005) or longer time-series (plantation cycles) (GOFC-GOLD, 2011). Fine spatial resolution radar and LiDAR sensors can identify forest types based on vegetation structure (Balzter, 2001; Dassot et al., 2011). Airborne hyperspectral sensors and the synergy of LiDAR and optical data, where structural and spectral information is combined, show most promise (Koch, 2010; GOFC-GOLD, 2011). The heterogeneity of forest types in the tropics makes mapping more difficult in comparison with temperate regions. So far, there are no standardized methods or classification schemes for tropical forest types (Sánchez-Azofeifa et al., 2009).

\subsection{Synthesis and recommendations}

\subsubsection{Technical capabilities of remote sensing sensors}

Remote sensing technologies are constantly evolving in terms of available satellite and airborne sensors, analysis methods, and experiences to use them for specific applications such as REDD+. Consequently, there is a challenge to keep track of the utility of different sensors suitable for REDD+ needs. Table 2.1 gives a synthesis of the technical capabilities of different remote sensing sources to contribute to the generation of REDD+ information products. It is obvious that remote sensing has, in general, great capabilities for contributing to the REDD+ monitoring process but not one sensor type alone can provide all the information necessary to monitor forests. It is rather a range of sensors that are needed to provide data streams for the different forest change information products.

\subsubsection{Operational capabilities of remote sensing sensors}

Despite the technical capabilities (Table 2.1), there are constraints which limit the operational use of various remote sensing data for REDD + monitoring in developing 
Table 2.1: Technical capabilities of remote sensing sensors for the generation of (national) REDD + information products (black = very suitable, dark grey $=$ suitable, grey $=$ contributing and light grey $=$ limited to no technical capabilities)

\begin{tabular}{|c|c|c|c|c|c|c|c|}
\hline \multirow{3}{*}{$\begin{array}{l}\text { Forest } \\
\text { information } \\
\text { product }\end{array}$} & \multicolumn{7}{|c|}{ Sensor type } \\
\hline & \multicolumn{3}{|c|}{ Optical/thermal } & \multicolumn{2}{|c|}{ Radar/SAR } & \multicolumn{2}{|c|}{ LiDAR } \\
\hline & Coarse & Medium & Fine & Medium & Fine & Satellite $^{\mathrm{a}}$ & Airborne $^{\mathrm{b}}$ \\
\hline $\begin{array}{l}\text { Forest area change } \\
\text { monitoring }\end{array}$ & & & & & & & \\
\hline $\begin{array}{l}\text { Near real-time } \\
\text { deforestation } \\
\text { detection }\end{array}$ & & & & & & & \\
\hline $\begin{array}{l}\text { Land use change } \\
\text { patterns and tracking } \\
\text { of human activities }\end{array}$ & & & & & & & \\
\hline $\begin{array}{l}\text { Forest degradation } \\
\text { monitoring }\end{array}$ & & & & & & & \\
\hline $\begin{array}{l}\text { Monitoring of } \\
\text { wildfires and burnt } \\
\text { areas }\end{array}$ & & & & & & & \\
\hline Biomass mapping & & & & & & & \\
\hline $\begin{array}{l}\text { Sub-national hotspot } \\
\text { monitoring }\end{array}$ & & & & & & & \\
\hline Forest type mapping & & & & & & & \\
\hline
\end{tabular}

${ }^{a}$ Large footprint

b Small footprint

A footprint is defined as the ground instantaneous field-of-view, which is a measure of the ground area viewed by a single detector element in a given instant in time.

countries. Having a satellite acquiring data is not enough to assume that the data are always accessible and useful for developing countries. Observations should be continuous (time-series) and ideally providing global coverage. In addition, raw observation data should be operationally processed to image datasets suitable for analysis, and the capacities in developing countries should be available to sustainably produce and use remote sensing products. Table 2.2 gives an overview of the status of these 3 requirements for the different sensor types. There are still significant operational constraints to be bridged, especially regarding the affordability and availability of standard fine resolution optical, SAR and LiDAR data. There are a multitude of sensors available but limitations exist in making the existing data available for REDD+ 
purposes. This emphasises the need for international coordination and cooperation between space agencies and implementation institutes to ensure global coverage and processing of tropical forests with different types of data, better access for developing countries to time-series archives and current adequate quality data at reasonable costs, and the need to build capacities in REDD+ countries.

\subsubsection{Status of remote sensing use for REDD+ monitoring}

The potential usefulness and suitability of many of the mentioned remote sensing data sources (Tables 2.1 and 2.2) for REDD+ monitoring can be judged by the maturity of approaches depending on whether they are mainly research subjects or are actively used by developing countries (Table 2.3). Commonly, remote sensing research starts from local project level studies, and if suitable moves towards larger area demonstrations or even global level analysis. Table 2.3 emphasizes the variability in operational level. Monitoring forest area change is most mature while approaches for mapping forest types or biomass are not yet used by many developing countries. This highlights, for some information products, the need to invest in fundamental research and move from small case studies to large area demonstrations. For others the need is to synthesize the experiences from research towards the use in developing countries. Often the appropriate and suitable methodology for generating forest information products is dependent on national circumstances (data costs and availability, technical capabilities, size of forest area, drivers), which makes further research on country level essential to determine national data needs and monitoring strategies. Regional and international coordinated effort is necessary to provide technical guidance on best practices and develop and validate appropriate methods for different country circumstances.

Most developing countries have to deal with a rather large capacity gap regarding national forest monitoring for REDD+ (Romijn et al., 2012) and remote sensing is currently only sparsely used by developing countries for their national monitoring (Tables 2.2 and 2.3). So, technology transfer and capacity building are an important aspect of the REDD+ process; not only for the international community but there also is an important role for remote sensing related regional cooperation (sharing capacities and costs) and South-South cooperation.

\subsubsection{Synergies of different data sources}

Methodologies for REDD+ MRV systems should preferably be as simple and straightforward as possible and if, for example, one single observation data source allows the 
Table 2.2: Operational availability of different remote sensing data sources for REDD+ (black $=$ very good, dark grey $=$ good, grey $=$ some and light grey $=$ limited to no availability)

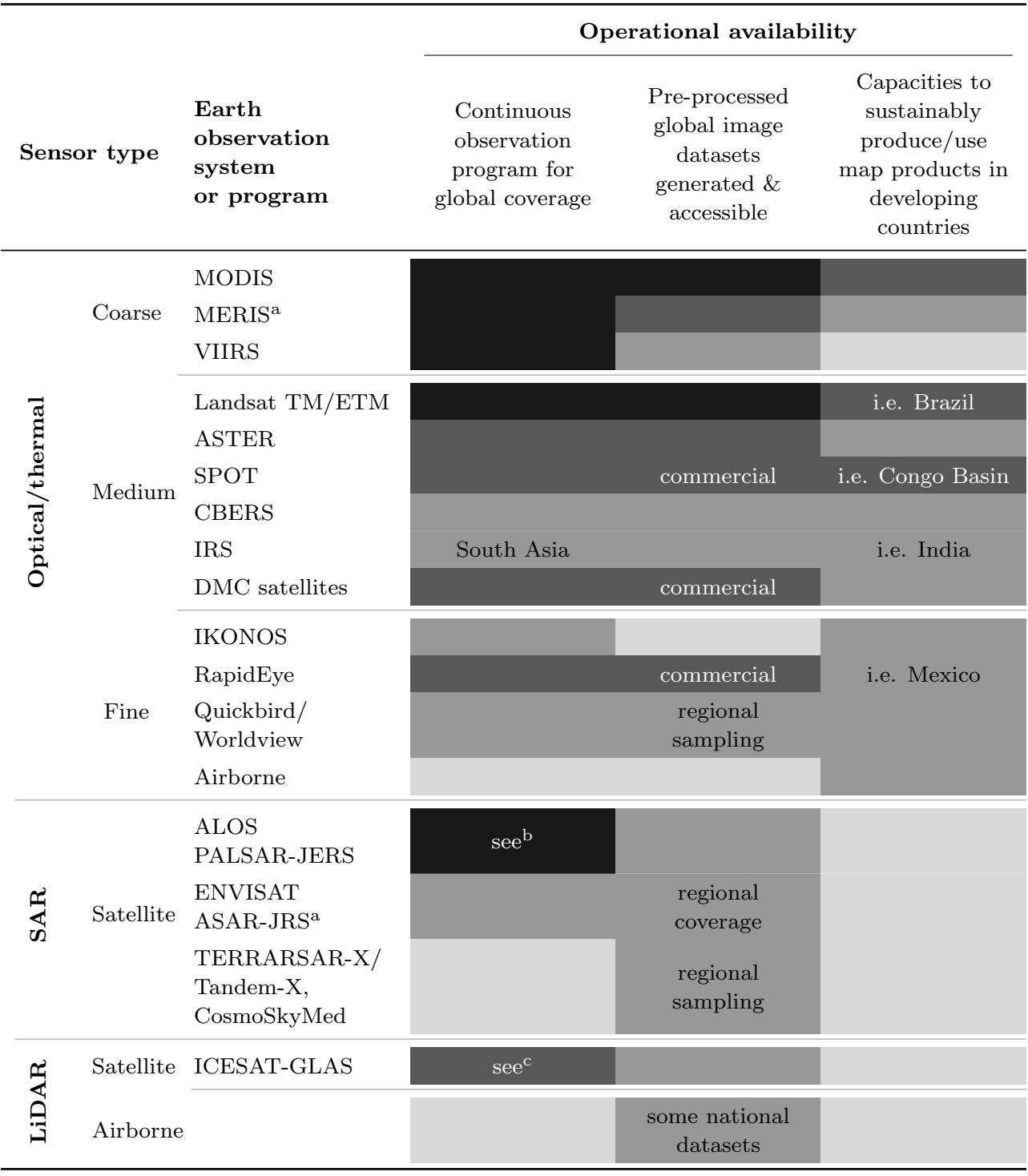

\footnotetext{
${ }^{\text {a }}$ ENVISAT acquisitions have ceased as of 8 April 2012.

b if ALOS-2 launches in 2012 to replace the failed ALOS-1

c if ICESAT-2 launches in 2016 to replace ICESAT-1
} 
Table 2.3: Operational level of forest information products in REDD + context (black = high, dark grey $=$ intermediate, grey $=$ low and light grey $=$ limited to no operationality)

\begin{tabular}{|c|c|c|c|}
\hline \multirow{2}{*}{$\begin{array}{l}\text { Forest } \\
\text { information } \\
\text { product }\end{array}$} & \multicolumn{3}{|c|}{ Operational level } \\
\hline & $\begin{array}{l}\text { Local pilot and } \\
\text { research studies }\end{array}$ & $\begin{array}{l}\text { Large area research } \\
\text { demonstrations }\end{array}$ & $\begin{array}{c}\text { Operational use at } \\
\text { national level }\end{array}$ \\
\hline $\begin{array}{l}\text { Forest area change } \\
\text { monitoring }\end{array}$ & & & i.e. Brazil,India \\
\hline $\begin{array}{l}\text { Near real-time deforestation } \\
\text { detection }\end{array}$ & & & only Brazil \\
\hline $\begin{array}{l}\text { Land use change patterns } \\
\text { and tracking of human } \\
\text { activities }\end{array}$ & & & i.e. Indonesia \\
\hline $\begin{array}{l}\text { Forest degradation } \\
\text { monitoring }\end{array}$ & & & \\
\hline $\begin{array}{l}\text { Monitoring of wildfires and } \\
\text { burnt areas }\end{array}$ & & & \\
\hline Biomass mapping & & & \\
\hline $\begin{array}{l}\text { Sub-national hotspot } \\
\text { monitoring }\end{array}$ & & & \\
\hline Forest type mapping & & & \\
\hline
\end{tabular}

derivation of suitable information products then this should be the choice. Using multiple data sources increases complexity of the analysis and can also result in problems with consistency and transparency when using time-series. However, the synergy among multiple sensors with different spectral, spatial and temporal resolutions can be useful to increase cost-efficiency and resolve issues of data coverage, clouds, seasonality, and the trade-off between spatial and temporal resolutions. The potential for key synergies is summarized in Table 2.4. The need for synergies can be driven by regional circumstances (i.e. using optical and SAR time-series in cloudy areas), or can be a more fundamental need especially for assessing biomass, biomass burning, forest degradation and carbon emissions (Eva et al., 2012). In general, the synergetic use of data sources as described in Table 2.4 is subject to research and not operationally applied. The benefits of this synergetic use of data sources need to be balanced against the significant additional capacities and resources required for applying them in developing countries. 
Table 2.4: Key synergy potentials for generating improved forest information products

\begin{tabular}{|c|c|}
\hline $\begin{array}{l}\text { Forest information } \\
\text { product }\end{array}$ & Key synergies in REDD+ context \\
\hline $\begin{array}{l}\text { Forest area change } \\
\text { monitoring }\end{array}$ & Use of optical medium resolution (Landsat) and SAR time-series \\
\hline $\begin{array}{l}\text { Near real-time } \\
\text { deforestation detection }\end{array}$ & $\begin{array}{l}\text { Combining coarse spatial resolution optical data (at high } \\
\text { temporal resolution) with medium spatial resolution optical data } \\
\text { (at moderate temporal resolution) }\end{array}$ \\
\hline $\begin{array}{l}\text { Land use change patterns } \\
\text { and tracking of human } \\
\text { activities }\end{array}$ & $\begin{array}{l}\text { High temporal (coarse optical data) and medium resolution } \\
\text { optical dense time-series data with ancillary datasets }\end{array}$ \\
\hline $\begin{array}{l}\text { Forest degradation } \\
\text { monitoring }\end{array}$ & $\begin{array}{l}\text { Multiple remote sensing sources necessary depending on } \\
\text { processes and activities e.g. commercial versus locally driven } \\
\text { degradation processes }\end{array}$ \\
\hline $\begin{array}{l}\text { Monitoring of wildfires and } \\
\text { burnt areas }\end{array}$ & Use of thermal and optical remote sensing data \\
\hline Biomass mapping & $\begin{array}{l}\text { Combination of LiDAR, SAR and/or optical data with in situ } \\
\text { data }\end{array}$ \\
\hline $\begin{array}{l}\text { Sub-national hotspot } \\
\text { monitoring }\end{array}$ & $\begin{array}{l}\text { Combining optical coarse to medium resolution data with fine } \\
\text { resolution data (optical, SAR and LiDAR) }\end{array}$ \\
\hline Forest type mapping & Optical fine resolution data and LiDAR or SAR \\
\hline
\end{tabular}

\subsubsection{Summary of key messages}

The review in this paper clarifies the potential and status of different available remote sensing approaches for REDD+ monitoring. Remote sensing is an essential component of monitoring forests for REDD+ on different spatial and temporal scales for a number of different information products; including deforestation, reforestation and afforestation, forest degradation, biomass and biomass burning. In summary:

There is technical capability of remote sensing technologies to provide a range of forest information products for REDD+ with different types of sensors useful for various monitoring targets.

There are many suitable remote sensing sensors available but their operational usefulness for REDD+ is often constrained by lack of consistent and continuous coverage and by data availability in developing countries in a suitable format for change analysis. Coordinated international efforts of the remote sensing community and data providers should improve this situation, in particular in the view of future planned satellite missions such as Landsat Data Continuity Mission and Sentinel-2 to 
be launched from 2013. In this way countries have the confidence that investments in building capacity for use of remote sensing forest monitoring will provide long-term benefits under REDD+.

The transition from remote sensing research to more operational generation of information products on the national level requires additional efforts including more dedicated demonstration activities, the development of best practice guidelines, and the need to work closely with developing countries.

Particular research efforts are needed to further develop and consolidate appropriate approaches for different national circumstances, including the exploration of synergies among different data sources and for integration of remote sensing and ground data for emissions estimation.

Remote sensing capacities do exist in developing countries and technological transfer and capacity development as part of South-South and regional cooperation need to be further developed.

\subsection{Acknowledgements}

The authors gratefully acknowledge the support of NORAD (Grant Agreement \#QZA-10/0468) and AusAID (Grant Agreement \#46167) for the CIFOR Global Comparative Study on REDD+. We thank the European Space Agency (ESA) for supporting GOFC-GOLD and the related project office www.gofcgold. wur.nl. 



\section{Chapter 3}

\section{An assessment of deforestation and forest degradation drivers in developing countries}

This chapter is based on:

Hosonuma, N., Herold, M., De Sy, V., De Fries, R.S., Brockhaus, M., Verchot, L., Angelsen, A., Romijn, E., 2012. An assessment of deforestation and forest degradation drivers in developing countries. Environmental Research Letters, \%, 044009 


\section{Abstract}

Countries are encouraged to identify drivers of deforestation and forest degradation in the development of national strategies and action plans for REDD+. In this letter we provide an assessment of proximate drivers of deforestation and forest degradation by synthesizing empirical data reported by countries as part of their REDD+ readiness activities, CIFOR country profiles, UNFCCC national communications and scientific literature. Based on deforestation rate and remaining forest cover 100 (sub)tropical non-Annex I countries were grouped into four forest transition phases. Driver data of 46 countries were summarized for each phase and by continent, and were used as a proxy to estimate drivers for the countries with missing data. The deforestation drivers are similar in Africa and Asia, while degradation drivers are more similar in Latin America and Asia. Commercial agriculture is the most important driver of deforestation, followed by subsistence agriculture. Timber extraction and logging drives most of the degradation, followed by fuelwood collection and charcoal production, uncontrolled fire and livestock grazing. The results reflect the most up to date and comprehensive overview of current national-level data availability on drivers, which is expected to improve over time within the frame of the UNFCCC REDD+ process. 


\subsection{Introduction}

Understanding drivers of deforestation and degradation is fundamental for the development of policies and measures that aim to alter current trends in forest activities toward a more climate and biodiversity friendly outcome. Parties to the United Nations Framework Convention on Climate Change (UNFCCC) are developing a mechanism for reducing emissions from deforestation and forest degradation, enhancing forest carbon stocks, sustainable management and conservation of forests (REDD+) in developing non-Annex I countries (UNFCCC, 2010). In addition to the discussion on policy incentives and modalities for measurements, reporting and verification (MRV), the issue of identifying drivers and activities causing forest carbon change on the national level for REDD + monitoring and implementation has received increasing attention in the REDD+ debate (Benndorf et al., 2007; UNFCCC, 2010). The UNFCCC negotiations (UNFCCC, 2009b, 2010) have encouraged developing countries to identify land use, land use change and forestry activities, in particular those that are linked to the drivers of deforestation and forest degradation, and to assess their potential contribution to the mitigation of climate change. Understanding is needed for assessing not only how much forests are changing but also how to define proper policies, and national REDD+ strategies and implementation plans (Boucher, 2011; Rudorff et al., 2011). Projections of expected developments, such as required for setting forest reference levels (UNFCCC, 2011), need to be based on knowledge of context-specific drivers or activities and their underlying causes, and perhaps should be considered separately for deforestation and degradation processes (Huettner et al., 2009). Thus, in addition to the fundamental importance of national data on forest area change and associated changes in forest carbon stocks to estimate emissions and removals, the need for national data on type and relative importance of deforestation and degradation drivers is rising to an almost equal level of relevance to support national REDD+ activities.

Despite this relevance, quantitative national-level information on drivers and activities causing deforestation and forest degradation are widely unknown. For example, the question of how much or what fraction of deforestation (emissions) in a country is caused by a specific driver (i.e. expansion of agriculture versus infrastructure) cannot be answered for many developing countries. Scientific research in the past (Geist and Lambin, 2001) has mainly been based on local-scale studies or regional to global assessments (DeFries et al., 2010; Boucher et al., 2011). They have highlighted the importance of differentiating between proximate or direct drivers and underlying or indirect causes. Proximate or direct drivers of deforestation are human activities that directly affect the loss of forests and 


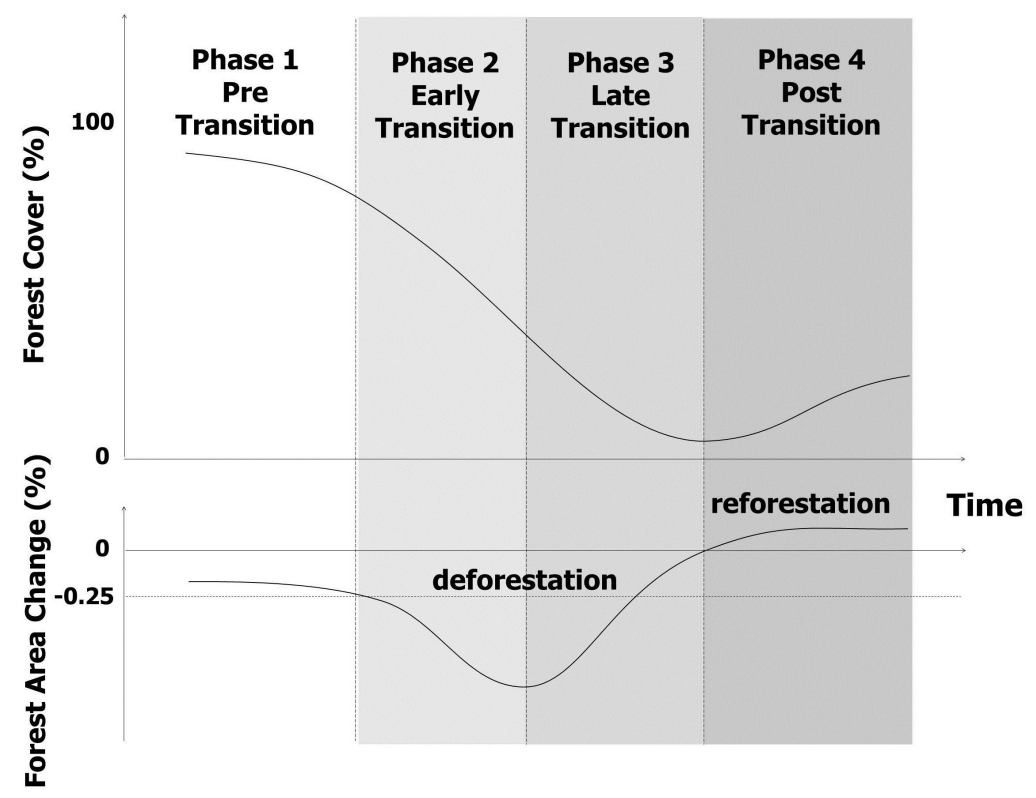

Figure 3.1: Four phases of the FT model as applied in this study.

thus constitute proximate sources of change, that result from complex interactions of underlying forces in social, political, economic, technological and cultural domains (Geist and Lambin, 2001). Direct drivers can be grouped into different categories such as agriculture expansion, expansion of infrastructure and wood extraction (Geist and Lambin, 2001). Although agricultural expansion has been determined as the key driver of deforestation in the tropics (Gibbs et al., 2010), drivers vary regionally and change over time (Rudel et al., 2009; Boucher et al., 2011).

The forest transition (FT) model identifies characteristic, human-induced changes and varying drivers of forest cover dynamics over time at the national scale (Rudel et al., 2005; Lambin and Meyfroidt, 2010). Mather (1992) introduced the FT concept to explain the transition from decreasing to expanding forest cover that has taken place in many developed countries. The model has subsequently been tested in several developing countries (Rudel et al., 2005; Kauppi et al., 2006) and it was found that forest cover at the national level followed an inverse J-shaped curve over time, based on empirical observation (Figure 3.1). Mustard et al. (2004) and DeFries et al. (2004) expanded the concept to incorporate the intensification of agriculture and urbanization that generally occurs in the course of economic development and accompanies the forest transition. 
Given the current gap in knowledge and understanding of drivers on national, regional and global levels, the research presented in this letter aims to provide an assessment of proximate drivers of deforestation and forest degradation by synthesizing empirical data from tropical and sub-tropical developing (non-Annex I) countries. While national data on proximate drivers have commonly not been available in the past, the recent efforts for REDD+ readiness, and national REDD+ plan and strategy development, have generated new information provided by countries. For example, all countries participating in the World Bank Forest Carbon Partnership Facility (FCPF, 2011) are asked to develop readiness plan proposals that include an assessment on deforestation and degradation drivers. Similar efforts are ongoing as part of the UN-REDD program (www.un-redd.org) and some research projects. Based on this information, the research efforts presented here follow two objectives.

1. Derive and, as far as possible, quantify deforestation and degradation drivers from existing national REDD+ reports and studies.

2. Assess the relative importance and patterns of different deforestation and forest degradation drivers reflecting approximately the period 2000-2010, to study driver variability in space (by continent) and time (using the FT model).

The results provide the first comprehensive and comparative assessment of drivers on the national level and provide input to the ongoing UNFCCC REDD+ negotiations, where the issue and importance of drivers is still subject to considerable debate (UNFCCC, 2010).

\subsection{Data and methodology}

\subsubsection{The forest transition model}

All 100 non-Annex I countries in this study were grouped into four FT phases (Figure 3.1) based on two factors: percent forest cover and rate of forest area change. The four FT phases are pre-transition, early transition, late transition and post-transition, which generally represent a time sequence of national development. Pre-transition countries have high forest cover and low deforestation rates. In early-transition countries, forest cover is lost at an increasingly rapid rate. Late-transition countries with a rather small fraction of remaining forests exhibit a slowing of the deforestation rate and eventually come into the post-transition phase, where the forest area change 


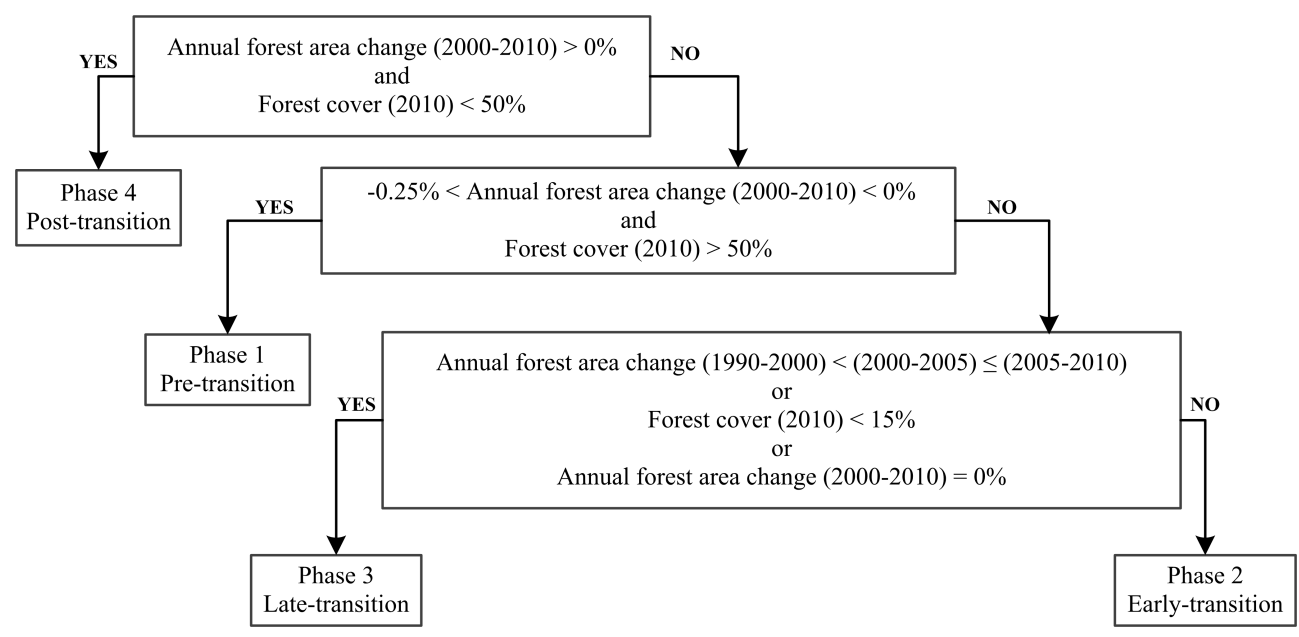

Figure 3.2: Decision tree for FT categorization.

rate becomes positive and forest cover increases through reforestation. The FT model reflects a broad-scale typology of tropical developing countries, applicable as a proxy for analyzing the temporal variability of drivers of deforestation and forest degradation.

In general, our methodology followed the one described by da Fonseca et al. (2007), where developing countries were stratified into four categories based on remaining forest cover and deforestation rate. A decision tree (Figure 3.2) was developed for categorizing all 100 countries into four FT phases using the percentage forest cover of 2010 and forest area change rates based on the 2010 Global Forest Resources Assessment (FRA) by FAO (FAO, 2010). Forest area change rates were calculated based on the amount of annual forest change relative to forest cover in 1990 for four periods: 1990-2000, 2000-05, 2005-10 and 2000-10. An annual forest area change rate of $0.25 \%$ was used to separate between pre- and early-transition countries as this is the annual average of 2005-10 for our study area. A forest area change rate of $0 \%$ and forest cover of $15 \%$ and $50 \%$ were selected as additional thresholds.

\subsubsection{Definitions and types of drivers}

The definition of drivers of deforestation and forest degradation in the REDD+ debate are often not clear. In scientific literature, there is a common separation of proximate/direct or underlying/indirect causes. It is often more difficult to establish clear 
links between underlying (or predisposing) factors and deforestation than between direct causes and deforestation. In this study, we will analyze data on the proximate or direct drivers, i.e. human activities that directly affect the loss of forests, and use the term 'driver' to indicate proximate drivers. This choice is based on available data and the way countries are reporting data on drivers.

The drivers are considered separately for deforestation and forest degradation. Deforestation in this letter denotes the (complete) removal of trees and the conversion from forest into other land uses such as agriculture, mining etc, with the assumption that forest vegetation is not expected to naturally regrow in that area. Forest degradation denotes thinning of the canopy and loss of carbon in remaining forests, where damage is not associated with a change in land use and where, if not hindered, the forest is expected to regrow. In some specific cases multiple proximate drivers work in combination, i.e. forest clearing for timber followed by land use change for agriculture. In this case and to avoid double counting, the land use change (to agriculture) has been identified as the primary cause of deforestation. Five deforestation drivers (Table 3.1) and four forest degradation drivers (Table 3.2) were considered in this study. We use these broad categories to provide a set of driver types for comparative analysis that allow for the variation in detail and quality of information reported by countries.

\subsubsection{Data sources and analysis of drivers}

Since countries have not been obliged to report on drivers, there are no comprehensive, recent and quantitative assessment data available concerning drivers of deforestation and forest degradation on a national level. Thus, this study builds upon new and useful REDD + readiness related data sources to help fill this gap including 26 Readiness Preparation Proposals (R-PP) and ten Readiness Plan Idea Notes (R-PIN) prepared for the World Bank Forest Carbon Partnership Facility (FCPF, 2011) by hosting countries. It is important to note that these data are basically self-reported by countries and they were taken on board independent of what these reports are based on. As another source of data, Matthews et al. (2010) describe proximate drivers of deforestation throughout history for 25 tropical countries by reviewing existing literature and data. In addition, we used several CIFOR country profiles (http://www.forestclimatechange.org/) that include driver and activity information for deforestation and forest degradation, and UNFCCC National Communications and other reports that have recently become available. Most of these data sources were developed between 2008 and 2011 and reflect more or less the period of 2005-2010 or 2000-2010 when the report has time series data. In total, driver data were available for 46 of the 100 (sub)tropical non-Annex I countries 
Table 3.1: Categories of deforestation drivers.

\begin{tabular}{ll}
\hline Category & \\
\hline Agriculture (commercial) & - Forest clearing for cropland, pasture and tree plantations \\
& • For both international and domestic markets \\
& - Usually large to medium scale \\
Agriculture (subsistence) & - For subsistence agriculture \\
& - Includes both permanent subsistence and shifting cultivation \\
& - Usually by (local) smallholders \\
Mining & All types of surface mining \\
Infrastructure & Roads, railroads, pipelines, hydroelectric dams \\
Urban expansion & Settlement expansion \\
\hline
\end{tabular}

Table 3.2: Categories of forest degradation drivers.

\begin{tabular}{ll}
\hline Category & \\
\hline Timber/logging & - Selective logging \\
& • For both commercial and subsistence use \\
& - Includes both legal and illegal logging \\
Uncontrolled fires & Includes all types of wildfire \\
Livestock grazing in forest & On both large and small scales \\
Fuelwood/charcoal & - Fuelwood collection \\
& - Charcoal production \\
& - For both domestic and local markets \\
\hline
\end{tabular}

Table 3.3: Availability of national datasets per continent and FT phase (dark gray, no national datasets available; light gray, limited national datasets available $(\leq 2)$ ).

\begin{tabular}{lccc}
\hline & \multicolumn{3}{c}{$\begin{array}{c}\text { Amount of national datasets } \\
\text { available/total datasets }\end{array}$} \\
\cline { 2 - 4 } Forest transition phase & Africa & America & Asia \\
\hline Pre-transition & $3 / 3$ & $4 / 6$ & $0 / 4$ \\
Early transition & $10 / 19$ & $6 / 11$ & $6 / 9$ \\
Late transition & $4 / 18$ & $5 / 9$ & $3 / 6$ \\
Post-transition & $0 / 6$ & $2 / 4$ & $3 / 5$ \\
\hline
\end{tabular}


(Appendix 3.A). These 46 countries account for $78 \%$ of the total forest area (in 2010 ), and $81 \%$ of forest loss (in 2000-2010) of the 100 countries under consideration, according to 2010 FAO FRA data (FAO, 2010), and cover a range of FT phases in each continent (Table 3.3). However, for some continent-FT phase combinations there are no or limited data available, namely for post-transition countries in Africa and Latin America and pre-transition countries in Asia.

The different data sources were analyzed and summarized to provide the current 'best' estimate of the relative importances of different drivers. First, all data were categorized given the driver categories listed in Tables 3.1 and 3.2. The relative importance of a driver within a country is reported in different formats in the different sources, either as a ratio scale (quantitative information), an ordinal scale (ranking) or a nominal scale (listing). The aim was to get as much quantitative information as possible about the relative importance of deforestation and forest degradation drivers as a national fraction (e.g., commercial agriculture was at $40 \%$ the most important cause of deforestation on the national level). Table 3.4 shows how different data scales were processed to allow for comparison. Depending on the scale of the source data, the same approach was used for all countries to ensure consistency. When ratio-scale data were available, this value was directly used. Ordinal data were quantified by assigning ratios (e.g. 3:2:1) in order of decreasing importance and assuming an equal interval. In the case of more than one dominant driver, the estimation procedure was adapted accordingly with the same weight for drivers reported as equally important (see example in Table 3.4). For nominal-scale data the values for attributing ratios were assumed equal. In cases where multiple and different-scale data sources exist for a country we prioritized the most quantitative data, so ratio data were preferred over ordinal data and ordinal data over nominal data. When multiple but same-scale data sources were available for a country, the average values were used. As shown in Table 3.4, countries with the highest quality ratio-scale data reflect $47 \%$ of the total forest loss (of 100 countries) and ordinal-scale data are available for countries responsible for $20 \%$ of the total forest loss. Although 19 countries have only nominal-scale data, these countries tend to be smaller in size and with lower contributions to forest loss (14\% of total forest loss).

\subsubsection{Estimations for countries without driver data}

The country driver data were aggregated for different continents and FT phases and also analyzed in that context (see Sections 3.3.2 and 3.3.3). The aggregation by continents and forest transition phases can be used as suitable proxies to describe the country circumstances in terms of active deforestation and degradation drivers; 
Table 3.4: Method of quantifying the national fraction of drivers (A, B and C are examples of drivers) with respect to three scales of source data.

\begin{tabular}{|c|c|c|c|c|}
\hline $\begin{array}{l}\text { Scale of } \\
\text { data source }\end{array}$ & Example & Quantification & $\begin{array}{c}\text { No. } \\
\text { countries }\end{array}$ & $\begin{array}{l}\text { Total forest loss } \\
\text { for } 100 \text { countries } \\
(\text { FAO, 2010) }(\%)\end{array}$ \\
\hline $\begin{array}{l}\text { Ratio scale } \\
\text { (quantity) }\end{array}$ & $\begin{array}{l}\text { Drivers } A=60 \% \\
B=C=20 \%\end{array}$ & $\begin{array}{l}A=60 \% \\
B=C=20 \%\end{array}$ & 12 & 47 \\
\hline \multirow[t]{2}{*}{$\begin{array}{l}\text { Ordinal scale } \\
\text { (ranking) }\end{array}$} & $\begin{array}{l}\text { Drivers } \mathrm{A}>\mathrm{B}>\mathrm{C} \\
\rightarrow \mathrm{A}: \mathrm{B}: \mathrm{C}=3: 2: 1\end{array}$ & $\begin{array}{l}\mathrm{A}=50 \%(3 / 6) \\
\mathrm{B}=33.3 \%(2 / 6) \\
\mathrm{C}=16.7 \%(1 / 6)\end{array}$ & 15 & 20 \\
\hline & $\begin{array}{l}\text { Drivers } \mathrm{A}=\mathrm{B}>\mathrm{C} \\
\rightarrow \mathrm{A}=\mathrm{B}: \mathrm{C}= \\
2: 2: 1\end{array}$ & $\begin{array}{l}\mathrm{A}=40 \%(2 / 5) \\
\mathrm{B}=40 \%(2 / 5) \\
\mathrm{C}=20 \%(1 / 5)\end{array}$ & & \\
\hline $\begin{array}{l}\text { Nominal } \\
\text { scale (listing) }\end{array}$ & $\begin{array}{l}\text { Main drivers are } \\
\mathrm{A}, \mathrm{B} \text { and } \mathrm{C}\end{array}$ & $\begin{array}{l}A=B=C= \\
33.3 \%(1 / 3)\end{array}$ & 19 & 14 \\
\hline
\end{tabular}

Table 3.5: Data availability and data estimation procedures for situations with limited or no driver data using proxy information (see Table 3.6).

\begin{tabular}{|c|c|c|}
\hline $\begin{array}{l}\text { Annotation } \\
\text { in Table } \\
3.6\end{array}$ & Availability driver data & Proxy estimation \\
\hline (no) & $\begin{array}{l}\text { Sufficient driver data: three or more } \\
\text { countries belonging to the same } \\
\text { continent and FT phase exist }\end{array}$ & Driver data are averaged \\
\hline $\mathrm{a}$ & $\begin{array}{l}\text { Few }(<3) \text { countries belonging to the } \\
\text { same continent and FT phase exist } \\
\text { but similar data are available from } \\
\text { countries belonging to the continent } \\
\text { with similar drivers and the same FT } \\
\text { phase }\end{array}$ & $\begin{array}{l}\text { Driver data of these countries and } \\
\text { countries belonging to the continent } \\
\text { with similar drivers and FT phases are } \\
\text { averaged }\end{array}$ \\
\hline $\mathrm{b}$ & $\begin{array}{l}\text { Few }(<3) \text { countries belonging to the } \\
\text { same continent and FT phase exist } \\
\text { and no similar data are available }\end{array}$ & $\begin{array}{l}\text { Driver estimation is based on average } \\
\text { of less than three countries belonging } \\
\text { to the same continent and FT phase }\end{array}$ \\
\hline $\mathrm{c}$ & $\begin{array}{l}\text { No driver data but similar data are } \\
\text { available from countries belonging to } \\
\text { the continent with similar drivers and } \\
\text { the same FT phase }\end{array}$ & $\begin{array}{l}\text { Driver data of countries belonging to } \\
\text { the continent with similar drivers and } \\
\text { FT phases are averaged }\end{array}$ \\
\hline d & $\begin{array}{l}\text { No driver data and no similar data } \\
\text { available }\end{array}$ & $\begin{array}{l}\text { Driver data for countries with the } \\
\text { same FT phase of all continents are } \\
\text { averaged }\end{array}$ \\
\hline
\end{tabular}


i.e., it can be assumed that a country (without current data on drivers) will have a similar situation to other countries on the same continent and the same FT phase where empirical data are available. Thus, building upon the continent and FT model proxies, the study has derived estimates for situations where currently limited country data have been reported (see Table 3.3). For situations with sufficient driver data, the driver data were averaged. Table 3.5 explains the data estimation procedures for situations with limited or no driver data using proxy information.

\subsection{Results}

\subsubsection{Categorization of 100 tropical non-Annex I countries into FT phases}

The 100 non-Annex I (sub)tropical countries are categorized into four FT phases (see Appendix 3.A) using the decision tree (Figure 3.2). Exceptions on the decision tree were made for Thailand and Costa Rica. These countries, while just not fulfilling the criteria, clearly belong in the post-transition phase. Of the 100 non-Annex I countries, 13 countries are in the pre-transition phase, 39 in early transition, 33 in late transition and 15 in post-transition. Thus the majority (72) of the 100 countries are either in early or late transition, which are the phases of rapid deforestation. The spatial distribution of FT phases across the (sub)tropics (Figure 3.3) shows that many pre-transition countries in Africa and America are located around the equator, surrounded by early-transition countries, and with late-transition countries mostly located in sub-tropical regions.

Forest cover (FAO, 2010) and intact forest area values (Potapov et al., 2008), both for 2005, were averaged for each FT phase for all 100 countries (Figure 3.4). The forest cover transition follows the conceptual framework shown in Figure 3.1. Intact forest area follows a similar FT curve to forest cover but the change in intact forest cover from the late- to post-transition phase remains quite small, suggesting that a large proportion of forests in post-transition countries remains degraded. The difference between forest cover and intact forest area, i.e. the disturbed forest area fraction, is an important indicator of degraded forest area.

\subsubsection{Analysis of drivers for each continent}

The driver data are summarized and analyzed for three continents, Africa, America and Asia (including Oceania) (Figure 3.5(A)). Agriculture is the main driver of 


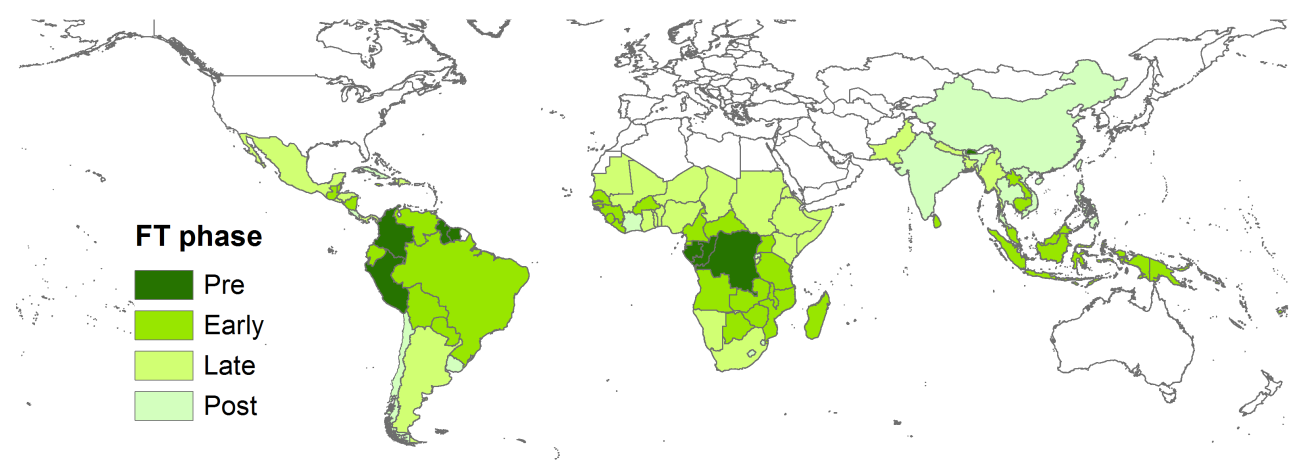

Figure 3.3: Spatial distribution of national FT phases.

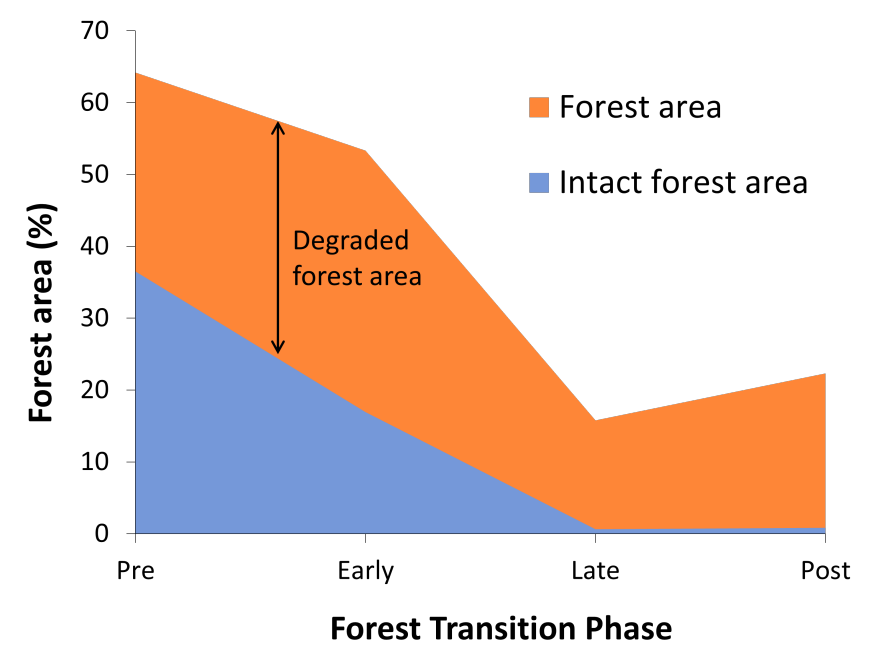

Figure 3.4: Average forest cover (FAO, 2010) and intact forest area in 2005 for each FT phase.

deforestation, but with differences in geographic distribution of the importance of commercial versus subsistence agriculture. Commercial agriculture is the most important driver in Latin America (68\%), while in Africa and Asia it contributes to around $35 \%$ of deforestation. Local and subsistence agriculture is quite equally distributed among the continents (27-40\%), which makes sense since this type of land use (change) remains widespread in all areas in the tropics and sub-tropics. Overall, agriculture reflects around $80 \%$ of deforestation worldwide, which is in line 
with estimates provided by Geist and Lambin (2001) for the 1980s and 1990s. Mining plays a larger role in Africa and Asia than in Latin America. Urban expansion is most significant in Asia. DeFries et al. (2010) state that further urban population growth is expected across the tropics, which will likely be associated with increased pressure on tropical forests.

Timber extraction and logging account for more than $70 \%$ of total degradation in Latin America and Asia (Figure 3.5(C)). Fuelwood collection and charcoal production is the main degradation driver for the African continent, and is of small to moderate importance in Asia and Latin America. Uncontrolled fires are most prominent in Latin America. In terms of absolute net forest area change over the period 2000-10 (Figure 3.5(B)), the largest driver remains commercial agriculture, with the largest deforested area located in Latin America. In Africa and Asia, subsistence and commercial agriculture contribute roughly equally to forest area change.

\subsubsection{Analysis of drivers for each FT phase}

The driver data are summarized and analyzed for four FT phases (Figure 3.6). The relative area contribution of commercial agriculture rises until the late-transition phase, after which it decreases again (Figure 3.6(A)). The relative importance of subsistence agriculture remains fairly stable throughout the different phases, while the relative importance of urban expansion and infrastructure is largest in the post-transition phase. The total area deforested, however, is largest in the early-transition phase and is driven by agriculture expansion (Figure 3.6(B)). This is in line with the FT model, where forest area change rates level off toward the later transition stages, and so total deforested area decreases as well. Intensification of agriculture and urbanization is expected in the course of economic development and decelerating deforestation, that generally accompanies the FT model (DeFries et al., 2004; Mustard et al., 2004). Mining seems to play an important role in deforestation in the pre-transition phase, but this is likely due to the presence of some resource-rich countries with large remaining forest cover in this phase (e.g. Guyana, Democratic Republic of the Congo).

Regarding degradation (Figure 3.6(C)), the relative degraded area caused by timber and logging activities is most pronounced in all phases but decreases in the late-transition phase. In the late-transition phase, fuelwood and charcoal as well as uncontrolled fires are much more prominent. This can be attributed to the fact the forest timber resources maybe largely exploited in the late transition and 


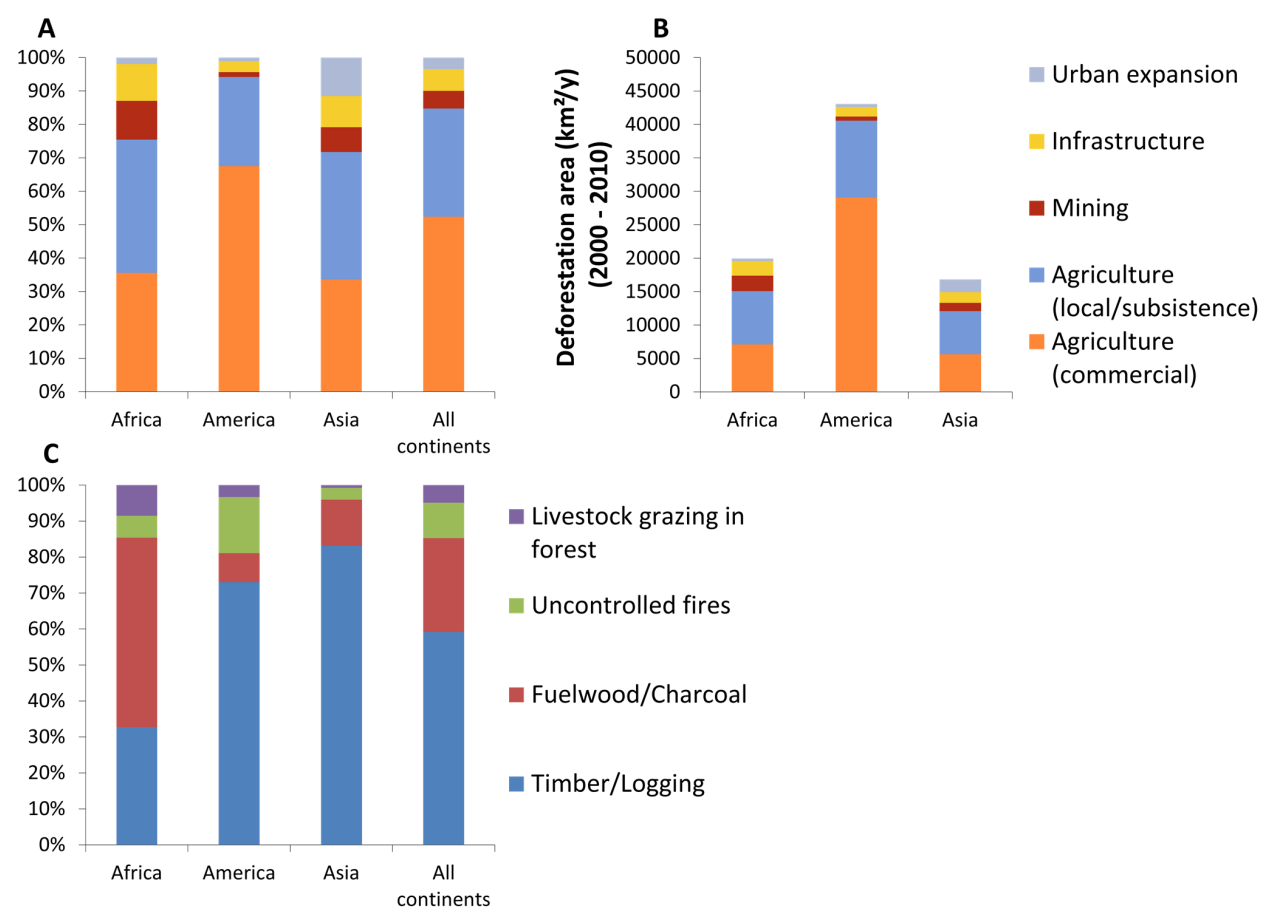

Figure 3.5: Continental-level estimations of the relative area proportion (A) and absolute net forest area change $\left(\mathrm{km}^{2} \mathrm{yr}^{-1}\right.$; (FAO, 2010) for the period 2000-10 (B) of deforestation drivers; and of the relative disturbed forest area fraction of degradation drivers (C), based on data from 46 tropical and sub-tropical countries.

the remaining forest area receives increasing pressure for wood fuel, in particular in many African woodland countries that are in the late-transition phase. In the post-transition phase, economic development will likely cause a decline in fuelwood collection and charcoal production as other energy sources become available, and timber extraction is usually better managed in this phase, which will cause a decline in the prevalence of fires.

\subsubsection{Considerations and estimations for countries without driver data}

Overall, the patterns of deforestation drivers are quite similar in Africa and Asia, while degradation patterns are more similar in Latin America and Asia (Figure 3.5). Building upon this relationship and the usefulness of the continent and FT model 


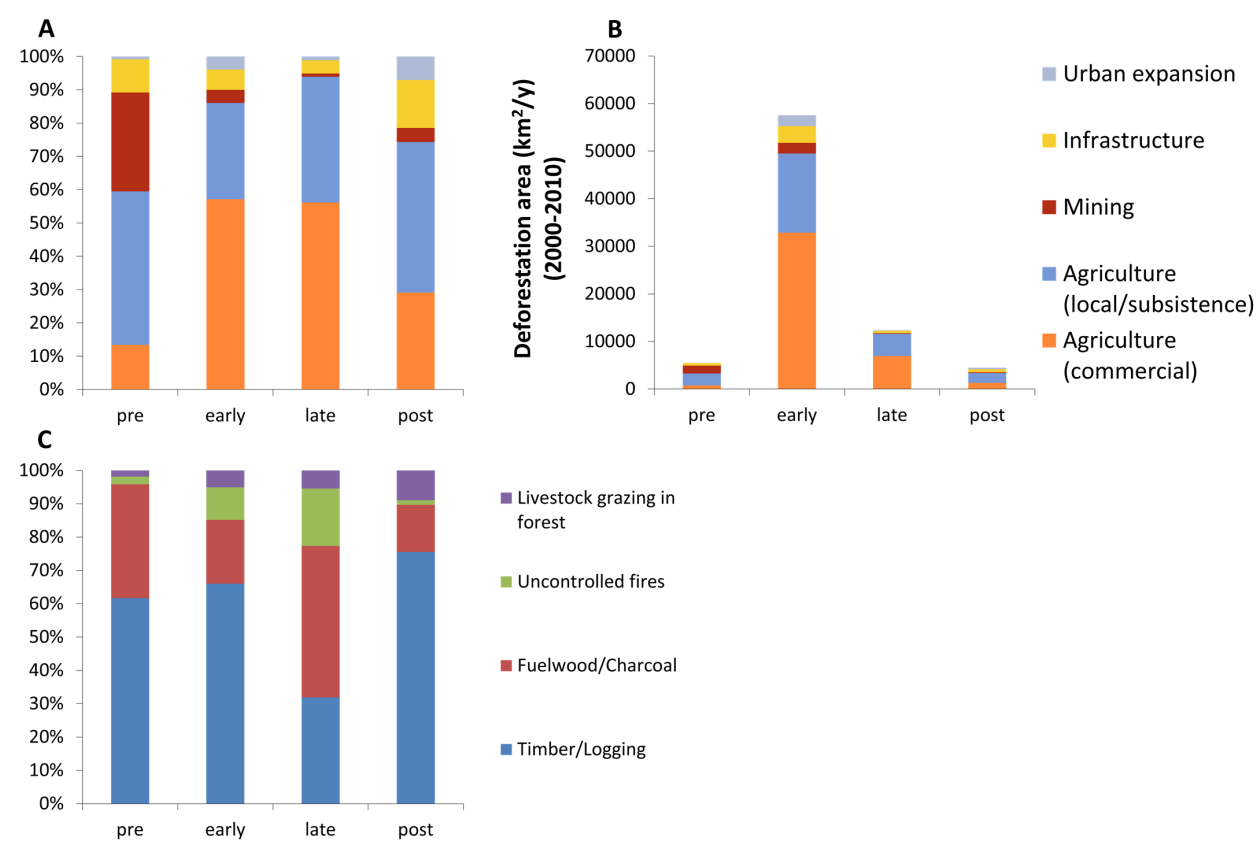

Figure 3.6: Forest transition phase estimations of the relative area proportion (A), and absolute net forest area change $\left(\mathrm{km}^{2} \mathrm{yr}^{-1}\right.$; (FAO, 2010) for the period 2000-10 (B) of deforestation drivers, and of the relative disturbed forest area fraction of degradation drivers (C), based on data from 46 tropical and sub-tropical countries.

proxies, the study has derived estimates for situations where currently limited country data have been reported, in particular for post-transition countries in Africa and Latin America, and the pre-transition countries in Asia. This provides an approach for incorporating all countries and can provide useful best current estimates for global policy development. The aim of the results presented in Table 3.6 is to estimate the importance of deforestation and degradation drivers, based on currently available data, for all 100 countries and thus to provide a pan-tropical assessment. It also highlights some of the remaining data gaps (estimates with an annotation, see Table 3.6) that will be potentially filled as countries progress in the REDD+ readiness phase. Table 3.5 in the methodology section indicates the procedures followed for annotated estimates with no or limited data availability. 


\subsection{Discussion and conclusion}

The study analyzed national data from 46 tropical and sub-tropical countries (reflecting $\sim 78 \%$ of the forest areas, and $81 \%$ of forest loss (in 2000-10) of all 100 tropical and sub-tropical countries, see Appendix 3.A) on drivers of deforestation and forest degradation that have been provided as part of REDD+ readiness documents and activities. Data on the drivers have been derived from national-level data, but, given the variability and different levels of confidence for these data, the analysis presented here uses aggregate averages with FT phases and continents as a proxy. As the need to report on drivers of deforestation and degradation is a new requirement for developing countries, the quality of the country data varies. Thus, the presented results are only based on aggregated data that allow for a pan-tropical assessment of the importance of different drivers, stratified by phases of the forest transition model and by continent.

The results highlight that commercial agriculture is the most prevalent deforestation driver, accounting for $40 \%$ of deforestation and most prominent in the early-transition phase. The other important land use is local/subsistence agriculture, which is related to $33 \%$ of deforestation. Other drivers are of less importance, with mining accounting for $7 \%$, infrastructure for $10 \%$ and urban expansion for $10 \%$ of the total. Thus, according to this study, agriculture alone causes $73 \%$ of all deforestation, which is in line with findings of Geist and Lambin (2002). The importance of deforestation drivers varies for the different FT phases and for different continents. For decades the common view was that growing populations of shifting cultivators and smallholders were the main driver of forest changes. More recently, it has been argued that commercial actors play an increasingly larger role in the expansion of agriculture into the forest (Geist and Lambin, 2002). This seems at least to be valid for the Amazon region and Southeast Asia. Here agribusinesses, producing for international markets (cattle ranching, soybean farming and oil palm plantations), were identified as main drivers of post-1990 deforestation (Rudel et al., 2009; Boucher et al., 2011). Looking at the development of deforestation drivers through time (Figure 3.6) the contribution of commercial agriculture increases. Currently, deforestation in Africa is still largely driven by small-scale subsistence activities (DeFries et al., 2010; Fisher, 2010), but this might change in the coming years. While the four African countries with the largest forest areas (Democratic Republic of the Congo, Angola, Zambia and Mozambique) (FAO, 2011a) are still in the pre- and early-transition phase, forest loss rates and the influence of commercial globalized agriculture are expected to increase, as these countries move to the next phase. 
ธุต

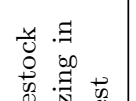

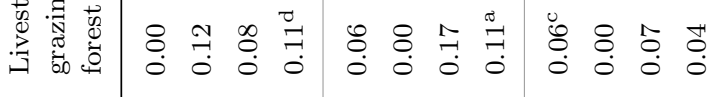

突

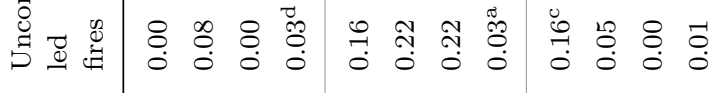

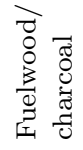

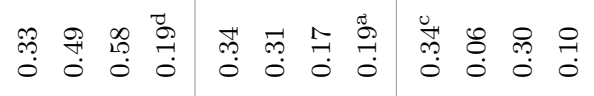

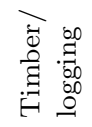

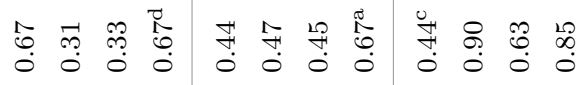

त

ธี

营弯

क्ष

$\overrightarrow{0}$

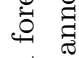

ซี

호 돈

要

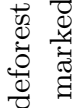

4 诘

궁

苞圷

苨苞

岹.

की

芫

落菏

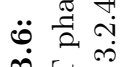

के

告

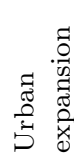

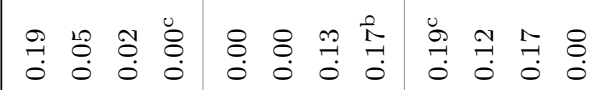

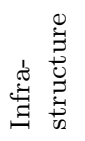

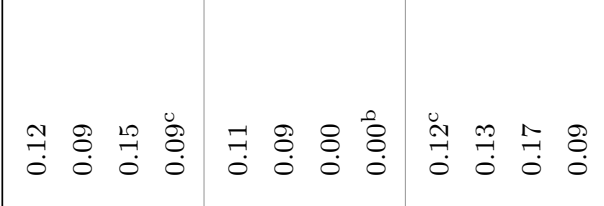

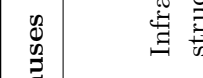

$\stackrel{20}{\Xi}$

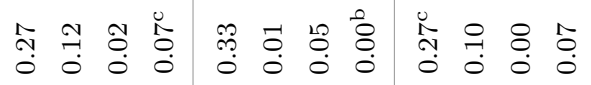

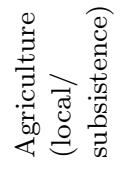

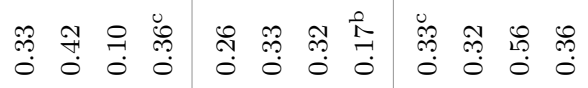

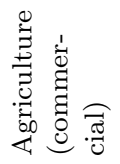

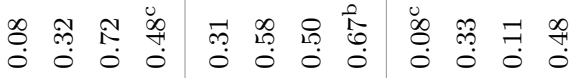

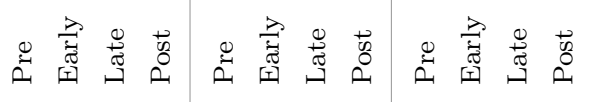
尊

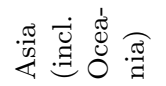


Regarding forest degradation, timber extraction and logging are related to about $52 \%$, fuelwood collection and charcoal production $31 \%$, uncontrolled fire $9 \%$ and livestock grazing $7 \%$ of forest degradation. The most prominent degradation driver for the Latin American and Asian continents is timber extraction and logging $(>70 \%)$. Fuelwood collection and charcoal is the main degradation driver for the African continent (48\%). This emphasizes that local small-scale activities (fuelwood collection, charcoal production and livestock grazing in forests) are the most relevant in large parts of Africa, while in the majority of the other country cases forest degradation is dominated by commercial wood extraction. The importance of the fuelwood/charcoal driver decreases in the post-transition phase. This can be explained by urbanization tied to economic development, and a progressing reliance on other energy resources. Commercial timber and logging activities on the other hand become more important in the post-transition phase.

The results presented here offer a first synthesis of REDD+ driven nationallevel data reported by countries on forest change, supported by data from other sources, to generate new understanding for national estimates of drivers of forest loss and degradation. It highlights that the availability of quantitative data on drivers is variable and still uncertain in many countries' cases, with only 12 of 100 countries being able to provide quantitative data, also highlighting the current limitations and data gaps. This study used national estimates of forest loss based on the FAO Forest Resource Assessment (FAO, 2010). However, other data sources are available, such as the remote sensing based estimates of Hansen et al. (2010), which might divert from the FAO estimates. One avenue of further research is assessing the sensitivity of driver estimation to uncertainties related to these different datasets. In addition, within the REDD + context, the national driver data should ultimately be linked to emissions. In a recent study by Houghton (2012), emission factors are linked to specific drivers, and this can be used as a starting point for further research on national emissions categorized by drivers.

Thus, this study focus on a larger area synthesis and also provided first coarse estimates using the continent and FT model as a proxy in countries where no data have been available so far: mainly to support current global policy synthesis. While the UNFCCC (2010) encourages countries to further identify and describe REDD+ activities and drivers, it is expected that such national data will improve over time. In particular, the increasing use of satellite remote sensing tools for national monitoring will be a key data source that will allow for a better national-level tracking of deforestation and forest degradation events and types, and the activities that cause them (Gibbs et al., 2010; Hansen et al., 2010). 


\subsection{Acknowledgments}

The authors gratefully acknowledge the support of NORAD for the CIFOR Global Comparative Study on REDD, under which parts of this research were carried out. N Hosonuma gratefully acknowledges support from the overseas fellowship for space development by the Ministry of Education, Culture, Sports, Science and Technology (MEXT) in Japan. 


\section{A Appendix}

Table 3.A1: Database of categorization and data sources for 100 tropical non-Annex I countries. (Note. Data sources written in italics were available but not used due to the coarser data scales. R-PIN: a Readiness Plan Idea Note is a report for the REDD+ financing mechanism of the Forest Carbon Partnership Facility (FCPF). R-PP: a Readiness Preparation Proposal is a report which the selected countries have to prepare as a follow up to the R-PIN (http://forestcarbonpartnership.org/fcp/). CIFOR: country profile report focused on socio-economic context of REDD, by Center for International Forestry Research (CIFOR). Matthews et al: country analysis of deforestation and forest degradation drivers by Department of Energy and Climate Change (DECC) of UK government (Matthews et al., 2010). NC: National communication to the UNFCCC.

\begin{tabular}{|c|c|c|c|c|}
\hline Country & Continent & $\begin{array}{l}\text { Forest transition } \\
\text { phase }\end{array}$ & Data source & $\begin{array}{l}\text { Scale of } \\
\text { data source }\end{array}$ \\
\hline Angola & Africa & $\begin{array}{l}\text { Phase } 2 \text { (early } \\
\text { transition) }\end{array}$ & Matthews et al. & Nominal \\
\hline Antigua and Barbuda & America & $\begin{array}{l}\text { Phase } 3 \text { (late } \\
\text { transition) }\end{array}$ & - & - \\
\hline Argentina & America & $\begin{array}{l}\text { Phase } 3 \text { (late } \\
\text { transition) }\end{array}$ & $\begin{array}{l}\text { R-PP } \\
\text { Matthews et al. }\end{array}$ & Ratio \\
\hline Bahamas & America & $\begin{array}{l}\text { Phase } 1 \\
\text { (pre-transition) }\end{array}$ & - & - \\
\hline Bangladesh & Asia & $\begin{array}{l}\text { Phase } 3 \text { (late } \\
\text { transition) }\end{array}$ & - & - \\
\hline Belize & America & $\begin{array}{l}\text { Phase } 2 \text { (early } \\
\text { transition) }\end{array}$ & - & - \\
\hline Benin & Africa & $\begin{array}{l}\text { Phase } 3 \text { (late } \\
\text { transition) }\end{array}$ & - & - \\
\hline Bhutan & Asia & $\begin{array}{l}\text { Phase } 1 \\
\text { (pre-transition) }\end{array}$ & - & - \\
\hline Bolivia & America & $\begin{array}{l}\text { Phase } 2 \text { (early } \\
\text { transition) }\end{array}$ & $\begin{array}{l}\text { R-Pin } \\
\text { CIFOR } \\
\text { (Matthews et } \\
\text { al.) }\end{array}$ & Ratio \\
\hline Botswana & Africa & $\begin{array}{l}\text { Phase } 2 \text { (early } \\
\text { transition) }\end{array}$ & - & - \\
\hline Brazil & America & $\begin{array}{l}\text { Phase } 2 \text { (early } \\
\text { transition) }\end{array}$ & $\begin{array}{l}\text { NC } \\
\text { Mongabay } \\
\text { (Matthews et } \\
\text { al.) CIFOR }\end{array}$ & Ratio \\
\hline Burkina Faso & Africa & $\begin{array}{l}\text { Phase } 2 \text { (early } \\
\text { transition) }\end{array}$ & - & - \\
\hline
\end{tabular}


Table 3.A1 Continued from previous page

\begin{tabular}{|c|c|c|c|c|}
\hline Country & Continent & $\begin{array}{l}\text { Forest transition } \\
\text { phase }\end{array}$ & Data source & $\begin{array}{l}\text { Scale of } \\
\text { data source }\end{array}$ \\
\hline Burundi & Africa & $\begin{array}{l}\text { Phase } 3 \text { (late } \\
\text { transition) }\end{array}$ & - & - \\
\hline Cambodia & Asia & $\begin{array}{l}\text { Phase } 2 \text { (early } \\
\text { transition) }\end{array}$ & $\begin{array}{l}\text { R-PP } \\
\text { Matthews et al. }\end{array}$ & Ordinal \\
\hline Cameroon & Africa & $\begin{array}{l}\text { Phase } 2 \text { (early } \\
\text { transition) }\end{array}$ & $\begin{array}{l}\text { CIFOR } \\
\text { Mongabay } \\
\text { (R-Pin) } \\
\text { (Matthews et } \\
\text { al.) }\end{array}$ & Ratio \\
\hline Cape Verde & Africa & $\begin{array}{l}\text { Phase } 4 \\
\text { (post-transition) }\end{array}$ & - & - \\
\hline $\begin{array}{l}\text { Central African } \\
\text { Republic }\end{array}$ & Africa & $\begin{array}{l}\text { Phase } 2 \text { (early } \\
\text { transition) }\end{array}$ & R-PP & Ordinal \\
\hline Chad & Africa & $\begin{array}{l}\text { Phase } 3 \text { (late } \\
\text { transition) }\end{array}$ & - & - \\
\hline Chile & America & $\begin{array}{l}\text { Phase } 4 \\
\text { (post-transition) }\end{array}$ & R-Pin & Nominal \\
\hline China & Asia & $\begin{array}{l}\text { Phase } 4 \\
\text { (post-transition) }\end{array}$ & - & - \\
\hline Colombia & America & $\begin{array}{l}\text { Phase } 1 \\
\text { (pre-transition) }\end{array}$ & R-PP & Ratio \\
\hline Comoros & Africa & $\begin{array}{l}\text { Phase } 3 \text { (late } \\
\text { transition) }\end{array}$ & - & - \\
\hline Congo & Africa & $\begin{array}{l}\text { Phase } 1 \\
\text { (pre-transition) }\end{array}$ & $\mathrm{R}-\mathrm{PP}$ & Ordinal \\
\hline Costa Rica & America & $\begin{array}{l}\text { Phase } 4 \\
\text { (post-transition) }\end{array}$ & R-PP & Nominal \\
\hline Cote d'Ivoire & Africa & $\begin{array}{l}\text { Phase } 4 \\
\text { (post-transition) }\end{array}$ & - & - \\
\hline Cuba & America & $\begin{array}{l}\text { Phase } 4 \\
\text { (post-transition) }\end{array}$ & - & - \\
\hline $\begin{array}{l}\text { Democratic Republic } \\
\text { of the Congo }\end{array}$ & Africa & $\begin{array}{l}\text { Phase } 1 \\
\text { (pre-transition) }\end{array}$ & $\begin{array}{l}\text { R-PP } \\
\text { Matthews et al. }\end{array}$ & Ordinal \\
\hline Dominica & America & $\begin{array}{l}\text { Phase } 3 \text { (late } \\
\text { transition) }\end{array}$ & - & - \\
\hline Dominican Republic & America & $\begin{array}{l}\text { Phase } 3 \text { (late } \\
\text { transition) }\end{array}$ & - & - \\
\hline Ecuador & America & $\begin{array}{l}\text { Phase } 2 \text { (early } \\
\text { transition) }\end{array}$ & Matthews et al. & Nominal \\
\hline El Salvador & America & $\begin{array}{l}\text { Phase } 3 \text { (late } \\
\text { transition) }\end{array}$ & R-Pin & Ordinal \\
\hline Equatorial Guinea & Africa & $\begin{array}{l}\text { Phase } 2 \text { (early } \\
\text { transition) }\end{array}$ & R-Pin & Ordinal \\
\hline
\end{tabular}


Table 3.A1 Continued from previous page

\begin{tabular}{|c|c|c|c|c|}
\hline Country & Continent & $\begin{array}{l}\text { Forest transition } \\
\text { phase }\end{array}$ & Data source & $\begin{array}{l}\text { Scale of } \\
\text { data source }\end{array}$ \\
\hline Eritrea & Africa & $\begin{array}{l}\text { Phase } 3 \text { (late } \\
\text { transition) }\end{array}$ & - & - \\
\hline Ethiopia & Africa & $\begin{array}{l}\text { Phase } 3 \text { (late } \\
\text { transition) }\end{array}$ & $\begin{array}{l}\text { R-PP } \\
\text { Matthews et al. }\end{array}$ & Nominal \\
\hline Fiji & Asia & $\begin{array}{l}\text { Phase } 2 \text { (early } \\
\text { transition) }\end{array}$ & $\begin{array}{l}\text { Carbon } \\
\text { Partnership }\end{array}$ & Ordinal \\
\hline Gabon & Africa & $\begin{array}{l}\text { Phase } 1 \\
\text { (pre-transition) }\end{array}$ & $\begin{array}{l}\text { R-PP } \\
\text { (Matthews et } \\
\text { al.) }\end{array}$ & Nominal \\
\hline Gambia & Africa & $\begin{array}{l}\text { Phase } 4 \\
\text { (post-transition) }\end{array}$ & - & - \\
\hline Ghana & Africa & $\begin{array}{l}\text { Phase } 3 \text { (late } \\
\text { transition) }\end{array}$ & $\mathrm{R}-\mathrm{PP}$ & Ratio \\
\hline Guatemala & America & $\begin{array}{l}\text { Phase } 2 \text { (early } \\
\text { transition) }\end{array}$ & R-PP & Nominal \\
\hline Guinea & Africa & $\begin{array}{l}\text { Phase } 2 \text { (early } \\
\text { transition) }\end{array}$ & - & - \\
\hline Guinea-Bissau & Africa & $\begin{array}{l}\text { Phase } 2 \text { (early } \\
\text { transition) }\end{array}$ & - & - \\
\hline Guyana & America & $\begin{array}{l}\text { Phase } 1 \\
\text { (pre-transition) }\end{array}$ & $\begin{array}{l}\text { R-PP Interim } \\
\text { Report }\end{array}$ & Ratio \\
\hline Haiti & America & $\begin{array}{l}\text { Phase } 3 \text { (late } \\
\text { transition) }\end{array}$ & - & - \\
\hline Honduras & America & $\begin{array}{l}\text { Phase } 3 \text { (late } \\
\text { transition) }\end{array}$ & R-Pin & Nominal \\
\hline India & Asia & $\begin{array}{l}\text { Phase } 4 \\
\text { (post-transition) }\end{array}$ & - & - \\
\hline Indonesia & Asia & $\begin{array}{l}\text { Phase } 2 \text { (early } \\
\text { transition) }\end{array}$ & $\begin{array}{l}\text { CIFOR } \\
\text { R-PP } \\
\text { NC (Mongabay) } \\
\text { (Matthews et } \\
\text { al.) }\end{array}$ & Ratio \\
\hline Jamaica & America & $\begin{array}{l}\text { Phase } 2 \text { (early } \\
\text { transition) }\end{array}$ & - & - \\
\hline Kenya & Africa & $\begin{array}{l}\text { Phase } 3 \text { (late } \\
\text { transition) }\end{array}$ & R-PP & Nominal \\
\hline Lesotho & Africa & $\begin{array}{l}\text { Phase } 4 \\
\text { (post-transition) }\end{array}$ & - & - \\
\hline $\begin{array}{l}\text { Lao People's } \\
\text { Democratic Republic }\end{array}$ & Asia & $\begin{array}{l}\text { Phase } 2 \text { (early } \\
\text { transition) }\end{array}$ & $\begin{array}{l}\text { R-PP } \\
\text { Matthews et al. }\end{array}$ & Nominal \\
\hline Liberia & Africa & $\begin{array}{l}\text { Phase } 2 \text { (early } \\
\text { transition) }\end{array}$ & $\mathrm{R}-\mathrm{PP}$ & Ordinal \\
\hline Madagascar & Africa & $\begin{array}{l}\text { Phase } 2 \text { (early } \\
\text { transition) }\end{array}$ & $\begin{array}{l}\text { R-PP } \\
\text { Matthews et al. }\end{array}$ & Nominal \\
\hline
\end{tabular}


Table 3.A1 Continued from previous page

\begin{tabular}{|c|c|c|c|c|}
\hline Country & Continent & $\begin{array}{l}\text { Forest transition } \\
\text { phase }\end{array}$ & Data source & $\begin{array}{l}\text { Scale of } \\
\text { data source }\end{array}$ \\
\hline Malawi & Africa & $\begin{array}{l}\text { Phase } 2 \text { (early } \\
\text { transition) }\end{array}$ & - & - \\
\hline Malaysia & Asia & $\begin{array}{l}\text { Phase } 2 \text { (early } \\
\text { transition) }\end{array}$ & Matthews et al. & Ratio \\
\hline Mali & Africa & $\begin{array}{l}\text { Phase } 3 \text { (late } \\
\text { transition) }\end{array}$ & - & - \\
\hline Mauritania & Africa & $\begin{array}{l}\text { Phase3 (late } \\
\text { transition) }\end{array}$ & - & - \\
\hline Mauritius & Africa & $\begin{array}{l}\text { Phase } 2 \text { (early } \\
\text { transition) }\end{array}$ & - & - \\
\hline Mexico & America & $\begin{array}{l}\text { Phase } 3 \text { (late } \\
\text { transition) }\end{array}$ & $\begin{array}{l}\text { R-PP } \\
\text { Matthews et al. }\end{array}$ & Ratio \\
\hline $\begin{array}{l}\text { Micronesia (Federated } \\
\text { States of) }\end{array}$ & Asia & $\begin{array}{l}\text { Phase } 1 \\
\text { (pre-transition) }\end{array}$ & - & - \\
\hline Mozambique & Africa & $\begin{array}{l}\text { Phase } 2 \text { (early } \\
\text { transition) }\end{array}$ & R-Pin & Nominal \\
\hline Myanmar & Asia & $\begin{array}{l}\text { Phase } 3 \text { (late } \\
\text { transition) }\end{array}$ & Matthews et al. & Ordinal \\
\hline Namibia & Africa & $\begin{array}{l}\text { Phase } 3 \text { (late } \\
\text { transition) }\end{array}$ & - & - \\
\hline Nepal & Asia & $\begin{array}{l}\text { Phase } 3 \text { (late } \\
\text { transition) }\end{array}$ & $\begin{array}{l}\text { R-PP } \\
\text { Matthews et al. }\end{array}$ & Nominal \\
\hline Nicaragua & America & $\begin{array}{l}\text { Phase } 2 \text { (early } \\
\text { transition) }\end{array}$ & R-Pin & Nominal \\
\hline Niger & Africa & $\begin{array}{l}\text { Phase } 3 \text { (late } \\
\text { transition) }\end{array}$ & - & - \\
\hline Nigeria & Africa & $\begin{array}{l}\text { Phase } 3 \text { (late } \\
\text { transition) }\end{array}$ & - & - \\
\hline Pakistan & Asia & $\begin{array}{l}\text { Phase } 3 \text { (late } \\
\text { transition) }\end{array}$ & - & - \\
\hline Palau & Asia & $\begin{array}{l}\text { Phase1 } \\
\text { (pre-transition) }\end{array}$ & - & - \\
\hline Panama & America & $\begin{array}{l}\text { Phase } 3 \text { (late } \\
\text { transition) }\end{array}$ & R-PP & Nominal \\
\hline Papua New Guinea & Asia & $\begin{array}{l}\text { Phase } 2 \text { (early } \\
\text { transition) }\end{array}$ & $\begin{array}{l}\text { R-PP } \\
\text { Matthews et al. }\end{array}$ & Ratio \\
\hline Paraguay & America & $\begin{array}{l}\text { Phase } 2 \text { (early } \\
\text { transition) }\end{array}$ & R-Pin & Nominal \\
\hline Peru & America & $\begin{array}{l}\text { Phase } 1 \\
\text { (pre-transition) }\end{array}$ & $\begin{array}{l}\text { R-PP } \\
\text { Matthews et al. }\end{array}$ & Ordinal \\
\hline Philippines & Asia & $\begin{array}{l}\text { Phase } 4 \\
\text { (post-transition) }\end{array}$ & Matthews et al. & Ordinal \\
\hline
\end{tabular}


Table 3.A1 Continued from previous page

\begin{tabular}{|c|c|c|c|c|}
\hline Country & Continent & $\begin{array}{l}\text { Forest transition } \\
\text { phase }\end{array}$ & Data source & $\begin{array}{l}\text { Scale of } \\
\text { data source }\end{array}$ \\
\hline Rwanda & Africa & $\begin{array}{l}\text { Phase } 4 \\
\text { (post-transition) }\end{array}$ & - & - \\
\hline Saint Lucia & America & $\begin{array}{l}\text { Phase } 1 \\
\text { (pre-transition) }\end{array}$ & - & - \\
\hline $\begin{array}{l}\text { Saint Vincent and the } \\
\text { Grenadines }\end{array}$ & America & $\begin{array}{l}\text { Phase } 2 \text { (early } \\
\text { transition) }\end{array}$ & - & - \\
\hline Samoa & Asia & $\begin{array}{l}\text { Phase } 1 \\
\text { (pre-transition) }\end{array}$ & - & - \\
\hline $\begin{array}{l}\text { Sao Tome and } \\
\text { Principe }\end{array}$ & Africa & $\begin{array}{l}\text { Phase } 3 \text { (late } \\
\text { transition) }\end{array}$ & - & - \\
\hline Senegal & Africa & $\begin{array}{l}\text { Phase } 2 \text { (early } \\
\text { transition) }\end{array}$ & - & - \\
\hline Sierra Leone & Africa & $\begin{array}{l}\text { Phase } 2 \text { (early } \\
\text { transition) }\end{array}$ & - & - \\
\hline Singapore & Asia & $\begin{array}{l}\text { Phase } 3 \text { (late } \\
\text { transition) }\end{array}$ & - & - \\
\hline Solomon islands & Asia & $\begin{array}{l}\text { Phase } 2 \text { (early } \\
\text { transition) }\end{array}$ & - & - \\
\hline Somalia & Africa & $\begin{array}{l}\text { Phase } 3 \text { (late } \\
\text { transition) }\end{array}$ & - & - \\
\hline South Africa & Africa & $\begin{array}{l}\text { Phase } 3 \text { (late } \\
\text { transition) }\end{array}$ & - & - \\
\hline Sri Lanka & Asia & $\begin{array}{l}\text { Phase } 2 \text { (early } \\
\text { transition) }\end{array}$ & - & - \\
\hline Sudan & Africa & $\begin{array}{l}\text { Phase } 3 \text { (late } \\
\text { transition) }\end{array}$ & Matthews et al. & Nominal \\
\hline Surinam & America & $\begin{array}{l}\text { Phase } 1 \\
\text { (pre-transition) }\end{array}$ & $\mathrm{R}-\mathrm{PP}$ & Nominal \\
\hline Swaziland & Africa & $\begin{array}{l}\text { Phase } 4 \\
\text { (post-transition) }\end{array}$ & - & - \\
\hline Tanzania & Africa & $\begin{array}{l}\text { Phase } 2 \text { (early } \\
\text { transition) }\end{array}$ & $\begin{array}{l}\text { R-PP } \\
\text { Matthews et al. }\end{array}$ & Ordinal \\
\hline Thailand & Asia & $\begin{array}{l}\text { Phase } 4 \\
\text { (post-transition) }\end{array}$ & $\begin{array}{l}\text { R-Pin } \\
\text { Matthews et al. }\end{array}$ & Ordinal \\
\hline Timor-Leste & Asia & $\begin{array}{l}\text { Phase } 2 \text { (early } \\
\text { transition) }\end{array}$ & - & - \\
\hline Togo & Africa & $\begin{array}{l}\text { Phase } 3 \text { (late } \\
\text { transition) }\end{array}$ & - & - \\
\hline Trinidad and Tobago & America & $\begin{array}{l}\text { Phase } 2 \text { (early } \\
\text { transition) }\end{array}$ & - & - \\
\hline Uganda & Africa & $\begin{array}{l}\text { Phase } 2 \text { (early } \\
\text { transition) }\end{array}$ & $\begin{array}{l}\text { R-PP } \\
\text { Matthews et al. }\end{array}$ & Ordinal \\
\hline
\end{tabular}


Table 3.A1 Continued from previous page

\begin{tabular}{|c|c|c|c|c|}
\hline Country & Continent & $\begin{array}{l}\text { Forest transition } \\
\text { phase }\end{array}$ & Data source & $\begin{array}{l}\text { Scale of } \\
\text { data source }\end{array}$ \\
\hline Uruguay & Africa & $\begin{array}{l}\text { Phase } 4 \\
\text { (post-transition) }\end{array}$ & - & - \\
\hline Vanuatu & Asia & $\begin{array}{l}\text { Phase } 3 \text { (late } \\
\text { transition) }\end{array}$ & R-Pin & Nominal \\
\hline Venezuela & America & $\begin{array}{l}\text { Phase } 2 \text { (early } \\
\text { transition) }\end{array}$ & - & - \\
\hline Vietnam & Asia & $\begin{array}{l}\text { Phase } 4 \\
\text { (post-transition) }\end{array}$ & $\begin{array}{l}\text { CIFOR } \\
\text { R-PP } \\
\text { (Matthews et } \\
\text { al.) }\end{array}$ & Ratio \\
\hline Zambia & Africa & $\begin{array}{l}\text { Phase } 2 \text { (early } \\
\text { transition) }\end{array}$ & Matthews et al. & Nominal \\
\hline Zimbabwe & Africa & $\begin{array}{l}\text { Phase } 2 \text { (early } \\
\text { transition) }\end{array}$ & - & - \\
\hline
\end{tabular}





\section{Chapter 4}

\section{Land use patterns and related carbon losses following deforestation in South America}

This chapter is based on:

De Sy, V., Herold, M., Achard, F., Beuchle, R., Clevers, J.G.P.W., Lindquist, E., Verchot, L., 2015. Land use patterns and related carbon losses following deforestation in South America. Environmental Research Letters, 10, 124004 


\section{Abstract}

Land use change in South America, mainly deforestation, is a large source of anthropogenic $\mathrm{CO}_{2}$ emissions. Identifying and addressing the causes or drivers of anthropogenic forest change is considered crucial for global climate change mitigation. Few countries however, monitor deforestation drivers in a systematic manner. Nationallevel quantitative spatially explicit information on drivers is often lacking. This study quantifies proximate drivers of deforestation and related carbon losses in South America based on remote sensing time series in a systematic, spatially explicit manner. Deforestation areas were derived from the 2010 global remote sensing survey of the Food and Agricultural Organisation Forest Resource Assessment. To assess proximate drivers, land use following deforestation was assigned by visual interpretation of high-resolution satellite imagery. To estimate gross carbon losses from deforestation, default Tier 1 biomass levels per country and ecozone were used. Pasture was the dominant driver of forest area $(71.2 \%)$ and related carbon loss $(71.6 \%)$ in South America, followed by commercial cropland (14\% and $12.1 \%$ respectively). Hotspots of deforestation due to pasture occurred in Northern Argentina, Western Paraguay, and along the arc of deforestation in Brazil where they gradually moved into higher biomass forests causing additional carbon losses. Deforestation driven by commercial cropland increased in time, with hotspots occurring in Brazil (Mato Grosso State), Northern Argentina, Eastern Paraguay and Central Bolivia. Infrastructure, such as urban expansion and roads, contributed little as proximate drivers of forest area loss (1.7\%). Our findings contribute to the understanding of drivers of deforestation and related carbon losses in South America, and are comparable at the national, regional and continental level. In addition, they support the development of national REDD+ interventions and forest monitoring systems, and provide valuable input for statistical analysis and modelling of underlying drivers of deforestation. 


\subsection{Introduction}

Land use change, mainly deforestation, is the second largest source of anthropogenic $\mathrm{CO}_{2}$ emissions, and causes a net reduction of carbon storage in terrestrial ecosystems as well as other environmental impacts such as biodiversity loss (IPCC, 2013). The vast majority of land use change occurs in tropical regions, with Central and South America having the highest net emissions from land use change from the 1980s to 2000s (IPCC, 2013). Reducing emissions from deforestation and forest degradation, and enhancing carbon stocks (REDD+) in (sub-) tropical countries is thus a necessary component of global climate change mitigation. Within the REDD+ framework, participating countries are given incentives to develop national strategies and implementation plans that reduce emissions and enhance sinks from forests and to invest in low carbon development pathways. Identifying and addressing the causes or drivers of anthropogenic forest change is considered crucial within the REDD + framework (UNFCCC, 2014), and should be incorporated in national forest monitoring systems.

Few countries, however, monitor deforestation drivers in a systematic manner and national-level quantitative spatially explicit information on drivers is often lacking (De Sy et al., 2012; Hosonuma et al., 2012). The distinction between proximate and underlying drivers is important for assessment purposes. Proximate or direct drivers of deforestation are human activities that directly affect the loss of forests (Geist and Lambin, 2001), and can be assessed by linking forest area change to specific human activities and follow-up land use (De Sy et al., 2012). Remote sensing can provide essential information on the intensity, type and pattern of deforestation, and on the follow-up land use in order to attribute deforestation to specific human activities (Gibbs et al., 2010; De Sy et al., 2012; GOFC-GOLD, 2014). Statistical analysis and modelling of this information, in turn, can be useful for the assessment of underlying drivers (Kissinger et al., 2012) which are complex interactions of social, political, economic, technological and cultural forces (Geist and Lambin, 2001).

Forest loss and related carbon losses in South America have been extensively studied from the continental to the (sub)national scale (DeFries et al., 2002; Baccini et al., 2012; Eva et al., 2012; Harris et al., 2012; Hansen et al., 2013; Achard et al., 2014; Beuchle et al., 2015; Velasco Gomez et al., 2015) but the link to specific proximate drivers is not made. Clark et al. (2012) and Graesser et al. (2015) studied land use change across the South American continent in a systematic manner with MODIS imagery which gives some insight into drivers of deforestation. MODIS imagery, however, cannot accurately detect small-scale agricultural clearings $(<25$ 
ha) and infrastructure expansion due to its low spatial resolution (GOFC-GOLD, 2014). Other research that links forest loss or forest carbon emissions to drivers used aggregated continental scale (Geist and Lambin, 2002; Hosonuma et al., 2012; Houghton, 2012) or local scale data (Morton et al., 2006; Barona et al., 2010; Clark et al., 2010; Müller et al., 2012, 2014; Gibbs et al., 2015). Several studies link overall deforestation rates directly to underlying drivers (DeFries et al., 2010; Malingreau et al., 2012). Linking driver-specific deforestation rates (e.g. agricultural expansion) to relevant underlying drivers (e.g. agricultural commodity prices) can provide more insight into complex deforestation pathways.

Although it is clear that agricultural expansion is the main driver of deforestation in South America (Geist and Lambin, 2002; Gibbs et al., 2010; Hosonuma et al., 2012; Houghton, 2012), less is known about the magnitude and the spatial and temporal distribution of different types of agricultural and non-agricultural drivers contributing to forest loss and related carbon emissions. Gaining insight in spatiotemporal dynamics is essential since drivers of forest loss vary from region to region and change over time (Rudel et al., 2009; Boucher et al., 2011).

Accordingly, our research aims to quantify proximate drivers of deforestation, their spatiotemporal dynamics and related carbon losses in South America at continental and national scales using a comprehensive, systematic remote sensing analysis. This new dataset will provide insight into complex deforestation pathways and be a valuable source of information for international climate change mitigation and REDD+ monitoring strategies.

\subsection{Data and methods}

The 2010 global Remote Sensing Survey of the United Nations Food and Agricultural Organisation (FAO) Forest Resource Assessment was used as input to determine deforestation areas (Section 4.2.1). To assess proximate drivers, land use following deforestation was assigned by visual interpretation of high-resolution satellite imagery (Section 4.2.2). To estimate gross carbon losses from deforestation, default Tier 1 biomass levels per country and eco-zone were used (Section 4.2.3).

\subsubsection{Forest area loss}

In a coordinated effort, the European Joint Research Centre (JRC) and the FAO produced estimates of forest land use change from 1990 to 2005 for the Remote Sens- 
ing Survey of the Global Forest Resources Assessment 2010 of FAO (FAO FRA-2010 RSS) (FAO \& JRC, 2012). These estimates were based on a systematic sampling design with sample units of $10 \times 10 \mathrm{~km}$ centred on each degree latitude-longitude confluence point (Eva et al., 2012; FAO \& JRC, 2012; Achard et al., 2014).

Unfortunately the FAO FRA-2010 RSS currently only covers a limited time period from 1990 to 2005. As mentioned in the introduction, other deforestation datasets are available (e.g. Hansen et al. (2013)) that provide wall-to-wall data extending to 2010 or even later. The FAO FRA-2010 RSS, however, employs a land use classification that is better suited for assessing drivers than a land cover classification. In addition, the FAO FRA-2010 RSS is a global study with consistent methods and time series that could be extended to include more recent periods. Despite the time period limitation, and in view of the paucity of quantitative data on deforestation drivers and related carbon losses, this study provides an unique and relevant overview of the drivers of deforestation in South America, as well as showing that this is achievable with a sample-based time series approach.

We briefly describe the methodology of the FAO FRA-2010 RSS dataset (FAO \& JRC, 2012), because it served as input data for our study. Medium resolution satellite imagery (mainly Landsat) was acquired for each sample unit, as close as possible to reference years 1990, 2000 and 2005. After preprocessing, the satellite imagery was used in an automated multi-date image segmentation to subdivide the sample unit (10 000 ha) into delineated areas (polygons) with similar spectral and structural attributes. The target minimum mapping unit was 5 ha. On the segmented imagery, a supervised automated land cover classification was carried out, which later was converted to a land use classification with the help of expert human interpretation. The main land use classes were Forest, Other wooded land, and Other land, which are based on FAO forest definitions (FAO, 2010). Areas lacking data due to clouds, poor satellite coverage or low quality imagery in any of the reference years were considered an unbiased loss of information and were not analysed. This sample grid provided 1542 sample units in South America, of which 1392 sample units had data for all years and were consequently processed (Figure 4.1).

\subsubsection{Follow-up land use}

Land use following a deforestation event was assigned a more detailed land use class, i.e. follow-up land use class, as a proxy for the proximate cause of change. Assessing land use is more challenging than assessing land cover, as factors other than spectral reflectance are important. So, expert human interpretation and relatively fine-scale 


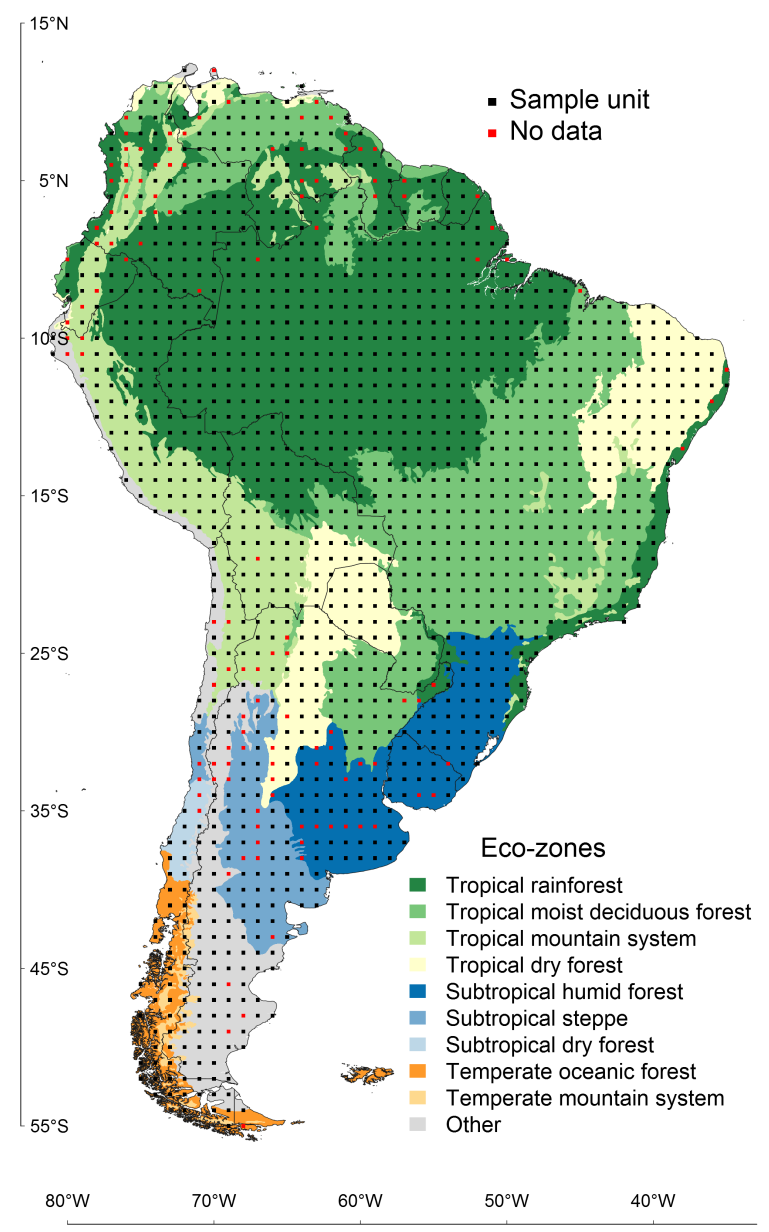

Figure 4.1: Location of sample units (FAO \& JRC, 2012), and FAO ecological zones (FAO, 2001) in South America.

satellite imagery are required to interpret the proximate causes of deforestation. To assign follow-up land use in this study, we used parameters such as land cover, the presence of certain features within or near changed areas (e.g. crop rows, watering holes, fences) and to a limited extent the spatial context and location of change (e.g. distance to settlements, concessions).

Table 4.1 gives an overview of the follow-up land use classes and their descriptions, that we used as proxies for the proximate deforestation driver. These land use classes are based on the proximate deforestation drivers as described in Hosonuma 
et al. (2012) i.e. agricultural expansion, mining, infrastructural and urban expansion. The class 'other land use' was added for deforested areas where no clear human activity could be distinguished. The 'other land use' subclasses are chosen in such a way that our classification could be translated to IPCC land categories (e.g. wetlands, grasslands) (IPCC, 2013) and FAO land use definitions (e.g. other wooded land) (FAO, 2010). The water class was added to account for forest loss due to inundation by lakes, meandering rivers and dam reservoirs.

We have used several key criteria to classify land uses. Cropland can be detected by plough lines, rectilinear shapes, and nearby roads and infrastructure (Clark et al., 2010). We used field size as a proxy for agricultural development and mechanisation (Kuemmerle et al., 2013; Fritz et al., 2015). We classified cropland with very small to small fields ( $<2$ ha) as smallholder cropland, and cropland with medium to large fields ( $>2$ ha) as commercial cropland $(>2$ ha). Tree crops can be recognised by perennial vegetation and the regular spacing of the tree plants (Clark et al., 2010). Pasture can be distinguished by trails and watering holes, and is usually more heterogeneous in colour and texture than cropland (Clark et al., 2010).

In order to achieve a detailed follow-up land use classification, we performed the following steps:

1. We selected those polygons of each sample unit within the FAO FRA-2010 RSS dataset that were deforested, either in the interval between 1990 and 2000 or 2000 and 2005 according to the FAO FRA-2010 RSS classification, i.e. changed from Forest to Other wooded land or to Other land.

2. Each of these deforested polygons was assigned a single follow-up land use class (Table 4.1) by means of visual interpretation by an expert. If more than one land use was present, the most dominant one in terms of area or human activity (e.g. a road with shrubs on the side is assigned road) was chosen. For the visual interpretation a variety of satellite imagery was used such as Landsat, Google Earth imagery (Google Earth, 2015) and ESRI world imagery basemaps. For the Brazilian Amazon, Terraclass 2008 data (Coutinho et al., 2013) was used to help with the interpretation. We used satellite imagery acquired as close as possible to the deforestation period (e.g. 2000 or 2005).

3. In addition to follow-up land use, the source and year of the satellite imagery used for the interpretation (e.g. Google Earth 2009) and the confidence (lowmedium-high) in the interpretation was documented.

4. For the areas with low confidence, e.g. due to low resolution imagery, land use and remote sensing experts with local knowledge were consulted. These experts were provided with the follow-up land use classification and descriptions in order 
Table 4.1: Follow-up land use classes and their description.

\begin{tabular}{|c|c|c|}
\hline & Follow-up land use & Description \\
\hline \multirow{5}{*}{ 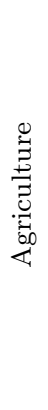 } & Mixed agriculture & Mix of agricultural land uses \\
\hline & Commercial crop & $\begin{array}{l}\text { Land under cultivation for crops, characterised by medium } \\
(2-20 \text { ha) to large }(>20 \text { ha) field sizes }\end{array}$ \\
\hline & Smallholder crop & $\begin{array}{l}\text { Land under cultivation for crops, characterised by very small } \\
(<0.5 \mathrm{ha}) \text { to small field sizes }(0.5-2 \text { ha) }\end{array}$ \\
\hline & Tree crops & $\begin{array}{l}\text { Miscellaneous tree crops (e.g. coffee, palm trees), orchards } \\
\text { and groves }\end{array}$ \\
\hline & Pasture & $\begin{array}{l}\text { Land used predominantly for grazing; in either } \\
\text { managed/cultivated (pastures) or natural (grazing land) } \\
\text { setting; includes grazed woodlands }\end{array}$ \\
\hline \multirow{3}{*}{ 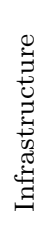 } & Urban and Settlements & Urban, settlements and other residential areas \\
\hline & Roads and built-up & $\begin{array}{l}\text { Roads, built-up areas and other transport, industrial and } \\
\text { commercial infrastructures }\end{array}$ \\
\hline & Mining & $\begin{array}{l}\text { Land used for extractive subsurface and surface mining } \\
\text { activities (e.g. underground and strip mines, quarries and } \\
\text { gravel pits), including all associated surface infrastructure }\end{array}$ \\
\hline \multirow{5}{*}{ 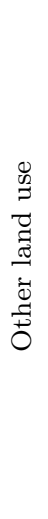 } & Other land use (general) & $\begin{array}{l}\text { All land that is not classified as forest, agriculture, } \\
\text { infrastructure, mining and water }\end{array}$ \\
\hline & Bare land & Barren land (exposed soil, sand, or rocks) \\
\hline & Other wooded land & $\begin{array}{l}\text { Land not classified as forest, spanning more than } 0.5 \text { ha; } \\
\text { with trees higher than } 5 \mathrm{~m} \text { and canopy cover of } 5 \%-10 \% \text {, or } \\
\text { trees able to reach these thresholds in situ, or with a } \\
\text { combined cover of shrubs, bushes and trees above } 10 \% \text {. It } \\
\text { does not include land that is predominantly under } \\
\text { agricultural or urban land use (FAO, 2010) }\end{array}$ \\
\hline & Grass and herbaceous & Land covered with (natural) herbaceous vegetation or grasses \\
\hline & Wetlands & $\begin{array}{l}\text { Areas of natural vegetation growing in shallow water or } \\
\text { seasonally flooded environments. This category includes } \\
\text { Marshes, swamps, and bogs }\end{array}$ \\
\hline \multicolumn{2}{|c|}{ Water } & $\begin{array}{l}\text { Natural (river, lake etc) or man-made waterbodies (e.g. } \\
\text { reservoirs) }\end{array}$ \\
\hline \multicolumn{2}{|c|}{ Unknown land use } & $\begin{array}{l}\text { All land that cannot be classified (e.g. due to low resolution } \\
\text { imagery) }\end{array}$ \\
\hline
\end{tabular}


to classify the areas based on their local knowledge, and additional sources available to them such as high resolution satellite imagery and land use maps.

5. Finally, all areas were double checked, and if necessary corrected for errors and consistency. This means each forest loss area has been looked at least twice by one or more experts.

In the end, $77.8 \%$ of follow-up land use classification was assigned with high confidence, $17.6 \%$ with medium confidence and only $4.6 \%$ with low confidence. In general, small-scale land uses, such as smallholder cropland, were classified with less confidence due to their smaller scale and because these land uses occur more in locations with higher cloud cover and with lower availability of high resolution imagery (Andean countries, Amazon rainforest). In addition, the class 'other land use' also had a higher portion of low confidence classification since it is not always possible to assess whether these areas are used for agriculture. For all land uses, the confidence level was also influenced by the date of the available imagery.

\subsubsection{Carbon losses}

Gross carbon loss per sample unit was calculated using spatially explicit forest biomass information. A recent study by Langner et al. (2014) combined a global forest mask derived from the Globcover-2009 map (Bontemps et al., 2011), FAO ecological zones (eco-zones; FAO (2001)) and the pan-tropical above ground biomass (AGB) datasets of Saatchi (Saatchi et al., 2011b) and Baccini (Baccini et al., 2012) to derive mean AGB levels in forests (for intact, non-intact and overall forest) per eco-zone and country as an alternative to IPCC Tier 1 values.

We used the country eco-zone AGB forest values derived from the combined Saatchi and Baccini AGB maps (Table 3 in supplementary information of Langner et al. (2014)). We used AGB values for the overall forest category since we did not have information on whether the deforested area had intact or non-intact forest. For those AGB forest values where the number of samples per eco-zone was too small, we used the combined AGB values of that eco-zone at the continental (South America) or tropical scale. If these AGB values were also not present we used IPCC Tier 1 AGB values for America (IPCC, 2006). For Argentina and Chile, which were not included in Langner et al. (2014), we used the same procedure. Table 4.2 provides an overview of the AGB values per country eco-zone used in our study.

We derived total biomass from AGB by applying equation 4.1 used by Saatchi et al. (2011b): 


$$
\text { Total Biomass }=\mathrm{AGB}+0.489 * \mathrm{AGB}^{0.89}
$$

Total carbon was considered to be $50 \%$ of total biomass as in Achard et al. (2014). We considered only the maximum potential loss of carbon stock from deforestation, assuming a carbon stock of zero in potential follow-up land uses, that could be emitted to the atmosphere over a long time period. We did not account for soil carbon loss.

\subsubsection{Aggregation to regional scale}

Deforestation and related carbon losses per driver were scaled up from the sample to the continental and national scales using a statistical extrapolation similar to FRA-2010 RSS (FAO \& JRC, 2012). Cloudy areas were considered an unbiased loss of data, with the assumption that cloudy areas had the same proportion of land uses as cloud-free areas within a single sample unit. This was accomplished by considering the ratio of forest area or carbon loss per driver proportional to the 'visible land' area of the sample unit. The 'visible land' area was the full sample unit area $\left(100 \mathrm{~km}^{2}\right)$ minus cloudy and 'permanent water' areas (i.e. sea or inland water in all considered years).

Estimates of forest area and carbon losses per driver for each sample unit for the two periods (1990-2000 and 2000-2005) were annualised based on the acquisition dates of the imagery for that sample unit, with the assumption that the change rates were constant during the two time intervals. The average time length across all sample units was 11.9 years for the 1990-2000 epoch and 4.9 years for the 2000-2005 epoch.

Each sample unit was assigned a weight $\left(\mathrm{w}_{\mathrm{i}}\right)(4.2)$, equal to the cosine of its latitude $\left(\right.$ coslat $\left._{\mathrm{i}}\right)$, because the actual area represented by a sample unit decreased with latitude due to the curvature of Earth:

$$
w_{i}=\frac{\operatorname{coslat}_{i}}{\sum_{i} \operatorname{coslat}_{i}}
$$

The proportions of forest area changes and carbon losses per driver were extrapolated to a given region (the full continent or one specific country) using the Horvitz-Thompson direct estimator (Särndal et al., 1992) (4.3) 


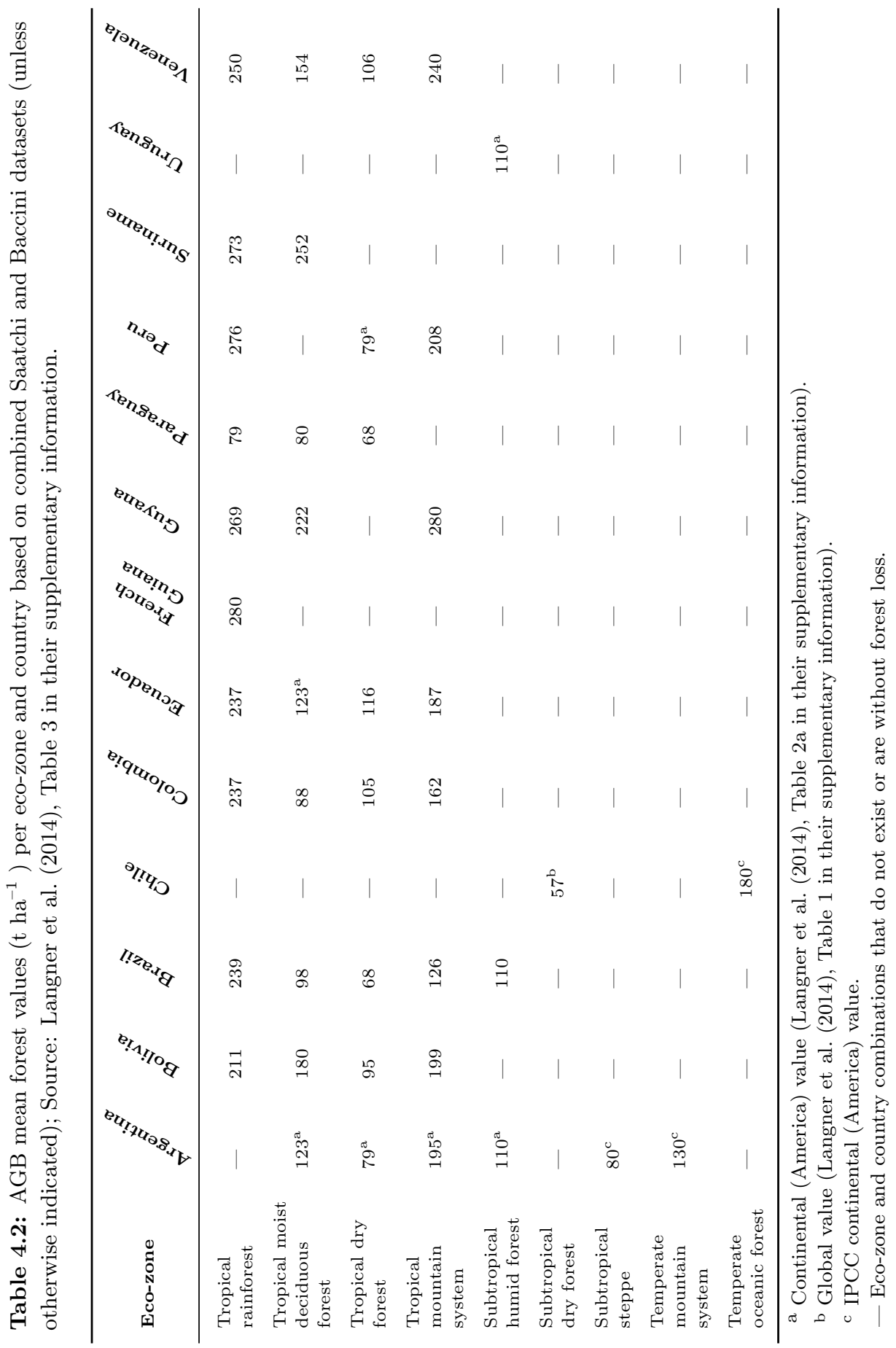




$$
\bar{x}_{c}=\frac{1}{M} \times \sum_{i=0}^{n}\left(w_{i} \times x_{i c}\right),
$$

where

$$
M=\sum_{i=0}^{n} w_{i}
$$

and where $\mathrm{x}_{\mathrm{ic}}$ is the proportion of forest cover change or carbon loss in the $i$ th sample unit and $\mathrm{w}_{\mathrm{i}}$ is the weight of the $i$ th sample unit. The total area of change or total loss of carbon for this region (Driver ${ }_{\text {region}}$ ) is then obtained from:

$$
\text { Driver }_{\text {region }}=A \times \bar{x}_{c} \text {, }
$$

where $A$ is the total area of the region (excluding permanent water).

We used the usual variance estimation of the mean for this systematic sampling as follows:

$$
s^{2}=\frac{1}{M} \times \sum_{i=0}^{n} w_{i} \times\left(\bar{x}_{c}-x_{i c}\right)^{2}
$$

The standard error (SE) is then calculated as:

$$
\mathrm{SE}=A \times \frac{s}{\sqrt{n}}
$$

The SE represents only the sampling error. Countries or states with a SE of more than $35 \%$ for forest area and carbon losses estimates were not reported at the national scale (i.e. French Guyana, Guyana, Ecuador and Chile).

\subsection{Results}

\subsubsection{Deforestation and carbon losses per driver from 1990 to 2005}

We estimated that total deforested area and related gross carbon losses in South America from 1990 to 2005 reached 57.7 million ha and $6460 \mathrm{Tg}$ C, respectively 
Table 4.3: Estimates of deforested area $\left(10^{3}\right.$ ha (SE) and per cent of total) and related carbon loss (Tg C (SE) and per cent of total) per follow-up land use from 1990 to 2005.

\begin{tabular}{|c|c|c|c|c|}
\hline \multirow[b]{2}{*}{ Follow-up land use } & \multicolumn{2}{|l|}{ Area } & \multicolumn{2}{|c|}{ Carbon loss } \\
\hline & $10^{3}$ ha (SE) & $\%$ & $\operatorname{Tg} \mathrm{C}(\mathrm{SE})$ & $\%$ \\
\hline Mixed agriculture & $470(233)$ & 0.8 & $57(32)$ & 0.9 \\
\hline Smallholder crop & $1168(272)$ & 2.0 & $173(42)$ & 2.7 \\
\hline Commercial crop & $8100(1463)$ & 14.0 & $782(162)$ & 12.1 \\
\hline Tree crops & $243(75)$ & 0.4 & $20(6)$ & 0.3 \\
\hline Pasture & $41118(3244)$ & 71.2 & $4624(431)$ & 71.6 \\
\hline Agriculture total & $51099(3618)$ & 88.5 & $5657(472)$ & 87.6 \\
\hline Infrastructure & $985(346)$ & 1.7 & $124(52)$ & 1.9 \\
\hline Other land use & $3770(517)$ & 6.5 & $433(65)$ & 6.7 \\
\hline Water & $1748(543)$ & 3.0 & $228(79)$ & 3.5 \\
\hline Unknown land use & $131(108)$ & 0.2 & $18(15)$ & 0.3 \\
\hline Other total & $6634(897)$ & 11.5 & $802(123)$ & 12.4 \\
\hline Total & $57733(3837)$ & 100 & $6460(501)$ & 100 \\
\hline
\end{tabular}

(Table 4.3). Agriculture was the dominant follow-up land use (88.5\%), in particular pasture $(71.2 \%)$ and to a lesser extent commercial cropland $(14.0 \%)$. In the non-agricultural category, other land use was the largest driver (6.5\%). This class can be further subdivided in other wooded land $(4.4 \%)$, wetlands $(1.4 \%)$, grass and herbaceous $(0.6 \%)$ and bare land $(0.1 \%)$. The contribution of smallholder cropland $(2.0 \%)$, infrastructure $(1.7 \%)$ and water $(3.0 \%)$ was small. Within the infrastructure class, urban and settlements accounted for $0.9 \%$, roads and built-up areas for $0.6 \%$ and mining for $0.2 \%$ of deforestation. The water driver can be divided into natural $(1.3 \%)$ and man-made water bodies $(1.8 \%)$. Unknown land use only represented a small fraction $(0.2 \%)$ of total deforestation.

The spatially explicit nature of our dataset shows the distribution of follow-up land use across the continent (Figure 4.2(a)). The Brazilian arc of deforestation was dominated by pasture expansion, except for a commercial crop agriculture cluster in Mato Grosso State. Considerable deforestation, mainly due to the expansion of pasture, occurred in the Brazilian Pantanal and Cerrado ecoregions. Toward the Atlantic coast, in the Mata Atlântica ecoregion, the follow-up land use became more diverse with a mix of pasture, commercial cropland and tree crops. Pasture expansion was also an important driver of deforestation in the Western Paraguayan and Argentinean Chaco. Commercial crop expansion was prevalent in Eastern Paraguay, Central Bolivia (around La Paz) and Northern Argentina; while 
smallholder crop expansion occurred mostly in the Andean region (Peru, Ecuador, Colombia, Venezuela and Bolivia).

Forest biomass levels in East Brazil, Paraguay and Argentina were much lower than in the Brazilian Amazon (Figure 4.2(b)). This influenced the relative contribution of follow-up land uses for forest carbon losses as compared to deforested area (Table 4.3). For example, commercial crop agriculture proportionally contributed more to deforested area (14.0\%) than to forest carbon losses $(12.1 \%)$ indicating that this follow-up land use, as well as tree crops, occurred more in lower forest biomass eco-zones as compared to pasture, mixed and smallholder crop agriculture, water and infrastructure.

Deforestation drivers at the national level varied in their contribution to deforestation (Figure 4.3, for more detail see Table 4.A1 in Appendix 4.A). Pasture expansion caused at least $35 \%$ or more of forest loss in all countries except in Peru (19.9\%) where smallholder cropland (41.9\%) was a more dominant driver. In Argentina deforestation caused by commercial cropland (43.4\%) was almost as dominant as pasture driven deforestation (44.6\%). Commercial crop expansion could also be found in Paraguay (25.5\%) and Bolivia (27.2\%), while in Colombia smallholder crop and mixed agriculture (23.6\% together) was more important for deforestation. In Bolivia one fifth $(20.0 \%)$ of deforestation was followed up by other land use, mostly wetlands (13.4\%) and other wooded land (6.0\%). For other land use in Peru (16.2\%) most was other wooded land $(8.9 \%)$ and wetlands $(7.3 \%)$. In Colombia (12.7\%) and Venezuela $(13.7 \%)$ other land use, mainly other wooded land also played a considerable role in deforestation. In Peru infrastructure was a relatively large driver (5.6\%) compared to the other countries, due to mining activities $(2.0 \%)$ and substantial urban, roads and built-up development (3.7\%). Water as a follow-up land use contributed considerably to deforestation in Venezuela (38.2\%) due to two large dam projects. In Peru (14.2\%) and Bolivia (5.9\%) deforestation followed up by water was the result of natural processes such as meandering rivers.

Brazil emitted the most carbon from 1990 to 2005 (4372 Tg C), followed by Bolivia (488 Tg C), Argentina (297 Tg C) and Colombia (289 Tg C). Paraguay (179 Tg C), Venezuela (174 Tg C) and Peru (170 Tg C) had less forest carbon losses in the same period (Table 4.A2 in Appendix 4.A). 

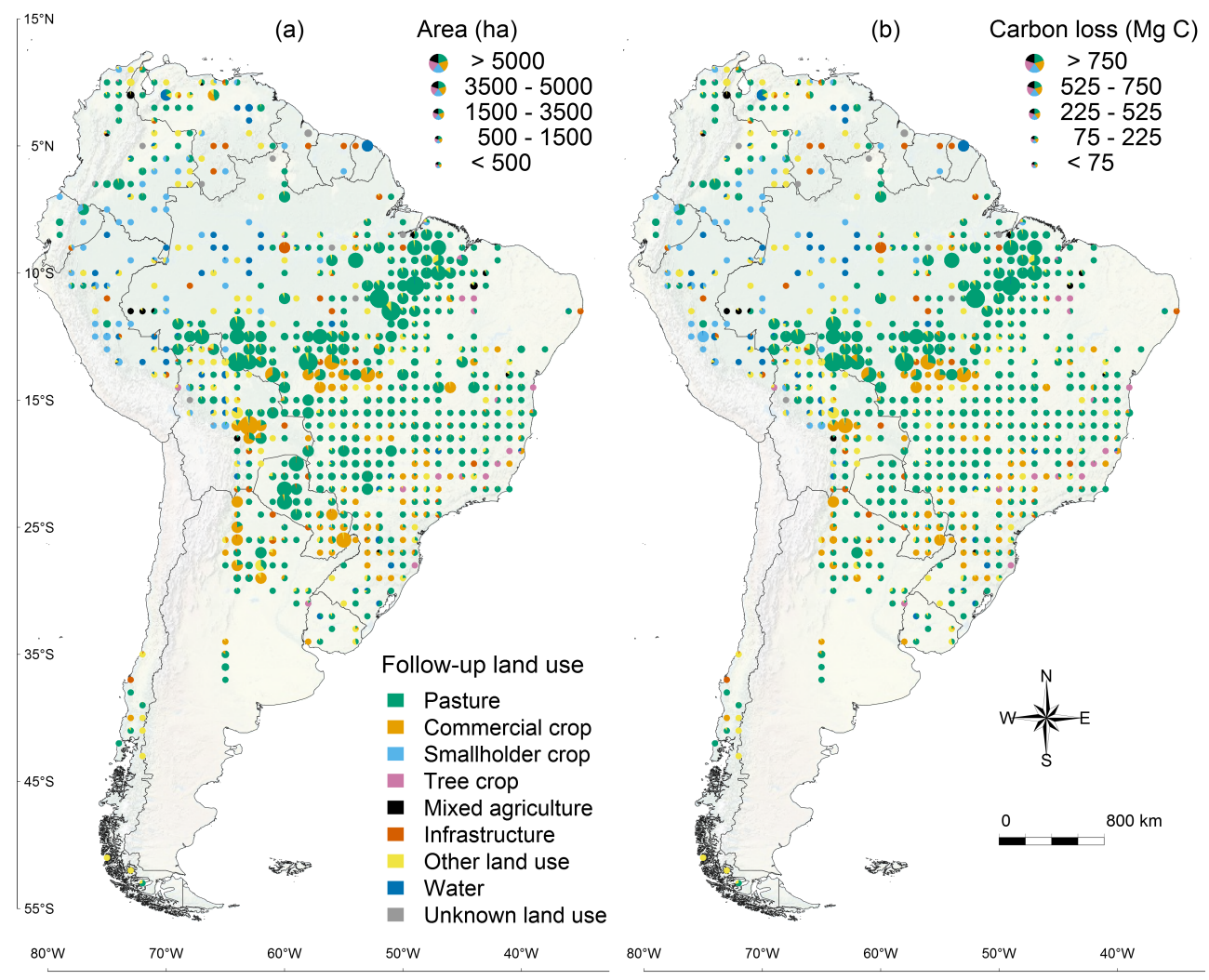

Figure 4.2: (a) Forest area loss (ha) and (b) related forest carbon losses ( $\mathrm{Mg} \mathrm{C}$ ) per follow-up land use from 1990 to 2005, in South America.

\subsubsection{Trends in annual deforestation and carbon losses per driver from 1990 to 2000 and 2000 to 2005}

Annual deforestation increased from 3.62 to 4.46 million ha $\mathrm{yr}^{-1}$ between the periods 1990-2000 and 2000-2005, while the related carbon losses increased from 0.41 to $0.50 \mathrm{Pg} \mathrm{C} \mathrm{yr}^{-1}$ (Table 4.4). The increase in carbon losses was partly driven by an increase of forest area loss due to commercial cropland, pasture and other land use. Water, mixed and smallholder crop agriculture, on the other hand, decreased as drivers of deforestation. Not all the increase in carbon losses can be attributed to an increase in forest area loss alone. Pasture $\left(+9.17 \mathrm{Tg} \mathrm{C} \mathrm{yr}^{-1}\right)$ and commercial crop

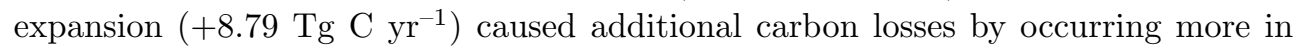
higher forest biomass ecozones in the 2 nd period, only minimally countered by other 


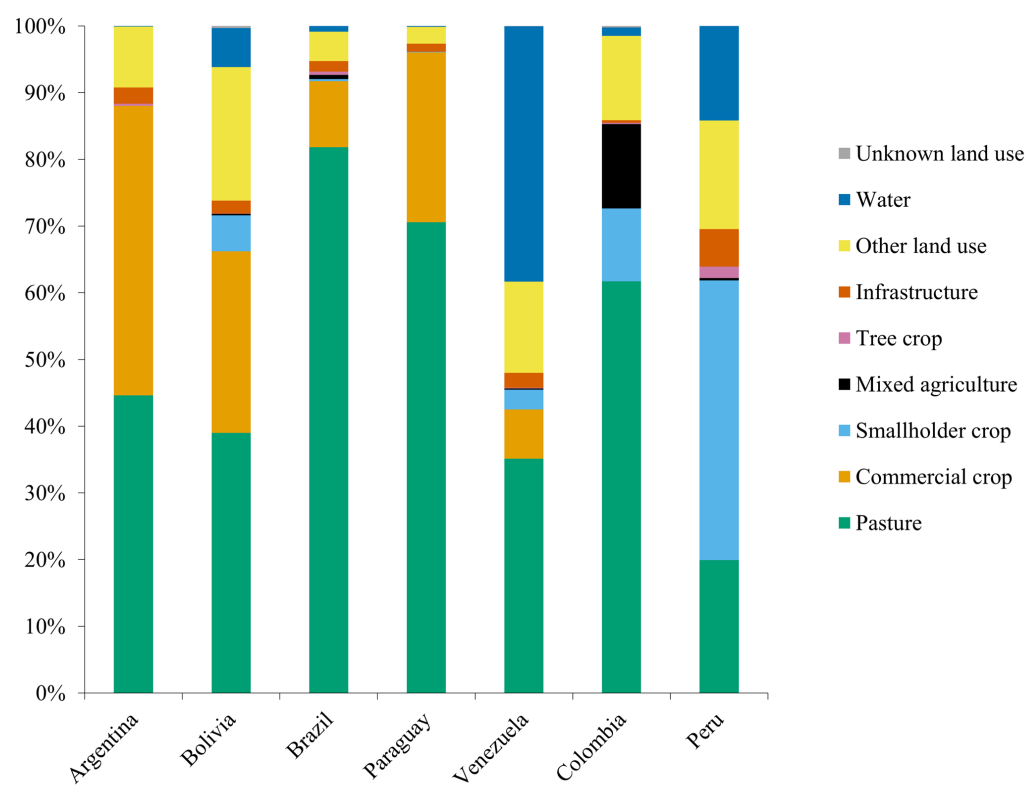

Figure 4.3: Area proportion of deforestation driver from 1990 to 2005 (\%) at the national scale.

drivers occurring more in lower forest biomass eco-zones (Table 4.4).

Clearly, the spatial distribution of hotspots of deforestation and their change in time has an influence on forest carbon losses. Moving hotspots of the two main deforestation drivers, crop agriculture (commercial and smallholder) (Figure 4.4(a)) and pasture (Figure 4.4(b)), illustrate this effect. Pasture expansion in Brazil occurred more and deeper in the Amazon (especially Rondônia and Pará States) in the 2nd period, and less in lower forest biomass ecoregions of the Cerrado and Mata Atlântica. In Paraguay, pasture expansion into forests moved away from urbanized areas in the first period to mainly the Alto Chaco region in the second period. Hot spots of crop expansion occurred in Mato Grosso State and the lowlands around Santa Cruz in Bolivia mainly in the 2nd period, while in Southern Paraguay crop expansion moved from Alto Paraná Department to central Paraguay. In Peru we see both crop and pasture related deforestation occurring deeper in the Amazon in the second period. In Northern Argentina, pasture and crop expansion occurred mainly near important highways. 


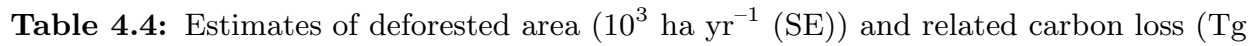
$\mathrm{C} \mathrm{yr}^{-1}$ (SE)) per follow-up land use for 1990-2000 and 2000-2005, and the change in carbon loss $\left(\mathrm{Tg} \mathrm{C} \mathrm{yr}^{-1}\right)$ in the second period additional to the change in forest area loss.

\begin{tabular}{|c|c|c|c|c|c|}
\hline \multirow[b]{2}{*}{$\begin{array}{l}\text { Follow-up } \\
\text { land use }\end{array}$} & \multicolumn{2}{|c|}{ 1990-2000 } & \multicolumn{2}{|c|}{ 2000-2005 } & \multirow{2}{*}{$\begin{array}{l}\text { Additional } \\
\text { change in } \\
\text { carbon loss }\end{array}$} \\
\hline & Area & Carbon loss & Area & Carbon loss & \\
\hline $\begin{array}{l}\text { Mixed } \\
\text { agriculture }\end{array}$ & $36(21)$ & $5(3)$ & $25(12)$ & $2(1)$ & -0.78 \\
\hline $\begin{array}{l}\text { Smallholder } \\
\text { crop }\end{array}$ & $85(22)$ & $13(3)$ & $58(13)$ & $9(2)$ & 0.02 \\
\hline $\begin{array}{l}\text { Commercial } \\
\text { crop }\end{array}$ & $409(84)$ & $37(7)$ & $802(180)$ & $82(21)$ & 8.79 \\
\hline Tree crops & $13(3)$ & $1(0)$ & $22(11)$ & $2(1)$ & -0.46 \\
\hline Pasture & $2642(224)$ & $295(30)$ & 3062 (307) & 351 (39) & 9.17 \\
\hline $\begin{array}{l}\text { Agriculture } \\
\text { total }\end{array}$ & 3186 (244) & $351(31)$ & 3969 (359) & $445(45)$ & 16.73 \\
\hline Infrastructure & $64(25)$ & $8(4)$ & $62(17)$ & $7(2)$ & -0.31 \\
\hline $\begin{array}{l}\text { Other land } \\
\text { use }\end{array}$ & $232(38)$ & $27(5)$ & $324(60)$ & $36(6)$ & -2.07 \\
\hline Water & $128(47)$ & $18(7)$ & $93(42)$ & $11(4)$ & -2.33 \\
\hline $\begin{array}{l}\text { Unknown } \\
\text { land use }\end{array}$ & $9(7)$ & $1(1)$ & $9(7)$ & $1(1)$ & -0.04 \\
\hline Other total & $433(73)$ & $54(10)$ & $489(77)$ & $55(8)$ & -4.75 \\
\hline Total & 3619 (261) & $405(34)$ & 4458 (382) & $500(48)$ & 11.98 \\
\hline
\end{tabular}

\subsection{Discussion}

In this study we quantified proximate drivers of deforestation and related carbon losses in South America between 1990 and 2005. Previous estimates of deforestation ranged from 3.74 to 4.09 million ha $\mathrm{yr}^{-1}$ for the $1990 \mathrm{~s}$, and 3.28 to 4.87 million ha $\mathrm{yr}^{-1}$ for (part of) the 2000s (DeFries et al., 2002; Hansen et al., 2008b, 2010; Eva et al., 2012; Harris et al., 2012; Achard et al., 2014; FAO, 2015). Previous estimates for carbon losses from deforestation ranged from 306 to $698 \mathrm{Pg} \mathrm{C}^{-1}$ for the $1990 \mathrm{~s}$, and 322 to $845 \mathrm{Pg} \mathrm{C} \mathrm{yr}^{-1}$ for (part of) the 2000s (DeFries et al., 2002; Baccini et al., 2012; Eva et al., 2012; Harris et al., 2012; Houghton, 2012; Achard et al., 2014; Tyukavina et al., 2015). Our estimates of deforestation and related carbon emissions are of similar magnitude, but comparisons between studies are difficult due to differences in methodology, forest definition, considered time frame and region 

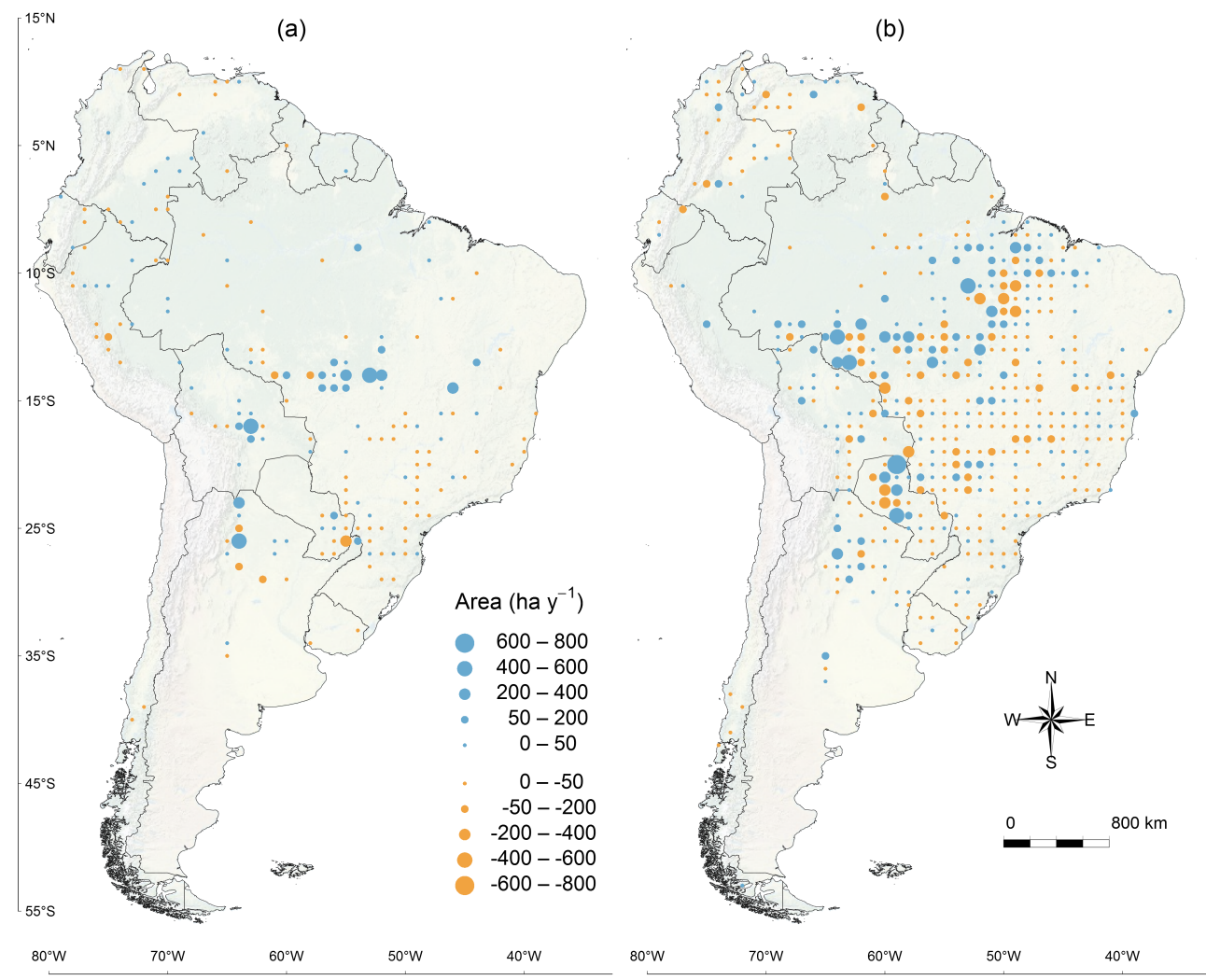

Figure 4.4: Changes in annual rate of deforestation (ha $\left.\mathrm{yr}^{-1}\right)$ followed up by crop agriculture (a) and pasture (b) between the periods 1990-2000 and 2000-2005, in South America.

(Keenan et al., 2015). The latter is also the case for previous studies (Hosonuma et al., 2012; Houghton, 2012) on proximate drivers of deforestation.

Agricultural expansion, in particular pasture, was the most dominant driver of deforestation in South America. Gross carbon losses from forest conversion to pasture were $4624 \mathrm{Tg} \mathrm{C}$ from 1990 to 2005. In the same time frame, carbon losses amounted to $782 \mathrm{Tg} \mathrm{C}$ for commercial crop agriculture and $173 \mathrm{Tg} \mathrm{C}$ for smallholder crop agriculture. Before the 1990s deforestation was mostly attributed to shifting cultivators and smallholder colonists (Rudel et al., 2009). More recent decades saw the rise of large-scale agribusinesses, increasingly producing for international markets, as the main agents of deforestation (Rudel, 2007; Rudel et al., 2009; Pacheco and 
Poccard-Chapuis, 2012). Our data confirmed this, especially in Brazil, Argentina, Paraguay and Bolivia where large ranches and commercial crop agriculture were the main drivers. In the Andean countries (Peru, Colombia and Venezuela) smallholder and mixed agriculture were still important drivers of deforestation.

Our study shows that the annual rate of deforestation driven by commercial crops doubled in the early 2000s compared to the 1990s. Although much of the increase in deforestation in the early 2000s could be attributed to commercial crop expansion, this driver contributed to only $14 \%$ of overall deforestation in South America. Our study identified hotspots of forest conversion for crop agriculture in Mato Grosso State (Brazil), Bolivia, Argentina and Paraguay. Several studies showed that the expansion of commercial crops (e.g. soybean) increased substantially in these regions (Morton et al., 2006; Macedo et al., 2012; Müller et al., 2012; Graesser et al., 2015). A large part of this expansion, however, was conversion of pasture and not forests (Graesser et al., 2015). Even so, crop expansion still places direct pressure on forests (Morton et al., 2006) and can be an indirect driver of land use change by pushing pasture lands forward into the forest frontier (Nepstad et al., 2006; Barona et al., 2010; Arima et al., 2011). These dynamics changed after 2005 when deforestation slowed down in the Amazon, particularly in Mato Grosso State, coinciding with a fall in crop commodity prices and the implementation of policy measures such as improved monitoring and enforcement, and other control actions (Macedo et al., 2012; Malingreau et al., 2012; Gibbs et al., 2015).

Hotspots of pasture- and crop-driven deforestation moved into higher forest biomass eco-zones in the early 2000s which caused additional carbon losses. Efforts to reduce carbon emissions might be in vain when countries only concentrate on reducing the deforested area without taking into account variations in forest biomass. However, beyond carbon emissions, the environmental impact (e.g. biodiversity loss) of high deforestation rates in low-carbon biomes such as the Cerrado in Brazil and the Chaco in Paraguay is considerable. This emphasises the importance of spatial and temporal information, not only on drivers of deforestation but also on biodiversity and other safeguards, in designing effective REDD+ interventions. In this study we used mean forest biomass values per eco-zone to estimate carbon losses as a simple and conservative approach (Langner et al., 2014). In reality, however, there are gradations of forest biomass within eco-zones (Saatchi et al., 2011b; Baccini et al., 2012) which might influence the spatial and temporal dynamics of carbon losses from different drivers.

Infrastructure, including urban expansion and roads, contributed little $(1.7 \%)$ to deforestation as a direct driver. As an indirect driver, however, urbanisation can 
contribute significantly to deforestation because it changes consumption patterns and increases the demand for agricultural products (DeFries et al., 2010). Better road infrastructure in the Amazon opened up the forest frontier and expanded the market for cattle (Rudel, 2007). In Peru, infrastructure was a relatively important driver, mostly due to (illegal) mining activities (2.0\% of deforestation) which in addition to forest carbon losses also causes other environmental impacts (Swenson et al., 2011; Asner et al., 2013). The example of Venezuela shows that large infrastructure projects, such as dams, can make a substantial contribution (37.8\% of deforestation) to national forest carbon emissions.

Deforestation drivers and their relative importance on the national level emphasise the need to understand drivers to design effective REDD+ policies. Countries have a variety of policy- and incentive-based interventions at their disposal (Angelsen and Brockhaus, 2009; Kissinger et al., 2012) to affect local to national drivers, which ideally should be adapted to the characteristics of these drivers. For example, countries mostly affected by deforestation due to commercial agriculture might opt for different interventions than countries mostly affected by deforestation due to smallholder agriculture. Most drivers of deforestation originate outside the forest sector which indicates that REDD+ interventions should include non-forest sectors such as the agricultural, urban and mining sectors instead of only focusing on forest interventions such as sustainable forest management. Salvini et al. (2014) found that most countries focus more on forest degradation than on deforestation interventions, and that countries with higher quality data on drivers include more non-forest sector interventions (e.g. agricultural intensification) in their REDD+ readiness documents. Clearly, REDD + countries are struggling with designing effective REDD+ policy interventions partly due to limited understanding of their deforestation drivers.

Unfortunately, our data only covers the timeframe between 1990 and 2005. This limits the applicability for designing up-to-date REDD+ strategies since, as discussed above, the drivers and processes of deforestation in South America have undergone changes after 2005. An important aspect to consider for further research is the influence of the temporal resolution on the follow-up land use. High resolution imagery is usually only available for few points in time within the 1990-2005 timeframe. The immediate follow-up land uses might be missed if a land use transition (e.g. pasture to crop) has occurred between the deforestation event and the closest available high-resolution imagery. In contrast, some land uses only become apparent after some time has passed (e.g. cleared land for urban development). Most REDD+ countries, however, have low capacities for forest monitoring (Romijn et al., 2012) and often do not have spatial quantitative data on drivers of deforestation at their disposal (Hosonuma et al., 2012). This study provides insight into specific drivers 
of deforestation that can help REDD + countries with targeted capacity-building and the stepwise improvement of their national forest monitoring systems to provide more up-to-date and detailed information on drivers of deforestation. In turn this allows for the (re)design of more effective national REDD+ strategies (Salvini et al., 2014).

\subsection{Conclusions}

In this paper we quantified proximate drivers of deforestation and related carbon losses in South America based on remote sensing time series in a systematic, spatially explicit manner. This contributes to the understanding of drivers of deforestation and related carbon losses at the national and continental level and allows for comparisons across national and regional boundaries. In addition, this spatially explicit quantitative information on deforestation can provide valuable input for statistical analysis and modelling of underlying drivers of deforestation. Our findings can also support the development of national REDD+ interventions and forest monitoring systems.

Our results show the importance of temporal and spatial patterns of deforestation drivers. The future priorities for getting more insight into drivers of deforestation in a REDD+ context lie in expanding the geographical area to all REDD+ focus areas (Central America, Sub-Saharan Africa, South East Asia), in using more recent remote sensing time series, and in using more detailed forest biomass maps to capture spatial forest biomass gradations.

\subsection{Acknowledgments}

The authors gratefully acknowledge the support of NORAD (Grant Agreement \#QZA-10/0468) and AusAID (Grant Agreement \#46167) for the CIFOR Global Comparative Study on REDD+. The authors would also like to thank German Baldi, Roberto Chavez, and Marcela Velasco-Gomez for lending their regional expertise in reviewing the drivers. In addition, the authors like to acknowledge the input of Sarah Carter, Maria Pereira, Simon Besnard and Arief Wijaya in the development of the methodology. 
4.A Appendix 


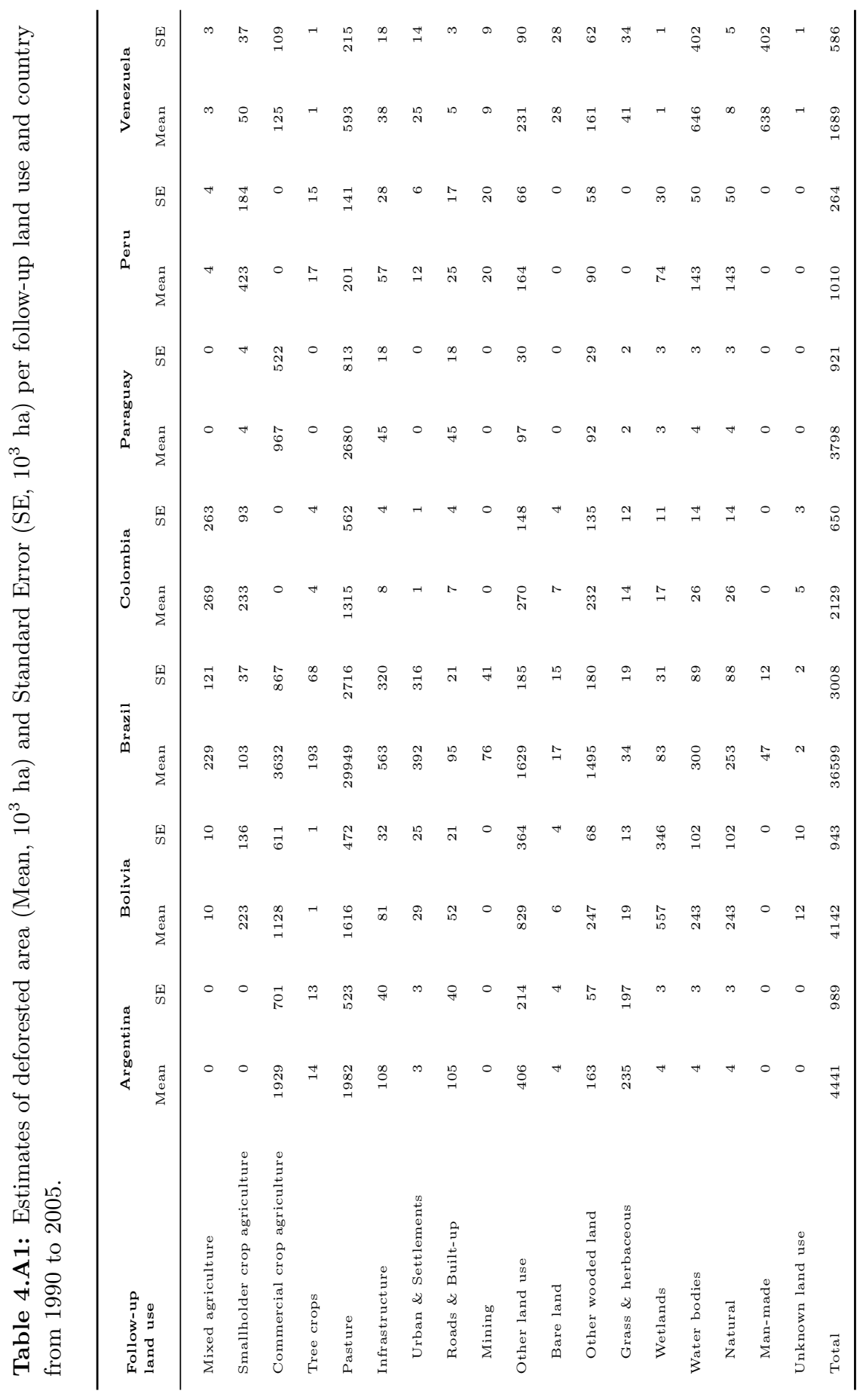




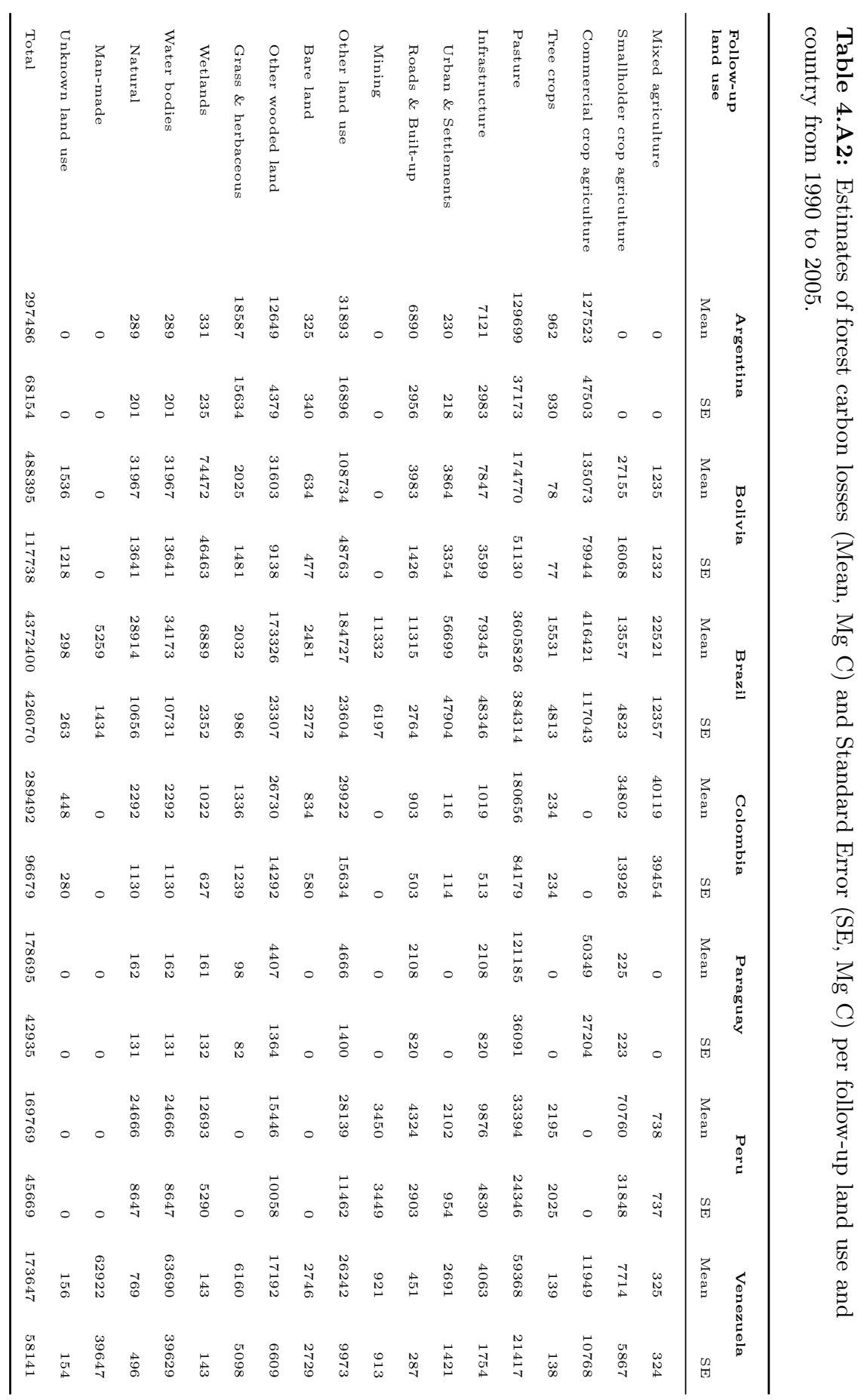




\section{Chapter 5}

\section{Estimation of carbon emission factors from tropical deforestation using remotely-sensed land use and biomass information}

This chapter is based on:

De Sy, V., Herold, M., Achard, F., Baccini, A., Carter, S., Clevers, J.G.P.W., Lindquist, E., Pereira, M., Verchot, L., 2016. Estimation of Carbon emission factors from tropical deforestation using remotely-sensed land use and biomass information, to be submitted 


\section{Abstract}

Reducing emissions from deforestation and forest degradation, and enhancing carbon stocks (REDD+) is a crucial component of global climate change mitigation, and systematically measuring, reporting and verifying forest carbon emissions and removals is essential. Remote sensing can provide continuous and spatially explicit above-ground biomass (AGB) estimates, which can be valuable for the analysis and quantification of carbon stocks and emission factors. Unfortunately, there is little information on the fate of the land following tropical deforestation and of the associated carbon stock. This study assessed carbon emission factors in a spatially explicit manner across the tropics, represented by eight South American countries, eight Asian countries and eleven African countries, by capitalising on newly available remote sensing data on land use following deforestation, AGB density and tree cover with high spatial resolutions. In South America, pasture was the most common post-deforestation land use $(74 \%)$, with commercial crop (11\%) a distant second. In Africa deforestation is often followed by smallholder crop (57\%) with a smaller role for pasture $(12 \%)$. In the Asian countries, tree crops are the most dominant agricultural follow-up land use $(32 \%)$, followed by smallholder crop (23\%). Emission factors showed high spatial variation within eco-zones and countries. Eco-zone averaged forest carbon stocks often did not accurately represent carbon stock of the specific forests that have undergone change. Emissions factors for specific land use conversions were mostly dependent on the spatial dynamics of the land use in combination with initial forest biomass. The fraction of carbon lost was more robust, which might offer some shortcuts for REDD + countries for generating local emission factors from forest inventory data or good quality biomass maps. Our approach yields considerable progress towards better quantification of carbon fluxes from deforestation, and gives added insight into their link to human activities. 


\subsection{Introduction}

At the Paris climate conference (COP21) in December 2015, a global climate deal was adopted by 195 countries. This agreement within the United Nations Framework Convention on Climate Change (UNFCCC) aims to limit global warming caused by anthropogenic greenhouse gas emissions, to below $2^{\circ}$ Celsius. Land use change, mainly deforestation, is the second largest source of anthropogenic $\mathrm{CO}_{2}$ emissions, with the majority of this land use change occurring in tropical regions (IPCC, 2013). Reducing emissions from tropical deforestation is therefore a crucial component of global climate change mitigation. Within the 'Reducing emissions from deforestation and forest degradation, and enhancing carbon stocks' (REDD+) framework, participating countries are encouraged to develop national strategies and implementation plans that reduce emissions and enhance sinks from forests. Systematically measuring, reporting and verifying (MRV) forest carbon emissions and removals is essential within the REDD+ framework.

The IPCC provides guidance to national greenhouse gas inventory compilers on estimating $\mathrm{CO}_{2}$ emissions and removals for land use, land use change and forestry (LULUCF) (IPCC, 2006). Carbon emissions from deforestation can be estimated by combining activity data with emission factors. Activity data (AD) here refer to the change in forest area, while emission factors (EF) refer to the changes in carbon stock per unit area, e.g. tons carbon emitted per hectare of deforestation.

The IPCC identifies 3 approaches to estimate AD related to deforestation (IPCC, 2006). In Approach 1 the total of each land use area change is identified without accounting for conversions between forest and other land uses, while Approach 2 tracks forest land use conversions to other specific land uses in a non-spatially explicit manner. Approach 3 consists of sampling or wall-to-wall mapping techniques to derive spatially explicit land use conversion information (GOFC-GOLD, 2014). Tracking land use conversions is desirable because human activities (i.e. drivers) can be attributed to forest area change, which can be useful for REDD+ policy making and implementation (De Sy et al., 2015). This is preferably done in a spatially explicit manner, in light of the spatio-temporal dynamics of drivers of forest area change (De Sy et al., 2015). Remote sensing is considered essential for monitoring forest and other land use changes (Herold and Johns, 2007; De Sy et al., 2012).

Carbon stock or flow information on the forest carbon pools can be obtained at each Tier according to the IPCC guidelines (IPCC, 2006). Tier 1 uses global default IPCC values (i.e. per ecological zone), while Tier 2 uses country-specific 
carbon stock or flow data. In Tier 3 more disaggregated data of carbon stocks in different pools are available from national inventories, through repeated measurements and supported by modelling. Similar to AD, spatially explicit data on carbon stock is valuable due to the large variation in forest biomass relating to environmental (slope, soil type etc.) and anthropogenic (management practices, land use history etc.) factors (Gibbs et al., 2007). Country or region specific carbon stock data are traditionally derived from forest inventories, which are valuable but often limited in geographic representativeness (Gibbs et al., 2007).

Capacities of REDD+ countries for forest area change monitoring at the national level have improved (Romijn et al., 2015), and some operational sub-national monitoring systems exist in REDD+ countries (e.g. for Brazilian Amazon). However, in many REDD + countries forest inventories are of insufficient quality and progress is slow (Romijn et al., 2015), which means that many countries will have to rely on IPCC Tier 1 default values or simplified assumptions until they build sufficient capacity. Remote sensing can provide continuous and spatially explicit above-ground biomass (AGB) estimates, which can be valuable for the analysis and quantification of carbon stocks and emission factors (Goetz et al., 2009; Saatchi et al., 2011b; Baccini et al., 2012). For example, Langner et al. (2014) provide improved Tier 1 values, based on pan-tropical AGB maps and other remote sensing data.

Several large scale studies have estimated carbon emissions from tropical deforestation for the 1990s and 2000s, using spatially explicit AD and EF data (DeFries et al., 2002; Baccini et al., 2012; Harris et al., 2012; Achard et al., 2014; Tyukavina et al., 2015; De Sy et al., 2015). All of these studies, however, only consider gross estimates of carbon emission, and do not consider the carbon stock of the land use following deforestation. The fate of the land, and associated carbon stock, will influence the total carbon losses from deforestation. For example, it is generally assumed that large-scale mechanised clearing for commercial agriculture results in a more complete removal of biomass than for smallholder farming and pastures (Houghton, 2012). Unfortunately, there is little spatially explicit information on the fate of the land following tropical deforestation (De Sy et al., 2015), and of the associated carbon stock. Integrating information on land use following deforestation, and its carbon stock into emission factors will provide more insight into the complex spatial dynamics of tropical forest carbon loss, and will be a valuable source of information for REDD+ monitoring and strategies.

Recently, new remote sensing data has become available that can help to address this issue. De Sy et al. (2015) quantified land use following deforestation in South America for the periods 1990-2000 and 2000-2005, with a methodology 
that can be extended to other tropical areas. Zarin et al. (2016) extended the methodology of Baccini et al. (2012) to generate a pan-tropical map of above-ground live woody biomass density at $30 \mathrm{~m}$ resolution for circa the year 2000. Hansen et al. (2013) released a globally consistent 30 meter resolution dataset of tree cover loss and gain for the years 2000 to 2013. These new datasets allow for the co-location of forest loss, post-deforestation land use and biomass estimates at similar spatial resolutions. Accordingly, our study aims to:

1. Explore how to combine these datasets to improve carbon emission factor estimates by including the carbon stock of the land use following deforestation

2. Assess and analyse carbon emission factors in a spatially explicit manner, taking into account land use following deforestation

3. Make recommendations on the use of these emission factor estimates as input for REDD+ forest monitoring

\subsection{Material and methods}

Our study area covers twenty-seven countries across the tropics: eight South American countries (Argentina, Bolivia, Brazil, Colombia, Ecuador, Paraguay, Peru and Venezuela), eight Asian countries (Cambodia, Indonesia, Lao PDR, Malaysia, Papua New Guinea, Philippines, Thailand and Vietnam) and eleven African countries (Angola, Democratic Republic of Congo, Ethiopia, Kenya, Malawi, Mozambique, Namibia, South Africa, Tanzania, Zambia and Zimbabwe). Figure 5.1 gives a conceptual overview of the steps in our methodology.

\subsubsection{Activity data and land use following deforestation per sample unit}

Land use following deforestation was obtained by extending the methodology of De Sy et al. (2015) to our study area. This methodology is based on assessing a detailed (follow-up) land use classification for each forest loss area identified by the Remote Sensing Survey of the Global Forest Resources Assessment 2010 of FAO (FAO FRA2010 RSS) (FAO \& JRC, 2012) (Figure 5.1a and b). We briefly describe this dataset as it was the basis for the assessment of land use following deforestation. FAO FRA-2010 RSS is a spatially explicit dataset of forest land use change from 1990 to 2005 (Figure 5.1a). The FAO FRA-2010 RSS used a systematic sampling design with sample units of $10 \times 10 \mathrm{~km}$ centred on each degree latitude-longitude confluence point (Eva et al., 2012; FAO \& JRC, 2012; Achard et al., 2014). For each sample unit, medium 


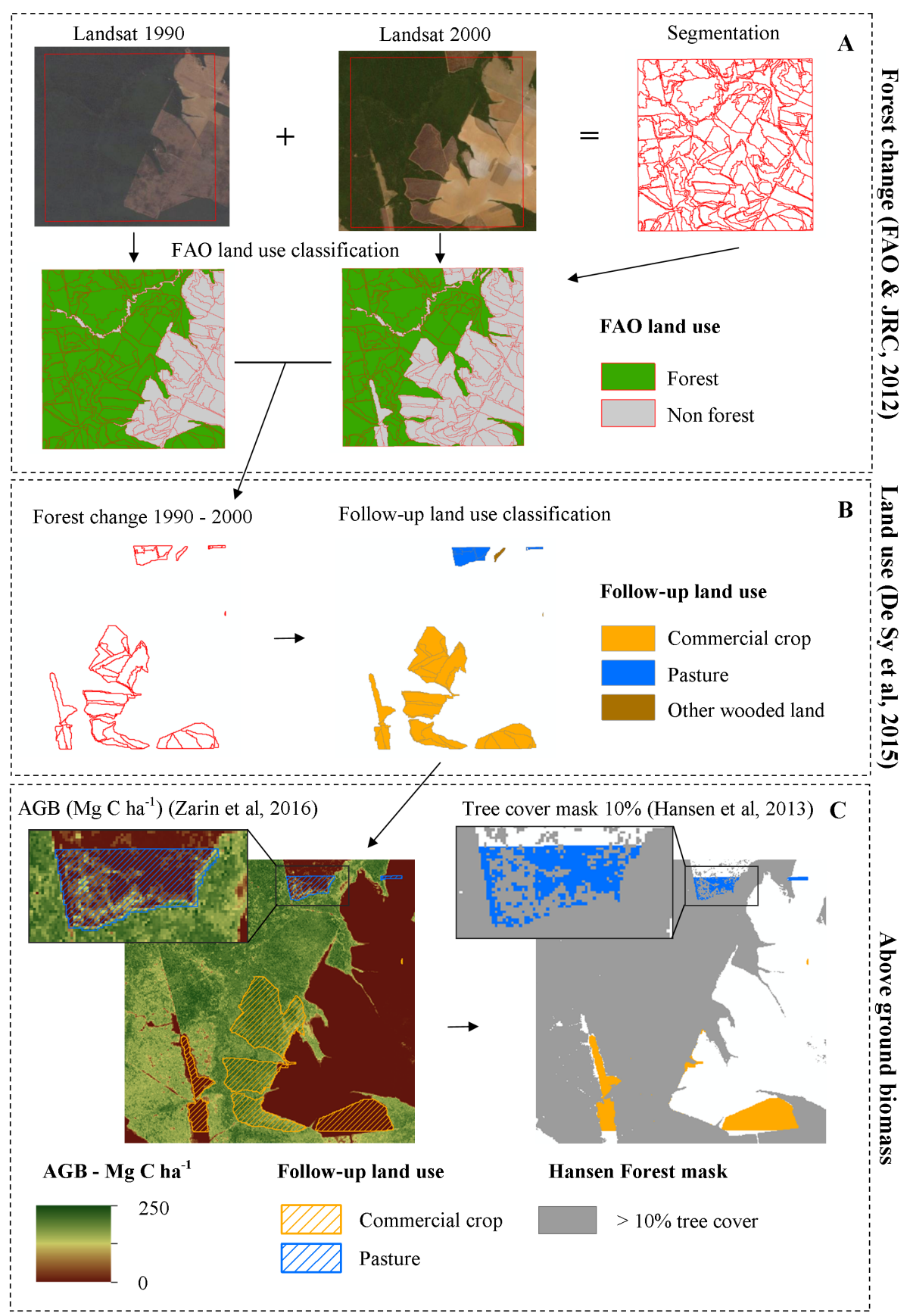

Figure 5.1: Conceptual framework of the methodological steps and datasets 
resolution satellite imagery (mainly Landsat), as close as possible to reference years 1990, 2000 and 2005, was used in an automated multi-date image segmentation to subdivide the sample unit into delineated areas (polygons) with similar spectral and structural attributes. The target minimum mapping unit was 5 ha. Then, a supervised automated land cover classification was carried out. This was later converted to a land use classification with the help of expert human interpretation. The main land use classes were Forest, Other wooded land, and Other land, which are based on FAO forest definitions (FAO, 2010). Areas lacking data due to clouds or poor satellite coverage were considered an unbiased loss of information. For this study, we only used the 1990 to 2000 data, as this corresponds best with the pan-tropical map of above-ground live woody biomass density (further referred to as AGB map). For this timeframe this sample grid provided 1394, 331 and 894 sample units for the South American, Asian and African study areas, respectively. Due to the limited extent of the AGB map, for estimating EFs the number of sample units was reduced to 1167 and 842 in respectively South America and Africa. Figure 5.2 gives an overview of the study area, all sample points and the FAO ecological zones (eco-zones) (FAO, 2001) in our study area.

Land use following deforestation was obtained by assigning a more detailed (followup) land use classification for each forest loss area (polygon) identified by the FAO FRA-2010 RSS (Figure 5.1b). The follow-up land use classification was done by visual interpretation, using parameters such as land cover, the presence of certain features within or near changed areas (e.g. crop rows, watering holes, fences) and the spatial context and location of change (e.g. distance to settlements, concessions). Table 5.1 gives an overview of the follow-up land use classes and their descriptions. A variety of satellite imagery was used for the visual interpretation such as Landsat, Google Earth imagery (Google Earth, 2015) and ESRI world imagery base maps. De Sy et al. (2015) provides more details on the follow-up land use classification methodology.

\subsubsection{Emission factors per sample unit}

The emission factor per follow-up land use for each sample unit was estimated by estimating forest carbon stock before deforestation $\left(\mathrm{C}_{\text {Forest }}\right)$, and the carbon stock of the land use following deforestation $\left(\mathrm{C}_{\mathrm{FLU}}\right)$. We only considered the five main land uses following deforestation: pasture, commercial cropland, smallholder cropland, perennial/tree crop and other land use.

A pan-tropical 30 meter resolution AGB map (Zarin et al., 2016) was used to derive the mean AGB density for forest and follow-up land uses for each sample unit (Figure 5.1c). This wall-to-wall AGB map represents AGB density for the year 
Table 5.1: Follow-up land use classes and their description.

\begin{tabular}{|c|c|c|}
\hline & Follow-up land use & Description \\
\hline \multirow{5}{*}{ 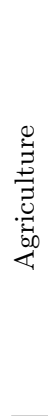 } & Mixed agriculture & Mix of agricultural land uses \\
\hline & Commercial crop & $\begin{array}{l}\text { Land under cultivation for crops, characterised by medium } \\
(2-20 \text { ha) to large }(>20 \text { ha) field sizes }\end{array}$ \\
\hline & Smallholder crop & $\begin{array}{l}\text { Land under cultivation for crops, characterised by very small } \\
(<0.5 \text { ha) to small field sizes }(0.5-2 \text { ha })\end{array}$ \\
\hline & Tree crops & $\begin{array}{l}\text { Miscellaneous tree crops (e.g. coffee, palm trees), orchards } \\
\text { and groves }\end{array}$ \\
\hline & Pasture & $\begin{array}{l}\text { Land used predominantly for grazing; in either } \\
\text { managed/cultivated (pastures) or natural (grazing land) } \\
\text { setting; includes grazed woodlands }\end{array}$ \\
\hline \multirow{3}{*}{ 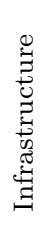 } & Urban and Settlements & Urban, settlements and other residential areas \\
\hline & Roads and built-up & $\begin{array}{l}\text { Roads, built-up areas and other transport, industrial and } \\
\text { commercial infrastructures }\end{array}$ \\
\hline & Mining & $\begin{array}{l}\text { Land used for extractive subsurface and surface mining } \\
\text { activities (e.g. underground and strip mines, quarries and } \\
\text { gravel pits), including all associated surface infrastructure }\end{array}$ \\
\hline \multirow{5}{*}{ 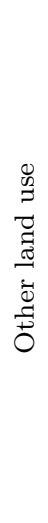 } & Other land use (general) & $\begin{array}{l}\text { All land that is not classified as forest, agriculture, } \\
\text { infrastructure, mining and water }\end{array}$ \\
\hline & Bare land & Barren land (exposed soil, sand, or rocks) \\
\hline & Other wooded land & $\begin{array}{l}\text { Land not classified as forest, spanning more than } 0.5 \mathrm{ha} \text {; } \\
\text { with trees higher than } 5 \mathrm{~m} \text { and canopy cover of } 5 \%-10 \% \text {, or } \\
\text { trees able to reach these thresholds in situ, or with a } \\
\text { combined cover of shrubs, bushes and trees above } 10 \% \text {. It } \\
\text { does not include land that is predominantly under } \\
\text { agricultural or urban land use (FAO, 2010) }\end{array}$ \\
\hline & Grass and herbaceous & Land covered with (natural) herbaceous vegetation or grasses \\
\hline & Wetlands & $\begin{array}{l}\text { Areas of natural vegetation growing in shallow water or } \\
\text { seasonally flooded environments. This category includes } \\
\text { Marshes, swamps, and bogs }\end{array}$ \\
\hline \multicolumn{2}{|c|}{ Water } & $\begin{array}{l}\text { Natural (river, lake etc) or man-made waterbodies (e.g. } \\
\text { reservoirs) }\end{array}$ \\
\hline \multicolumn{2}{|c|}{ Unknown land use } & $\begin{array}{l}\text { All land that cannot be classified (e.g. due to low resolution } \\
\text { imagery) }\end{array}$ \\
\hline
\end{tabular}




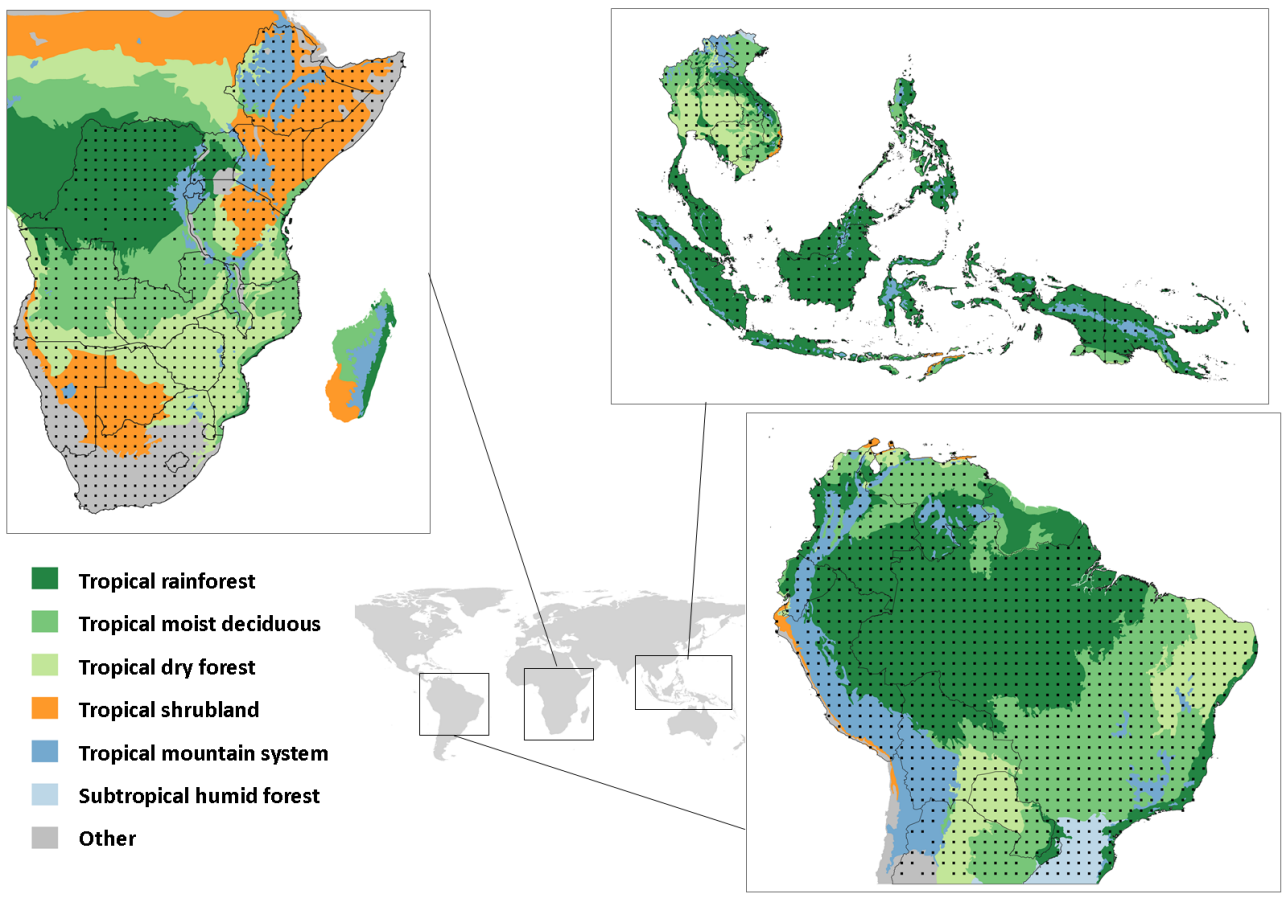

Figure 5.2: Location of sample units (FAO \& JRC, 2012), and ecological zones (FAO, 2001) in the study area

c. 2000, and was derived from 40000 Geoscience Laser Altimeter System (GLAS) LiDAR footprints distributed across the tropics. These GLAS-derived estimates were converted to a continuous gridded dataset using randomForest models with Landsat 7 ETM+ and other ancillary datasets as input (Baccini et al., 2012; Zarin et al., 2016).

We used the Hansen tree cover dataset (Hansen et al., 2013), which has the same resolution (30m) as the AGB map, as a forest mask for the year 2000 (Figure 5.1c) with forest defined as more than $10 \%$ tree cover. Although the FAO FRA- 2010 RSS provides a forest - non-forest classification, with forest defined as land spanning more than 0.5 hectares and a canopy cover of more than 10 percent (FAO, 2010), we used a minimum mapping unit of 5 ha. Within the 5 ha mapping unit, dominant forest patches might be mixed with small patches of other land uses and vice versa, which results in relatively higher AGB values for follow-up land use polygons and relatively lower AGB values for forest polygons. In addition since both datasets are from circa 2000, they might not exactly match temporally (e.g. the FRA-2010 RSS dataset is using imagery around 1st July 2000 as a target date but depending on data 
availability imagery is spread along the period 1999-2002, see Beuchle et al. (2011)). Use of the Hansen tree cover map corrected for this and for spatial inaccuracies between the FAO FRA-2010 RSS and AGB map, by masking out forest pixels in the follow-up land use polygons and non-forest pixels in stable forest polygons. An example for pasture and cropland is shown in Figure 5.1c. On the left, the follow-up land use polygons are combined with the AGB map. It is clear that there is a mismatch of timing of the deforestation event for the crop fields in the centre. The FAO FRA-2010 identified these fields as deforested before 2000, while in the AGB map high biomass levels are still present, which is associated with the presence of forest cover. This can be corrected by applying the Hansen tree cover mask as the right of Figure 5.1c shows. Only the pixels that were not covered by the forest mask (shown in blue and yellow) were used for estimating mean biomass. The pasture field at the top of the sample unit illustrates how we corrected for spatial inaccuracies along the edges of the field, and for the presence of tree cover within the field. For the analysis of mean AGB for tree crops, the tree cover mask was not applied because the Hansen tree cover dataset does not distinguish between trees in natural forest and tree plantations.

Our activity data represent areas deforested before 2000, so we can directly estimate the mean AGB of the follow-up land use per sample unit with zonal statistics using the masked AGB map. Since forest loss occurred before 2000, we used the mean AGB of the remaining stable forest (i.e. forest from 1990 to 2005) within a sample unit as a proxy for the AGB of the forest before deforestation.

We derived total biomass from AGB for both follow-up land use and stable forest per sample unit by applying the equation 5.1 used by Saatchi et al. (2011b):

$$
\text { Total Biomass }=\mathrm{AGB}+0.489 * \mathrm{AGB}^{0.89}
$$

Total carbon was considered to be $50 \%$ of total biomass as in Achard et al. (2014). We did not account for soil carbon loss.

Finally we derived the emission factor per follow-up land use (EF) per sample unit by:

$$
\mathrm{EF}=\mathrm{C}_{\text {Forest }}-\mathrm{C}_{\mathrm{FLU}}
$$

We also calculated the percentage of carbon lost $\left(\mathrm{EF}_{\%}\right)$ : 


$$
\mathrm{EF}_{\%}=\mathrm{EF} / \mathrm{C}_{\text {Forest }} * 100
$$

\subsubsection{Scaling to regional level}

Forest area loss, mean forest carbon stock of all forests, forest carbon stock of forests that were cleared $\left(\mathrm{C}_{\text {Forest }}\right)$, carbon stock of the land use following deforestation $\left(\mathrm{C}_{\mathrm{FLU}}\right)$ and emission factors per follow-up land use were scaled to the national, eco-zone (FAO, 2001) and continental level. The legal Amazon in Brazil (Acre, Amapá, Amazonas, Pará, Rondônia, Roraima and Tocantins, part of Mato Grosso and most of Maranhão) was added as a regional unit of analysis.

To scale up forest area loss per follow-up land use to the country, eco-zone and continental scales, the forest area loss within each sample unit is made proportional to the 'visible land' area of the sample unit. The 'visible land' area was the full sample unit area $\left(100 \mathrm{~km}^{2}\right)$ minus cloudy and 'permanent water' areas (i.e. sea or inland water in all considered years). In addition, each sample unit was assigned a weight $\left(\mathrm{w}_{\mathrm{i}}\right)(5.4)$, equal to the cosine of its latitude $\left(\right.$ coslat $\left._{\mathrm{i}}\right)$, because the actual area represented by a sample unit decreased as latitude increased due to the curvature of Earth:

$$
w_{i}=\frac{\operatorname{coslat}_{i}}{\sum_{i} \operatorname{coslat}_{i}}
$$

The proportions of forest area changes per follow-up land use were then extrapolated to a given region using the Horvitz-Thompson direct estimator (Särndal et al., 1992) (5.5).

$$
\bar{x}_{c}=\frac{1}{M} \times \sum_{i=0}^{n}\left(w_{i} \times x_{i c}\right),
$$

where

$$
M=\sum_{i=0}^{n} w_{i}
$$

and where $\mathrm{x}_{\mathrm{ic}}$ is the proportion of forest area change in the $\mathrm{i}^{\text {th }}$ sample unit and $\mathrm{w}_{\mathrm{i}}$ is the weight of the $\mathrm{i}^{\text {th }}$ sample unit. The total area of forest area change per follow-up land use for this region (FLU $\mathrm{Fegion}_{\text {) }}$ ) is then obtained from: 


$$
\mathrm{FLU}_{\text {region }}=A \times \bar{x}_{c}
$$

where $\mathrm{A}$ is the total area of the region (excluding permanent water).

The variance of the estimation of the mean for this systematic sample was calculated as follows:

$$
s^{2}=\frac{1}{M} \times \sum_{i=0}^{n} w_{i} \times\left(\bar{x}_{c}-x_{i c}\right)^{2}
$$

The standard error $(\mathrm{SE})$ is then calculated as:

$$
\mathrm{SE}=A \times \frac{s}{\sqrt{n}}
$$

The SE represents only the sampling error.

For scaling up the mean carbon stocks of all forests, the carbon stocks of forests that were cleared $\left(\mathrm{C}_{\text {Forest }}\right)$, the carbon stocks of the land uses following deforestation $\left(\mathrm{C}_{\mathrm{FLU}}\right)$ and emission factors per follow-up land use $(\mathrm{EF})$ to regional (i.e. country, eco-zone and continental) scales a weighted mean of all sample unit values within that specific region was calculated, using the same weight $\left(\mathrm{w}_{\mathrm{i}}\right)$ and 'visible land area' as above. If there were less than five sample units for a follow-up land use in a region, the results are not shown. If there were less than ten sample units present, an annotation was added.

\subsection{Results}

\subsubsection{Deforestation per follow-up land use from 1990 to 2000}

We estimated that the total deforested area from 1990 to 2000 reached 34.8 million hectare for the South American study area, 13.0 million hectare for the African study area and 1.7 million hectare for the Asian study area (Table 5.2). In all regions agriculture is the dominant follow-up land use. In the South American countries, deforestation is followed by pasture $(73.7 \%)$ and to a lesser extent by commercial cropland (11.0\%). In Africa deforestation is more often followed by smallholder cropland (56.8\%), with a smaller role for pasture (12.0\%). In the Asian countries, 
tree crops $(32.0 \%)$ are the most dominant agricultural follow-up land use, followed by smallholder cropland $(23.0 \%)$. In the non-agricultural category, other land use was important in the Asian region (38.7\%), particularly other wooded land $(31.2 \%)$, most likely fallows and swiddens. Other land use was less important in the African (18.4\%) and South American regions (6.8\%). Infrastructure accounted for $7.7 \%$ of deforestation in the African region, mainly due to settlement areas (7.3\%). In the Asian countries, infrastructure as follow-up land use was much less (3.7\%) important, consisting mainly of road expansion (1.5\%) and mining (1\%). In the South American countries, infrastructure expansion (1.7\%) mainly comprised settlement (1\%) and road expansion $(0.4 \%)$.

Figure 5.3 shows the distribution of follow-up land uses across the study areas. As mentioned above, pasture is particularly dominant as follow-up land use in South America (Figure 5.3a), especially in the Brazilian arc of deforestation, the Brazilian Pantanal and Cerrado ecoregions, Western Paraguay and the Argentinian Chaco. Deforestation followed by commercial cropland was more prevalent in the Brazilian Mato Grosso State, Eastern Paraguay, Central Bolivia and Northern Argentina, while smallholder cropland expansion mainly occurred in the Andean countries.

Among the African countries, hotspots of deforestation can be found in Mozambique, Democratic Republic of the Congo, Tanzania and Zambia, mainly due to smallholder cropland expansion and other land use (Figure 5.3b). Smallholder cropland is also the most dominant follow-up land use in Angola, Botswana, Ethiopia, Malawi, Swaziland and Zimbabwe. Deforestation followed by pasture is predominant in Botswana, Kenya and Somalia, and occurs to a lesser extent in Angola, Ethiopia, Zimbabwe, Namibia and Tanzania. Commercial cropland and tree crop as follow-up land use is less common in this region, but some hotspots of commercial cropland expansion can be found in Southern Zambia, with some occurrences in Kenya, South Africa and Zambia.

In the Asian region (Figure 5.3c), most deforestation between 1990 and 2000 occurs in Indonesia, mostly in North Sumatra and South Kalimantan. Tree crop is an important follow-up land use in Indonesia, as well as other land use (mostly other wooded land). In Malaysia, Thailand and the Philippines, tree crop is the dominant follow-up land use. In Vietnam, Cambodia and Lao PDR on the other hand, most deforestation is followed by smallholder cropland. Smallholder cropland is also important in Thailand, the Philippines and Papua New Guinea. In this last country, most deforestation is followed by other land use, such as other wooded land and grassland. Also in Cambodia and Lao PDR, deforestation is often followed by other wooded land. Pasture is not a common follow-up land use, and can only be 


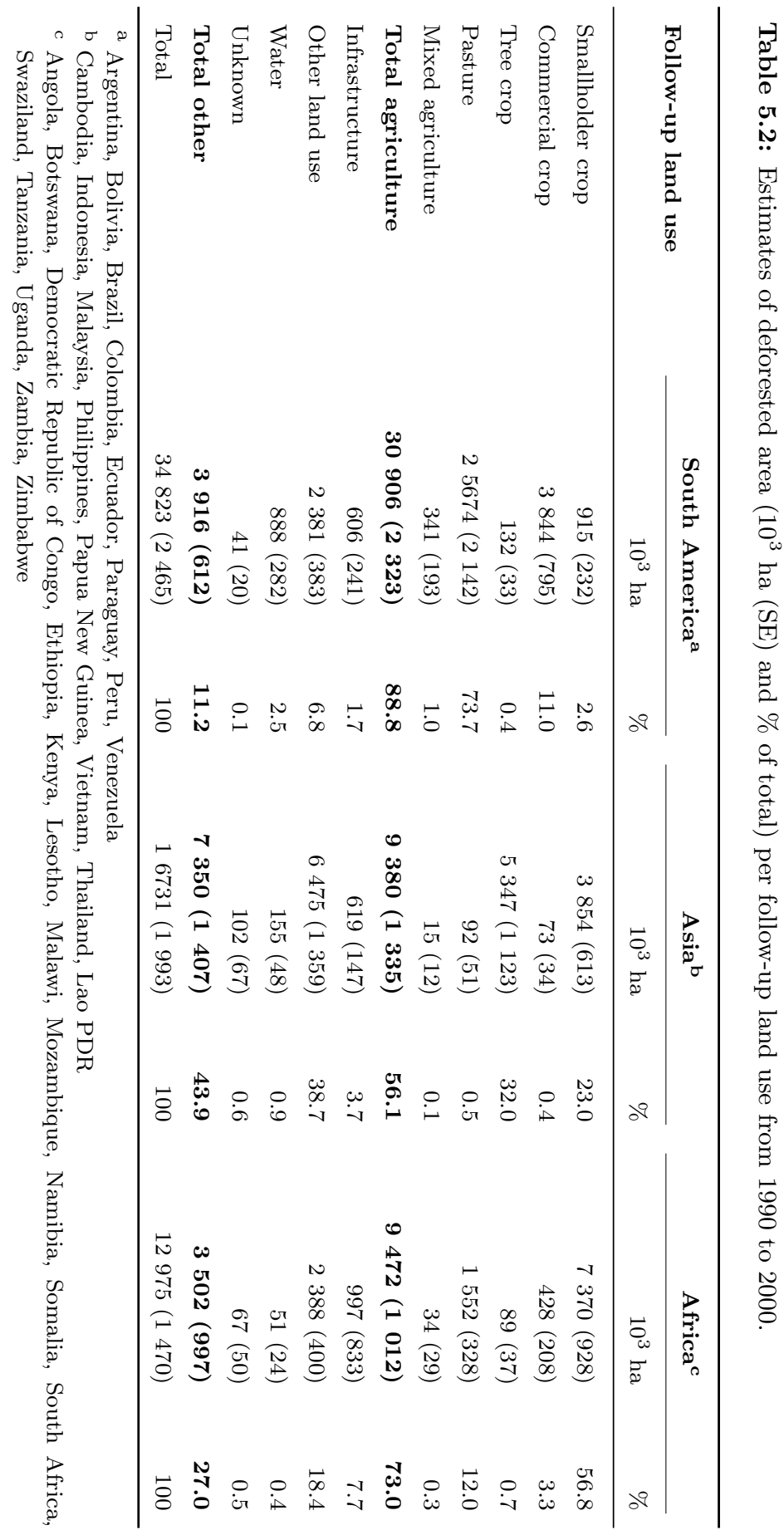


found in Lao PDR and Thailand.

\subsubsection{Emission factors per follow-up land use}

Table 5.3 presents the mean carbon stock of all forests $\left(\mathrm{Mg} \mathrm{C} \mathrm{ha}^{-1}\right)$ within an eco-zone, and the mean carbon stock of forests $\left(\mathrm{C}_{\text {Forest }}\right.$ in $\left.\mathrm{Mg} \mathrm{C} \mathrm{ha}{ }^{-1}\right)$ that were cleared and followed by pasture, commercial cropland, smallholder cropland, tree crop and other land use. In our African study region, the mean carbon stock of forests $(112 \mathrm{Mg} \mathrm{C}$ $\mathrm{ha}^{-1}$ ) was significantly higher than the mean carbon stock of forests cleared for pasture (37 $\mathrm{Mg} \mathrm{C} \mathrm{ha}{ }^{-1}$ ), commercial cropland (42 $\mathrm{Mg} \mathrm{C} \mathrm{ha}^{-1}$ ), smallholder cropland (50 Mg C $\left.\mathrm{ha}^{-1}\right)$ and other land use (33 $\left.\mathrm{Mg} \mathrm{C} \mathrm{ha}{ }^{-1}\right)$. In our Asian and South American study area we saw a similar pattern for all follow-up land uses. In the South American tropical rainforest forest conversion to smallholder croplands (157 $\left.\mathrm{Mg} \mathrm{C} \mathrm{ha}^{-1}\right)$ and pasture (117 $\mathrm{Mg} \mathrm{C} \mathrm{ha}{ }^{-1}$ ) occurred in forests that contained a higher carbon stock than forests that were converted to commercial cropland $\left(99 \mathrm{Mg} \mathrm{C}^{-1}\right)$. In contrast, in respectively the tropical moist deciduous and tropical dry forests of this continent, deforestation followed by commercial cropland (90 $\mathrm{Mg} \mathrm{C} \mathrm{ha}^{-1}, 91 \mathrm{Mg} \mathrm{C} \mathrm{ha}^{-1}$ ) happened in forests with a higher carbon stock than deforestation followed by pasture $\left(71 \mathrm{Mg} \mathrm{C}^{-1}, 46\right.$ $\mathrm{Mg} \mathrm{C} \mathrm{ha}{ }^{-1}$ ). In the Asian study area, mean carbon stocks in forests that were later cleared for tree crops (141 $\mathrm{Mg} \mathrm{C} \mathrm{ha}^{-1}$ ) were mostly higher than in forests cleared for smallholder cropland (119 $\mathrm{Mg} \mathrm{C} \mathrm{ha}^{-1}$ ) and other land uses (131 $\left.\mathrm{Mg} \mathrm{C} \mathrm{ha}^{-1}\right)$.

In Table 5.4 the mean carbon stock of the follow-up land uses $\left(\mathrm{C}_{\mathrm{FLU}}\right)$ are shown on the continental and eco-zone level. In the South American tropical rainforest higher carbon stocks remained on land converted to smallholder cropland $\left(8.3 \mathrm{Mg} \mathrm{C} \mathrm{ha}{ }^{-1}\right)$ or other land use $\left(8.6 \mathrm{Mg} \mathrm{C} \mathrm{ha} \mathrm{M}^{-1}\right)$ in comparison to land converted to pasture (4.0 $\mathrm{Mg} \mathrm{C} \mathrm{ha-1)} \mathrm{or} \mathrm{commercial} \mathrm{cropland}\left(1.9 \mathrm{Mg} \mathrm{C} \mathrm{ha}^{-1}\right)$. In the South American tropical moist deciduous forest, more carbon stock remained on commercial cropland $(5.5 \mathrm{Mg}$ $\mathrm{C} \mathrm{ha} \mathrm{h}^{-1}$ ) than on pastureland $\left(1.7 \mathrm{Mg} \mathrm{C} \mathrm{ha}{ }^{-1}\right)$, whereas the opposite was true for the South American tropical rainforest. In the African tropical dry forest more carbon stock remained on commercial cropland $\left(5.8 \mathrm{Mg} \mathrm{C}^{-1}\right)$ than on pastureland $(3.3 \mathrm{Mg}$ $\left.\mathrm{C} \mathrm{ha}{ }^{-1}\right)$.

Figure 5.4 shows the spatial variability of emission factor (EF) estimates per followup land use across the three continents. Emission factors for pasture ranged widely from $170 \mathrm{Mg} \mathrm{C} \mathrm{ha}^{-1}$ in the Brazilian tropical rainforest to $20 \mathrm{Mg} \mathrm{C} \mathrm{ha}^{-1}$ in the Kenyan tropical montane region. In the Asian region, pasture EFs were all in the 100 to $150 \mathrm{Mg} \mathrm{C} \mathrm{ha}^{-1}$ range, but in the South American and African regions they showed more spatial variability. Emission factors related to commercial cropland displayed a similar range and spatial variability from $23 \mathrm{Mg} \mathrm{C} \mathrm{ha}^{-1}$ in the tropical dry forest of Namibia to $126 \mathrm{Mg} \mathrm{C} \mathrm{ha}^{-1}$ in the Bolivian tropical rainforest. Emission 


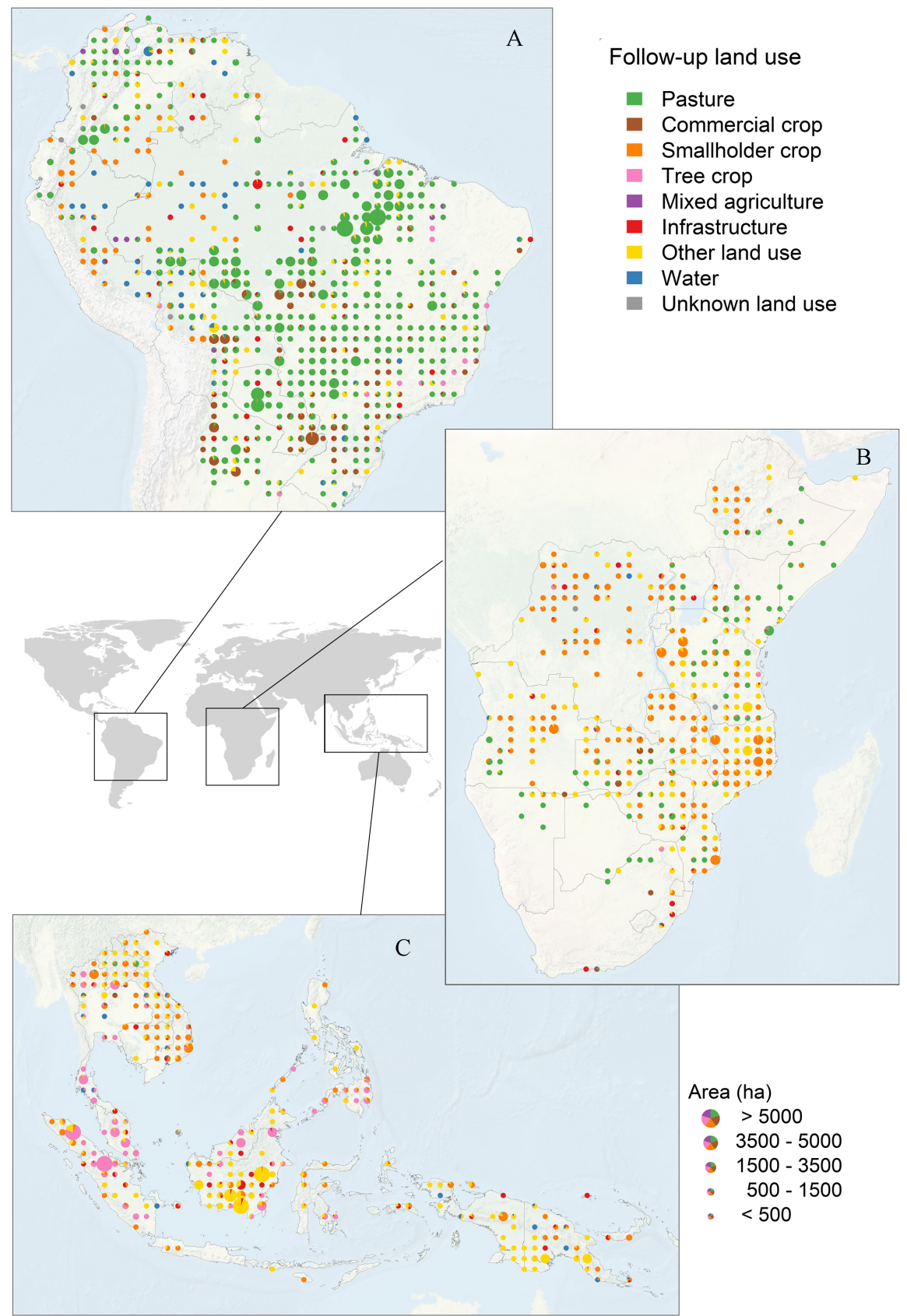

Figure 5.3: Forest area loss (ha) per follow-up land use from 1990 to 2000 in South America (A), Africa (B) and Asia (C) 


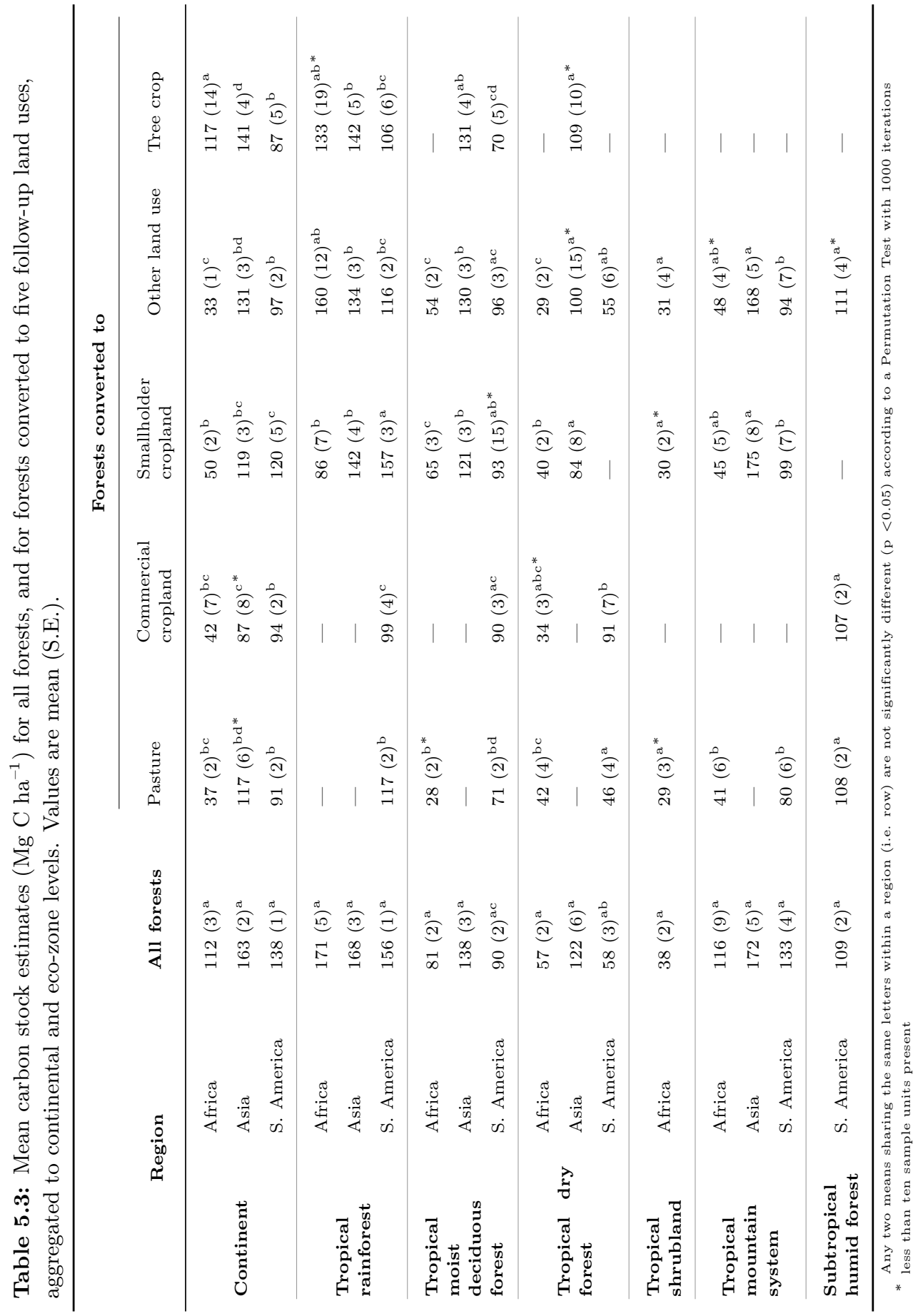




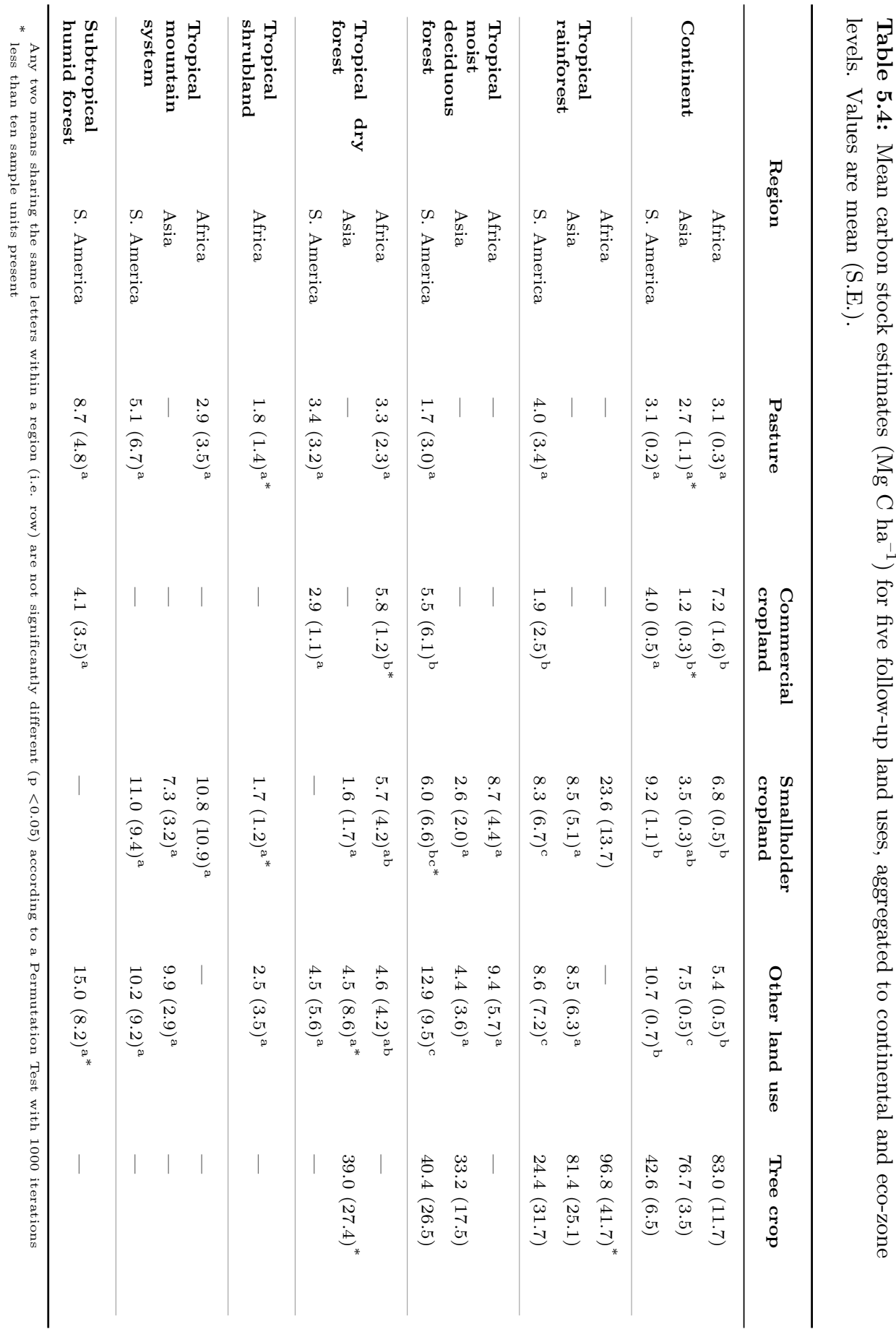


factors related to smallholder cropland were consistently high in Asia, most of South America, and in the Democratic Republic of Congo, with a maximum of $193 \mathrm{Mg} \mathrm{C}$ $\mathrm{ha}^{-1}$ in the Indonesian tropical rainforest. In the other African countries the EFs for smallholder cropland were lower with a minimum of $17 \mathrm{Mg} \mathrm{C}^{\text {ha }}{ }^{-1}$ in Somalia, and spatial variability was higher. The EFs associated with tree crops were relatively low in South America and Africa, while higher values could be found in Asia. They showed high variability across all continents, with a maximum of $140 \mathrm{Mg} \mathrm{C} \mathrm{ha}^{-1}$ in the tropical rainforest of Malaysia. For EFs from other land uses, we found values ranging from $17 \mathrm{Mg} \mathrm{C} \mathrm{ha}^{-1}$ in the Bolivian tropical dry forest to $173 \mathrm{Mg} \mathrm{C} \mathrm{ha}^{-1}$ in the Brazilian tropical rainforest, with high spatial variability in Africa, and to a lesser extent in South America.

Aggregated EFs at the continental level (Figure 5.5, left), showed that continental EFs for all follow-up land uses are lowest in the African region $\left(27-43 \mathrm{Mg} \mathrm{C} \mathrm{ha}{ }^{-1}\right)$. The highest continental EFs could be found in the Asian region $(64-124 \mathrm{Mg} \mathrm{C}$ $\mathrm{ha}^{-1}$ ), except for commercial cropland (86 $\mathrm{Mg} \mathrm{C} \mathrm{ha}^{-1}$ ) which had a slightly higher $\mathrm{EF}$ in South America $\left(90 \mathrm{Mg} \mathrm{C} \mathrm{ha}{ }^{-1}\right.$ ). For the other follow-up land uses, EFs in South America were positioned in the middle $\left(45-110 \mathrm{Mg} \mathrm{C} \mathrm{ha}{ }^{-1}\right)$. Continental EFs for smallholder croplands were generally higher than for pasture and commercial cropland. Continental EFs for pasture and commercial cropland were quite similar, except in the Asian region, where the continental EF for pasture was higher than for commercial cropland. On the eco-zone level in the South American region, EFs for commercial cropland were higher than for pasture, except in the tropical rainforest where the opposite was found. On the Asian continent, other land use had the highest continental EF, while on the African continent it was lowest. In South America the continental EF for other land use was similar to continental EFs for commercial cropland and pasture. On the eco-zone level, for all continents, no clear pattern emerged for other land use EFs. Emission factors for tree crops were in general low but showed high variability across eco-zones. On the African and South American continent, slightly higher EFs occurred in the tropical rainforest compared to other eco-zones. On the Asian continent, EFs were highest in the tropical mountain system. In Asia and South America, the percentage carbon lost (Figure 5.5, right) tended to be more comparable across follow-up land uses and eco-zones than EF estimates. In Africa, the percentage of carbon lost was generally lower than in Asia and South America. In addition, there was more variability of the percentage of carbon lost within eco-zones, and for smallholder cropland across different eco-zones. The percentage of carbon lost when converting forest to tree crop plantations was an exception, as it was lower than for all other forest conversions; moreover, it showed high variability across the whole study area.

Aggregated EFs on the national level (Figure 5.6) show that most EFs in Africa are 

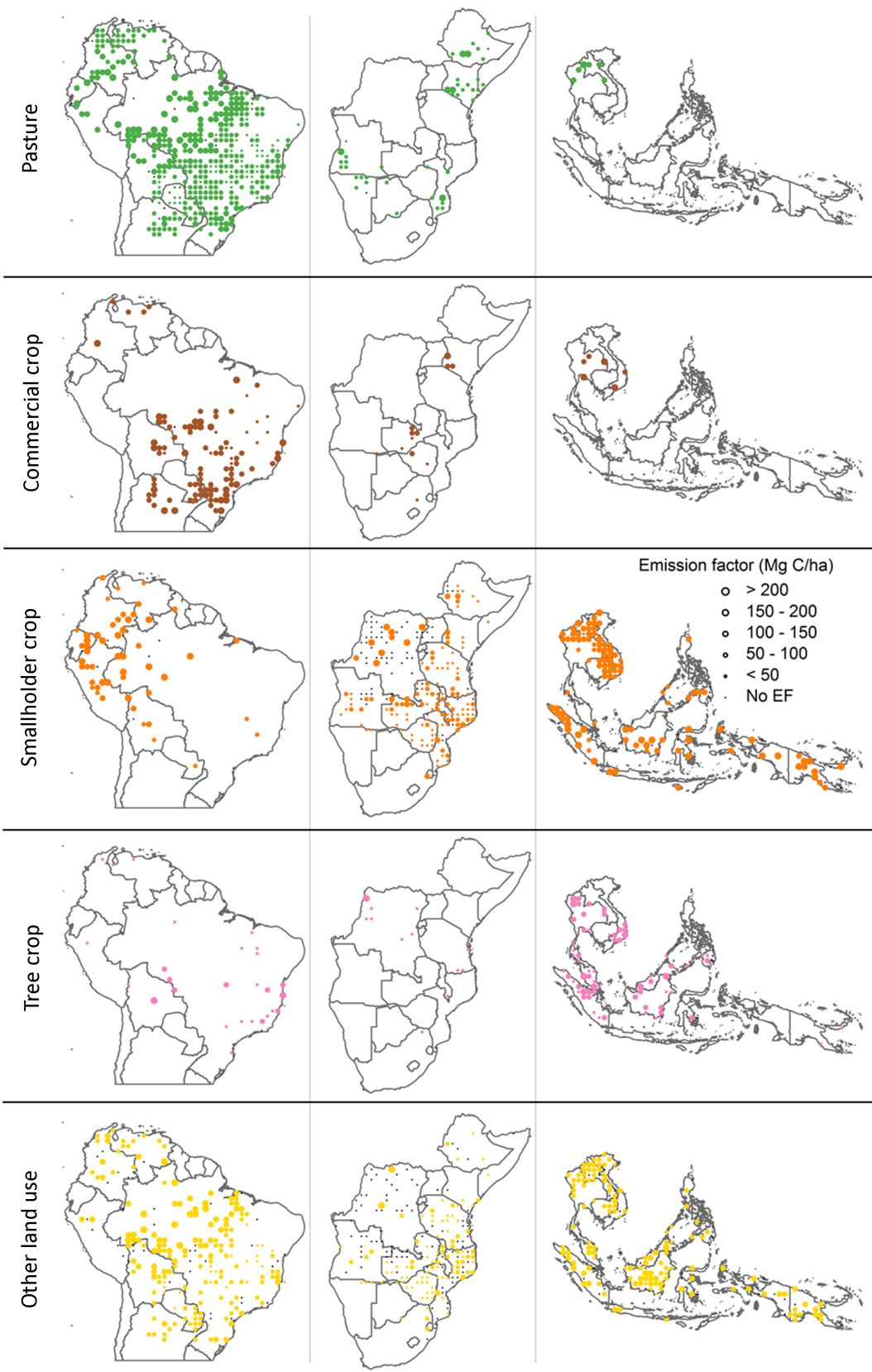

Figure 5.4: Spatial distribution of emission factors $\left(\mathrm{Mg} \mathrm{C} \mathrm{ha}^{-1}\right)$ per continent and follow-up land use 


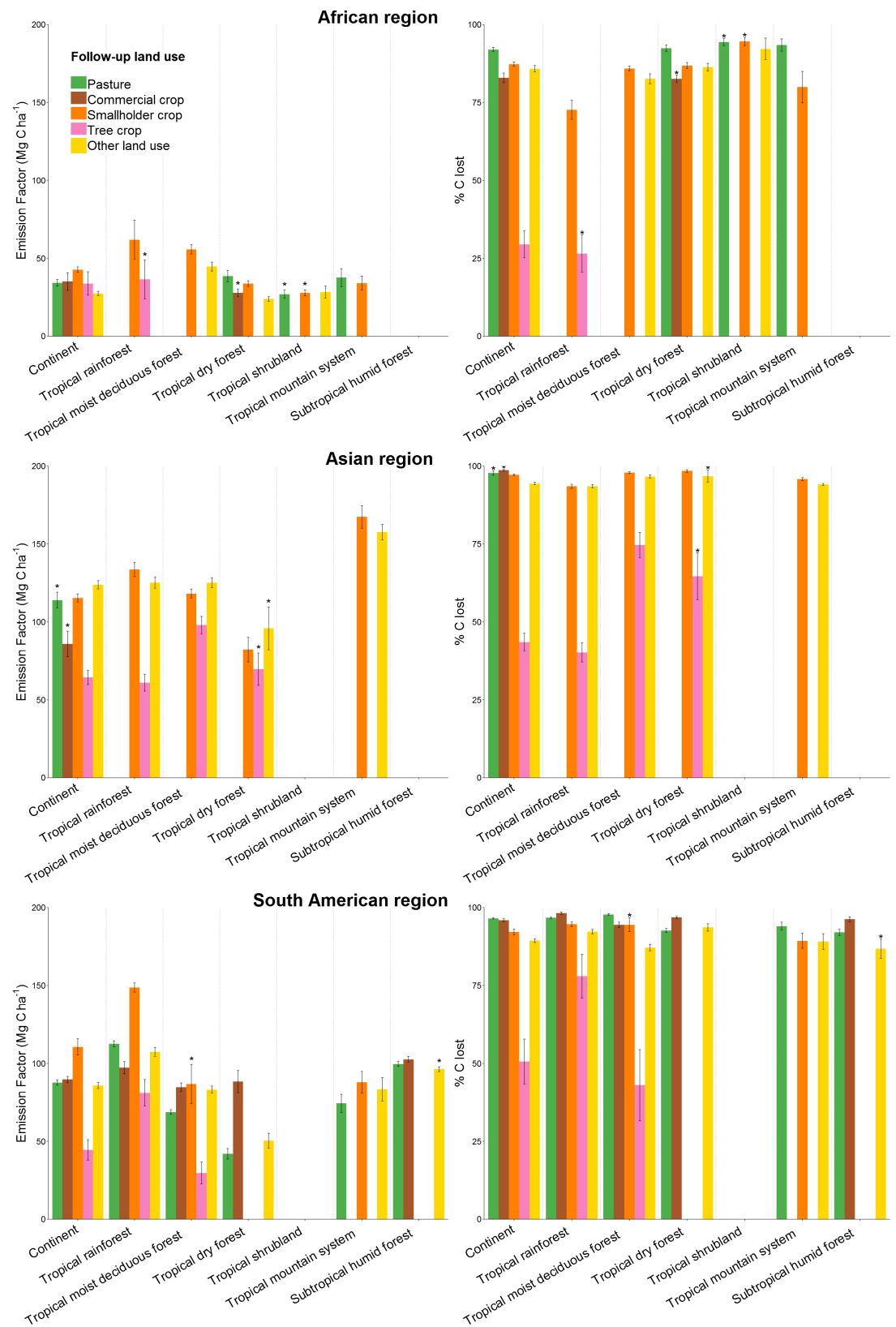

Figure 5.5: Emission factor and percentage carbon loss per follow-up land use in 2000, aggregated at continent and eco-zone level (All values can be found in Table 5.A1 in Appendix 5.A) 

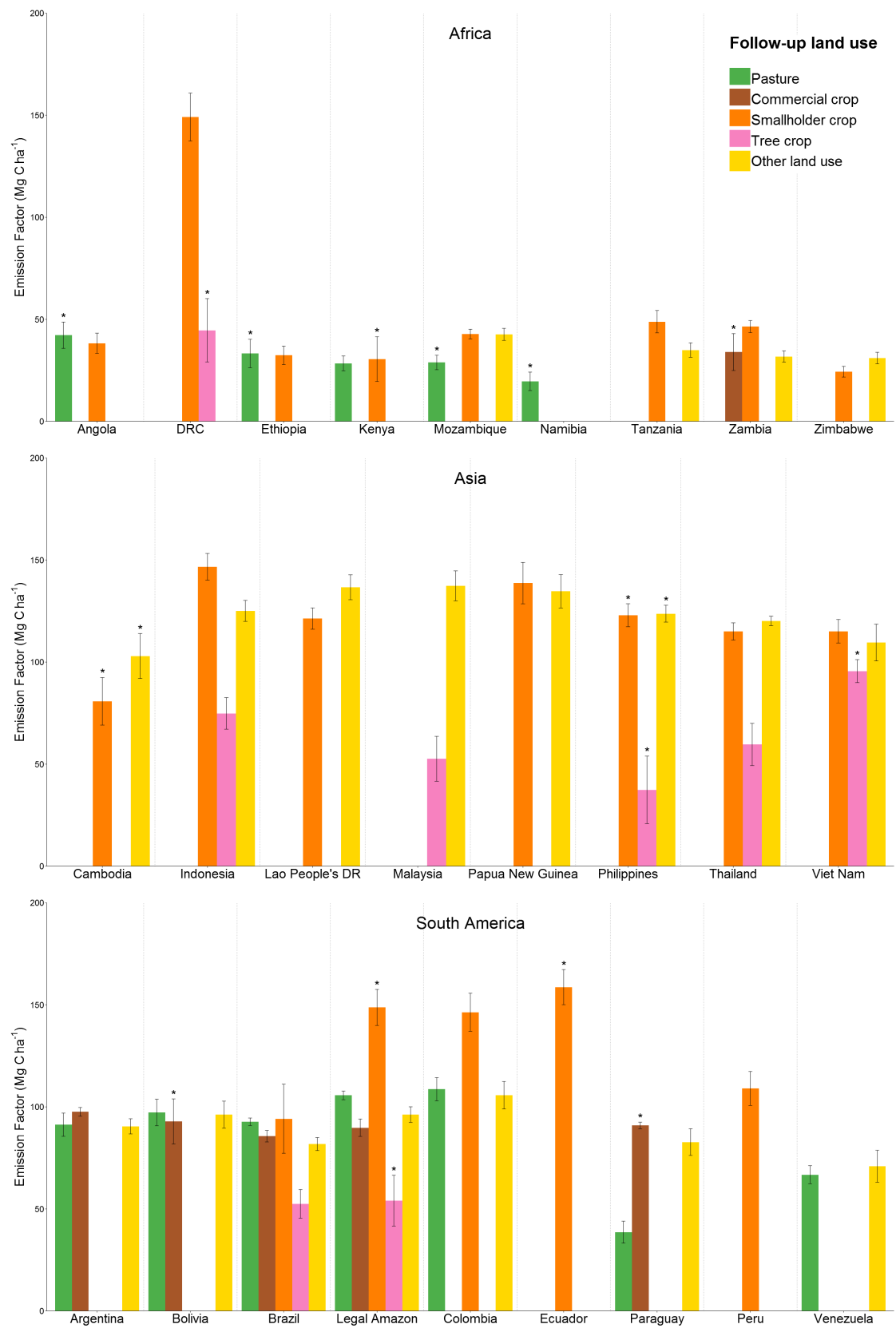

Figure 5.6: Emission factors per follow-up land use in 2000, aggregated to country level (All values can be found in Table 5.A2 and Table 5.A3 in Appendix 5.A) 
at most $50 \mathrm{Mg} \mathrm{C} \mathrm{ha}{ }^{-1}$, except for smallholder cropland in the Democratic Republic of Congo (150 Mg C ha ${ }^{-1}$ ). The highest EFs occurred in the Asian countries with most EF estimates between 100 and $150 \mathrm{Mg} \mathrm{C} \mathrm{ha}^{-1}$, except for tree crop which in most countries had an EF lower than $100 \mathrm{Mg} \mathrm{C}^{-1}$. In South America, higher EFs for smallholder cropland in the Brazilian legal Amazon region (149 $\mathrm{Mg} \mathrm{C} \mathrm{ha}^{-1}$ ), Colombia (146 Mg C ha ${ }^{-1}$ ) and Ecuador (159 $\mathrm{Mg} \mathrm{C}^{-1}$ ) stood out. Emission factors for pasture were lower for Paraguay $\left(39 \mathrm{Mg} \mathrm{C} \mathrm{ha}^{-1}\right.$ ) and Venezuela (67 $\mathrm{Mg} \mathrm{C} \mathrm{ha}{ }^{-1}$ ) than for the rest of this region $\left(91-109 \mathrm{Mg} \mathrm{C} \mathrm{ha}^{-1}\right)$.

\subsection{Discussion}

Our results show that agriculture was the most dominant land use following deforestation which occured between 1990 and 2000, but the dominance of specific agricultural land uses differ per continent. The findings for the Amazon region and for South East Asia are in line with previous studies that identified commercial agriculture, increasingly producing for international markets (cattle ranching, soybean farming and oil palm plantations), as the main driver of deforestation since the 1990s (Geist and Lambin, 2002; Rudel et al., 2009; Boucher et al., 2011; Romijn et al., 2013; Stibig et al., 2014). In contrast, deforestation in most of Africa is still largely due to small-scale and subsistence agriculture (DeFries et al., 2010; Fisher, 2010; Hosonuma et al., 2012). Small-scale and subsistence agriculture is also an important factor in deforestation in the Andean region and parts of the Asian region (Vietnam, Cambodia and Lao PDR).

In Papua New Guinea, Indonesia, Lao PDR and Cambodia, other land uses made up a considerable $(>40 \%)$ part of deforested areas. In Indonesia, this other land use mainly consisted of shrublands where no specific human activity could be identified. In the lowlands of Indonesia, this could partly be a consequence of the misuse of subsidies for establishing plantations (Romijn et al., 2013). Companies, which receive a licence and subsidies to establish plantations, instead only clear the forest to sell the timber and then abandon the land. In the highlands of Sumatra and Borneo and in montane mainland South East Asia, these shrublands are more likely to be part of swidden landscapes (Fox et al., 2014; Mertz, 2009). In Papua New Guinea, deforestation processes and the following land use trajectories were not so clear. Other studies found (unsustainable) logging to be an important driver of forest clearing, but fire and subsistence activities (agriculture, fuelwood collection and grazing) also played a role (Shearman et al., 2009; Stibig et al., 2014). In Lao PDR and Cambodia the other land use appeared to be linked to subsistence activities as well. Similarly, part of the other land use following deforestation in African countries 
could be found around villages, where fuelwood collection, grazing and fire were likely to have caused deforestation. In the African tropical dry forests, remote sensing techniques have difficulties mapping areas of open woodlands. At such low tree cover densities the distinction between forest (10\% tree cover) and other wooded land (5$10 \%$ tree cover) is difficult to determine, which can cause errors in identifying areas of deforestation (Lambin, 1999; FAO \& JRC, 2012; Keenan et al., 2015).

Our estimates of mean forest carbon stock of all forests within an eco-zone are comparable to alternative Tier 1 values derived from a wall-to-wall study (Langner et al., 2014) using a 500 meter AGB map from circa the year 2007 (Baccini et al., 2012) and a forest mask based on Globcover-2009 land cover map (Bontemps et al., 2011). Table 5.5 gives an overview of IPCC Tier 1 values, alternative Tier 1 values by Langner et al. (2014, from table $2 \mathrm{~b}$ in sup. mat.), both converted from AGB to total biomass and then to carbon stock according to our methodology, and estimates from this study. Our estimates tend to be higher than the alternative Tier 1 values in Africa and Asia, but lower for the tropical rainforest and tropical dry forest in South America. These differences could be explained by differences in pixel size used, timing and geographical extent. A smaller range for biomass values can be expected for larger pixel sizes due to spatial averaging (Mitchard et al., 2013). IPCC values are higher than our estimates, likely because IPCC default values are mainly derived from mature forest stands (Gibbs et al., 2007). In general, large uncertainties are associated with pan-tropical AGB maps, in particular in areas with few field data. However, these maps can provide reasonable carbon stock estimates when aggregated over large regions (Mitchard et al., 2013).

Our results show that mean carbon stocks of all forests within an eco-zone are often higher than the carbon stock of those forests that were cleared (Table 5.3). This indicates that mean carbon stocks across an eco-zone do not accurately represent the carbon stock of forest areas that have undergone change. This can introduce substantial bias in carbon emission estimates. We used carbon stocks of stable forests (i.e. forests remaining forests from 1990 to 2005) as a proxy for carbon stocks of forests that were cleared between 1990 and 2000. This might not be a perfect proxy as cleared forests might have had different biomass content than stable forests (e.g. in case of previous degradation), but since we lack time-series of spatially explicit AGB values we consider it as the best proxy available at the moment. This highlights the importance of time-series of spatially explicit data for both forest area change and forest carbon stock analyses.

For the IPCC Tier 1 default values, it is assumed that all biomass is cleared when preparing land for pasture and cropland use. The default IPCC Tier 1 
Table 5.5: IPCC default carbon stock values, mean carbon stock estimates $(\mathrm{Mg} \mathrm{C}$ $\mathrm{ha}^{-1}$ ) from Langner et al. (2014), and mean carbon stock estimates $\left(\mathrm{Mg} \mathrm{C} \mathrm{ha}^{-1}\right)$ for all forests from this study. Values are mean (S.E.).

\begin{tabular}{|c|c|c|c|c|}
\hline \multicolumn{2}{|c|}{ Region } & \multirow{2}{*}{$\frac{\mathbf{I P C C}^{\mathbf{b}}}{195}$} & \multirow{2}{*}{$\begin{array}{l}\text { Langner et al }(\mathbf{2 0 1 4})^{\mathbf{b}} \\
137\end{array}$} & \multirow{2}{*}{$\begin{array}{l}\text { This study } \\
171\end{array}$} \\
\hline & Africa & & & \\
\hline Tropical & $\mathrm{Asia}^{\mathrm{a}}$ & 220 & 156 & 168 \\
\hline & S. America & 189 & 164 & 156 \\
\hline \multirow{3}{*}{$\begin{array}{l}\text { Tropical } \\
\text { moist } \\
\text { deciduous } \\
\text { forest }\end{array}$} & Africa & 164 & 61 & 81 \\
\hline & $\operatorname{Asia}^{a}$ & 183 & 115 & 138 \\
\hline & S. America & 140 & 91 & 90 \\
\hline \multirow{3}{*}{$\begin{array}{l}\text { Tropical dry } \\
\text { forest }\end{array}$} & Africa & 77 & 48 & 57 \\
\hline & $\mathrm{Asia}^{\mathrm{a}}$ & 102 & 102 & 122 \\
\hline & S. America & 134 & 77 & 58 \\
\hline $\begin{array}{l}\text { Tropical } \\
\text { shrubland }\end{array}$ & Africa & 46 & 28 & 38 \\
\hline \multirow{3}{*}{$\begin{array}{l}\text { Tropical } \\
\text { mountain } \\
\text { system }\end{array}$} & Africa & $27-297$ & 91 & 116 \\
\hline & $\mathrm{Asia}^{\mathrm{a}}$ & $33-226$ & 164 & 172 \\
\hline & S. America & 39-146 & 136 & 133 \\
\hline $\begin{array}{l}\text { Subtropical } \\
\text { humid forest }\end{array}$ & S. America & 140 & 77 & 109 \\
\hline
\end{tabular}

${ }^{\text {a }}$ Values for insular Asia for IPCC and Langner et al. (2014)

b AGB values from Table 2a in sup. Mat. of Langner et al. (2014), converted to total biomass with Eq 5.1, assuming carbon stock is $50 \%$ of total biomass

${ }^{c}$ Values for All forests from Table 5.3

value for carbon stock in above-ground biomass for non-woody annual crops after one year is $5 \mathrm{Mg} \mathrm{C} \mathrm{ha}{ }^{-1}$, with a zero net accumulation of biomass carbon stocks occurring in the cropping system (Table 5.9 in IPCC 2006). For grasslands, the Tier 1 total (above- and below-ground) non-woody biomass carbon stock ranges from 4.35 (dry tropics) to 8.05 (moist and wet tropics) $\mathrm{Mg} \mathrm{C} \mathrm{ha}{ }^{-1}$ (Table 6.4 in IPCC 2006, converted from dry matter to C). The AGB map used in this study (Zarin et al., 2016) is primarily made for estimating and mapping AGB of live woody vegetation in forests. While the IPCC provide Tier 1 estimates for the non-woody vegetation, we provide estimates of the carbon stock of live woody vegetation still present after deforestation. This indicates that not all woody vegetation is cleared, or that regrowth occurs. For example up to $20 \%$ of the forest carbon stock can remain after forest conversion to smallholder cropland. For perennial (tree) crops 
the IPCC does provide default coefficients for above-ground woody biomass. The IPCC Tier 1 values for mature tree crops range from $9 \mathrm{Mg} \mathrm{C} \mathrm{ha}^{-1}$ in the dry tropics to $50 \mathrm{Mg} \mathrm{C} \mathrm{ha}{ }^{-1}$ in the wet tropics (Table 5.1 in IPCC 2006). Carbon stocks for tree crop show high variability across our study area. This can be partly because tree crops might be at different stages of maturity, contain different carbon stocks at maturity, and have different harvest cycles. Part of this variability, negative emission factors and the relatively high values from our study, can be explained from the presence of natural trees since we did not use the forest mask for this land use category.

In Africa, low emissions factors can be explained mostly by deforestation taking place in low carbon density forests. In addition, the most important follow-up land uses are smallholder cropland and other land use where substantial woody biomass remains after forest clearing. The only relatively high EF in the African region can be found in the Democratic Republic of Congo for forest conversion to smallholder cropland in the high carbon density tropical rainforest of the Congo Basin. This region is known for shifting cultivation practices with cycles of clearing, cultivation and forest regrowth (Mayaux et al., 2004; Potapov et al., 2012) which explains the high carbon stocks we found in this region for smallholder cropland ( > $20 \mathrm{Mg} \mathrm{C}^{-1}$ ).

In South America the main drivers of deforestation are clearing for pastures and for commercial crops such as soybean. Forest clearing for mechanised agriculture, associated with commercial croplands, typically involves a more thorough removal of biomass than clearing for pasture and small-scale agriculture (Houghton, 2012). Our results (Table 5.3) do not fully support this for all eco-zones. Whether forest conversion to commercial cropland or to pasture has a higher emission factor depends more on the initial biomass of the forest. In the Amazon, for example, forest conversion to pasture mostly occurs at the forest frontier where forests have higher carbon densities than forests in Mato Grosso State where commercial cropland expansion mostly occurs. Subsequently, the EF for pasture is higher than the EF for commercial cropland in the legal Amazon. In Paraguay the EF for commercial cropland is more than double than that of pasture. Cropland expansion in Paraguay occurs in the tropical moist deciduous forest while pasture expansion mostly occurs in the lower biomass tropical dry forests.

For our methodology we combined activity data that were obtained using a land use definition of forest (FAO FRA 2010-RSS) with a forest mask that used a tree cover definition. The largest discrepancy between these 2 datasets (FAO FRA 210 RSS and Global Tree Cover change from Hansen et al. 2013) can be found for deforestation followed by smallholder cropland and other land use in Democratic Republic of Congo, and for other land use in the rest of Africa and parts of South 
America (Figure 5.4). This can be explained by the difference in scale (30 m pixel versus 5 ha polygon), regrowth cycles of shifting cultivation and other land uses, and the previously mentioned difficulty of remote sensing to distinguish between forest $(>10 \%)$ and other wooded land $(5-10 \%)$.

A full analysis of carbon emissions from tropical deforestation would involve among others quantification of land cover change, fate of the cleared land, initial carbon stock of vegetation, mode of clearing and fate of cleared carbon, and soil carbon stock and its response to land cover change (Ramankutty et al., 2007; Houghton, 2012). This study makes progress towards a more complete analysis of carbon emissions from tropical deforestation. The co-location of data on forest loss, biomass and fate of the land provides further opportunities to link follow-up land use to other aspects such as fate of the carbon and land use management practices.

Our EF estimates are based on historical (1990-2000) data on deforestation and biomass, which results in emission factors which are representative for this period. Our results show that emission factors for most land uses are mainly determined by the initial forest carbon stock. A study by De Sy et al. (2015) illustrated that hotspots of forest conversion by specific drivers change over time and accordingly the key areas of deforestation change to lower or higher biomass forests, which would influence the emission factors. The percentages of carbon lost seem to be more robust, and less dependent on initial forest biomass, which might offer some shortcuts to generating local emission factors from forest inventory data. Ideally, mean EF estimates per follow-up land use would be derived for country and eco-zone combinations, but the systematic sampling design of our forest loss and land use dataset would result in few samples for some zones, increasing the risk of deriving non-representative values. Since REDD+ countries are unlikely to have detailed information on the fate and carbon stock of the land following deforestation, we recommend the use of our country or eco-zone estimates of percentage of carbon lost combined with good quality forest biomass estimates.

This study links deforestation with the fate of the land, deriving initial forest carbon stock and remaining carbon stock of land use following deforestation, using high resolution spatially and temporally consistent remote sensing datasets. This yields considerable progress towards better quantification and insight into carbon fluxes from deforestation, and their link to human activities. It provides a valuable dataset for attributing forest loss and carbon emissions to underlying drivers of deforestation, and for incorporating land use management and fate of the land into carbon emission estimates. In addition, REDD+ countries can use our emission factor estimates on the eco-zone and country level (Table 5.A1, Table 5.A2 and Table 
5.A3 in Appendix 5.A) instead of IPCC Tier 1 values.

\subsection{Acknowledgments}

This research was generously supported by the contributions of the governments of Australia (Grant Agreement \#46167), the United States Agency for International Development (Grant Agreement EEM-G-00-04-00010-00) and Norway (Grant Agreement \#QZA-10/0468) to the Center for International Forestry Research. This work was carried out as part of the Consultative Group on International Agricultural Research programs on Trees, Forests and Agroforestry (FTA) and Climate Change Agriculture and Food Security (CCAFS). The authors would also like to thank Anika Paschalidou, Gijs van Lith, Sanjiwana Arjasakusuma and Prisca Masango for their contribution in the visual interpretation of the land use. 
5.A Appendix 


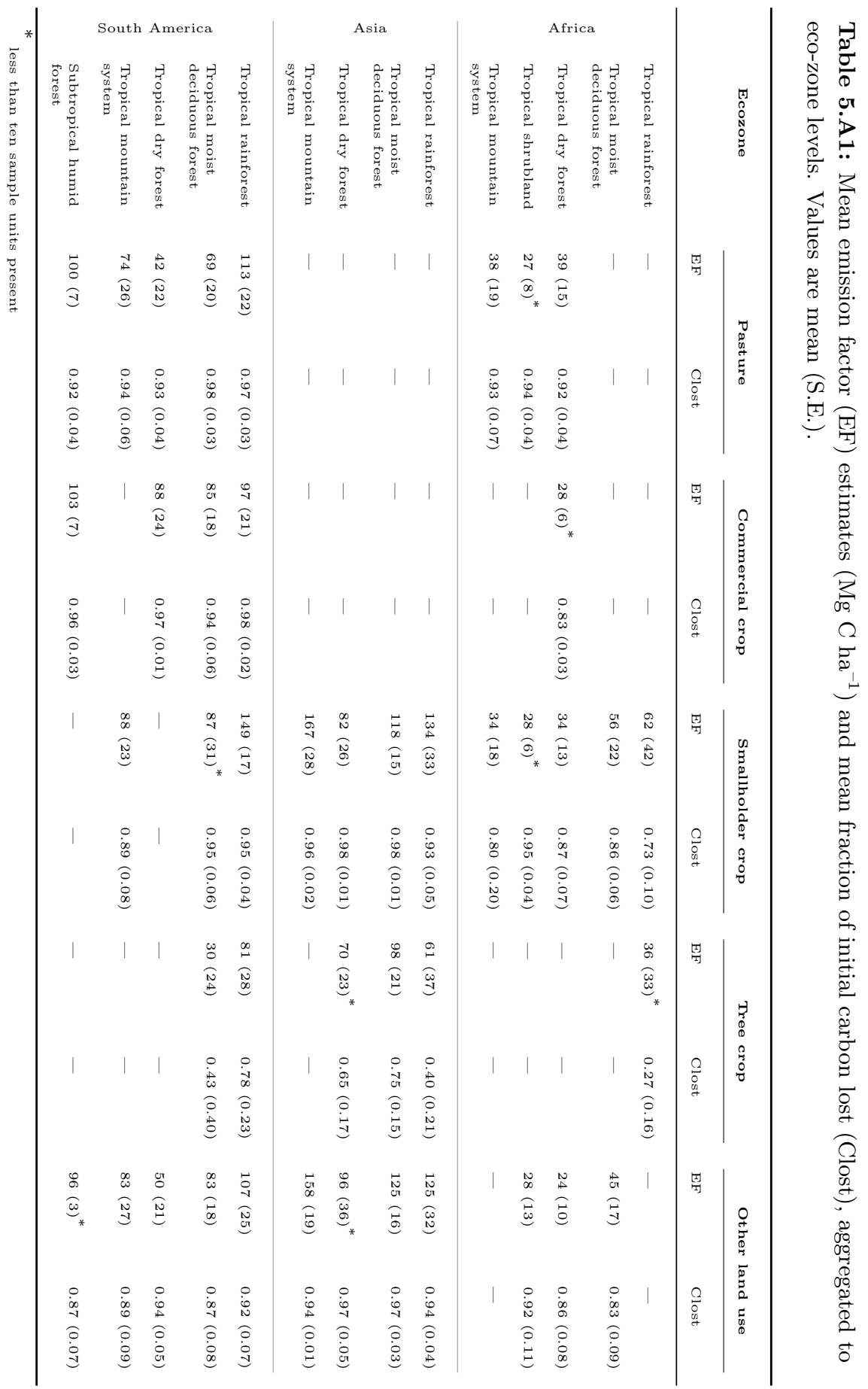


Table 5.A2: Mean emission factor estimates (EF) $\left(\mathrm{Mg} \mathrm{C} \mathrm{ha}^{-1}\right)$, aggregated to (sub-)national level. Values are mean (S.E.).

\begin{tabular}{|c|c|c|c|c|c|}
\hline Region & Pasture & $\begin{array}{l}\text { Commercial } \\
\text { crop }\end{array}$ & $\begin{array}{l}\text { Smallholder } \\
\text { crop }\end{array}$ & Tree crop & Other land use \\
\hline Angola & $42(17)^{*}$ & - & $38(17)$ & - & - \\
\hline DRC & - & - & $149(35)^{*}$ & $45(41)^{*}$ & - \\
\hline Ethiopia & $33(18)^{*}$ & - & $32(14)^{*}$ & - & - \\
\hline Kenya & $28(12)$ & - & $31(27)^{*}$ & - & - \\
\hline Mozambique & $29(9)^{*}$ & - & $43(14)$ & - & $43(15)$ \\
\hline Namibia & $20(10)^{*}$ & - & - & - & - \\
\hline Tanzania & - & - & $49(24)$ & - & $35(15)$ \\
\hline Zambia & - & $34(20)^{*}$ & $46(15)$ & - & $32(11)$ \\
\hline Zimbabwe & - & - & $24(9)$ & - & $31(11)$ \\
\hline Cambodia & - & - & $81(33)^{*}$ & - & $103(27)^{*}$ \\
\hline Indonesia & - & - & $147(39)$ & $75(37)$ & $125(37)$ \\
\hline Lao PDR & - & - & $121(21)$ & - & $137(22)$ \\
\hline Malaysia & - & - & - & $53(36)$ & $137(26)$ \\
\hline PNG & - & - & $139(32)$ & - & $135(27)$ \\
\hline Philippines & - & - & $123(15)^{*}$ & $37(44)^{*}$ & $124(12)^{*}$ \\
\hline Thailand & - & - & $115(16)$ & $60(40)$ & $120(8)$ \\
\hline Vietnam & - & - & $115(22)$ & $96(15)^{*}$ & $110(30)$ \\
\hline Argentina & $91(24)$ & $98(7)$ & - & - & $90(10)^{*}$ \\
\hline Bolivia & $97(33)$ & $93(29)^{*}$ & - & - & $96(29)$ \\
\hline Brazil & $93(31)$ & $86(24)$ & $94(56)$ & $52(32)$ & $82(34)$ \\
\hline Legal Amazon & $106(26)$ & $90(21)$ & $149(26)^{*}$ & $54(30)^{*}$ & $96(33)$ \\
\hline Colombia & $109(29)$ & - & $146(32)$ & - & $106(21)$ \\
\hline Ecuador & - & - & $159(19)^{*}$ & - & - \\
\hline Paraguay & $39(24)$ & $91(5)^{*}$ & - & - & $83(24)$ \\
\hline Peru & - & - & $109(31)$ & - & - \\
\hline Venezuela & $67(20)$ & - & - & - & $71(26)$ \\
\hline
\end{tabular}

\footnotetext{
less than ten sample units present
} 
Table 5.A3: Mean fraction of initial carbon lost (Clost), aggregated to (sub-)national level. Values are mean (S.E.).

\begin{tabular}{|c|c|c|c|c|c|}
\hline Region & Pasture & $\begin{array}{l}\text { Commercial } \\
\text { crop }\end{array}$ & $\begin{array}{l}\text { Smallholder } \\
\text { crop }\end{array}$ & Tree crop & Other land use \\
\hline Angola & $0.93(0.02)$ & - & $0.87(0.08)$ & - & - \\
\hline DRC & - & - & $0.85(0.15)$ & $0.26(0.22)$ & - \\
\hline Ethiopia & $0.94(0.05)$ & - & $0.79(0.22)$ & - & - \\
\hline Kenya & $0.90(0.05)$ & - & $0.88(0.03)$ & - & - \\
\hline Mozambique & $0.91(0.08)$ & - & $0.82(0.07)$ & - & $0.82(0.06)$ \\
\hline Namibia & $0.97(0.03)$ & - & - & - & - \\
\hline Tanzania & - & - & $0.90(0.04)$ & - & $0.82(0.09)$ \\
\hline Zambia & - & $0.82(0.03)$ & $0.82(0.04)$ & - & $0.81(0.08)$ \\
\hline Zimbabwe & - & - & $0.90(0.09)$ & - & $0.82(0.07)$ \\
\hline Cambodia & - & - & $0.98(0.02)$ & - & $0.98(0.01)$ \\
\hline Indonesia & - & - & $0.93(0.05)$ & $0.49(0.22)$ & $0.94(0.02)$ \\
\hline Lao PDR & - & - & $0.98(0.01)$ & - & $0.95(0.06)$ \\
\hline Malaysia & - & - & - & $0.34(0.18)$ & $0.96(0.02)$ \\
\hline PNG & - & - & $0.96(0.02)$ & - & $0.88(0.06)$ \\
\hline Philippines & - & - & $0.91(0.03)$ & $0.27(0.31)$ & $0.94(0.04)$ \\
\hline Thailand & - & - & $0.99(0.01)$ & $0.47(0.30)$ & $0.98(0.01)$ \\
\hline Vietnam & - & - & $0.97(0.02)$ & $0.75(0.13)$ & $0.96(0.03)$ \\
\hline Argentina & $0.91(0.05)$ & $0.96(0.04)$ & - & - & $0.84(0.08)$ \\
\hline Bolivia & $0.96(0.04)$ & $0.98(0.02)$ & - & - & $0.92(0.05)$ \\
\hline Brazil & $0.97(0.03)$ & $0.99(0.02)$ & $0.96(0.05)$ & $0.61(0.33)$ & $0.93(0.07)$ \\
\hline Legal Amazon & $0.97(0.03)$ & $0.99(0.02)$ & $0.94(0.04)$ & $0.64(0.31)$ & $0.92(0.07)$ \\
\hline Colombia & $0.93(0.04)$ & - & $0.97(0.02)$ & - & $0.91(0.13)$ \\
\hline Ecuador & - & - & $0.92(0.07)$ & - & - \\
\hline Paraguay & $0.93(0.04)$ & $0.90(0.06)$ & - & - & $0.93(0.04)$ \\
\hline Peru & - & - & $0.89(0.06)$ & - & - \\
\hline Venezuela & $0.92(0.07)$ & - & - & - & $0.92(0.03)$ \\
\hline
\end{tabular}


Chapter 6

\section{Synthesis}




\subsection{Main findings}

The main objective of this thesis was to explore the role of remote sensing for monitoring tropical forests for REDD+ in general, and for assessing land use and related carbon emissions linked to drivers of tropical deforestation in particular. Based on this objective, three research questions were defined in Section 1.5. Each of these questions is addressed below, based on the main findings from the previous chapters.

\subsubsection{What is the current role and potential of remote sensing technolo- gies and methodologies for monitoring tropical forests for REDD+ and for assessing drivers of deforestation?}

We addressed this research question in Chapter 2, 4 and 5. In Chapter 2 we reviewed the availability, potential and limitations of different remote sensing data sources for REDD+ forest monitoring with a focus on synergies among various approaches. Types of remote sensing data include optical and thermal, Synthetic Aperture Radar (SAR) and Light Detection And Ranging (LiDAR) data. Given the REDD+ requirements, remote sensing can contribute to several relevant forest information products or services such as monitoring of forest area change, land use change patterns, forest degradation, subnational forest change hotspots, wildfires and burnt areas. In addition, it can contribute to near real-time deforestation detection and mapping of biomass and forest types.

Our review of the technical capabilities of remote sensing sensors for the generation of REDD+ information products revealed that, in general, great technical capabilities exist but not one sensor type alone can provide all the information necessary to monitor forests. It is rather a range of sensors that are needed to provide data streams for the different forest change information products. Having a satellite acquiring data is not enough to assume that the data are always accessible and useful for developing countries. There are still significant operational constraints to be bridged regarding the provision of continuous observations with global coverage, the generation and availability of pre-processed image datasets suitable for change analysis, and the capacities in developing countries to sustainably produce and use remote sensing products.

Commonly, remote sensing research starts from local project level studies, and if suitable moves towards larger area demonstrations or even global level analysis. We looked at the current operational role of remote sensing forest information products by looking whether they are mainly research subjects or are actively 
used by REDD+ countries. Monitoring forest area change is most mature while approaches for mapping biomass are not yet used by many developing countries. Most developing countries have to deal with a rather large capacity gap regarding national forest monitoring for REDD+ and remote sensing is currently only sparsely used by developing countries for their national monitoring.

The synergy among multiple sensors with different spectral, spatial and temporal resolutions can be useful to increase cost-efficiency and resolve issues of data coverage, clouds, seasonality, and the trade-off between spatial and temporal resolutions. We identified several key synergy potentials for generating improved forest information products. In general, the synergetic use of data sources as described in Chapter 2 is subject to research and not operationally applied. The benefits of this synergetic use of data sources need to be balanced against the significant additional capacities and resources required for applying them in developing countries. Using multiple data sources increases complexity of the analysis and can also result in problems with consistency and transparency when using time-series.

In response to these findings we provided recommendations in Chapter 2 on how to improve the role of remote sensing for implementing REDD+. For some information products, there is a need to invest in fundamental research and move from small case studies to large area demonstrations. For others the need is to synthesize the experiences from research towards the use in developing countries. Often the most appropriate and suitable methodology for generating forest information products is dependent on national circumstances (data costs and availability, technical capabilities, size of forest area, drivers), which makes further research at country level essential to determine national data needs and monitoring strategies. A regional and international coordinated effort is necessary to build the necessary capacities in REDD+ countries, and to provide technical guidance on best practices and develop and validate appropriate methods for different national circumstances. International coordination and cooperation between space agencies and data providers is essential to provide consistent and continuous global coverage and ensure the availability of data at reasonable costs and in a format suitable for analysis. There is also an important role for regional and South-South cooperation regarding technology transfer and sharing of regional capacities and costs.

The review of Chapter 2 revealed that national-scale quantitative, spatially explicit information on the drivers of deforestation remains scarce and thus emphasized a data gap that remote sensing can contribute in filling. Remote sensing can provide information on land change patterns and associated human activities, which can generate understanding about proximate causes and drivers of deforestation 
and degradation. In Chapter 4 and 5 we explored how to quantify and assess land use following deforestation and associated carbon losses using remote sensing data sources. We illustrated that a spatially-explicit analysis of drivers of deforestation is possible, mainly using freely available remote sensing data sources and a fairly simple and straightforward methodology. In Section 6.1 .3 we will dive deeper into the results of this analysis.

\subsubsection{What is the current state of knowledge of drivers of deforestation and degradation in REDD+ countries?}

In Chapter 3 we provided an assessment of proximate drivers of deforestation and forest degradation by synthesizing data from existing national REDD+ reports and studies. For 100 tropical and sub-tropical REDD+ countries we reviewed the data reported by these countries as part of their REDD + readiness activities, including 26 Readiness Preparation Proposals (R-PP) and ten Readiness Plan Idea Notes (R-PIN) prepared for the World Bank Forest Carbon Partnership Facility (FCPF, 2011). Additional sources of data were a review on drivers of deforestation throughout history for 25 tropical countries (Matthews et al., 2010), CIFOR country profiles, UNFCCC National Communications and other reports that have recently become available.

In Chapter 3 we illustrate that quantitative national-level information on drivers and activities causing deforestation and forest degradation are widely unknown. For example, the question of how much or what fraction of deforestation (emissions) in a country is caused by a specific driver (e.g., expansion of agriculture versus infrastructure) cannot be answered for many REDD + countries. It highlights that the availability of quantitative data on drivers is variable and still uncertain for many countries, with only 12 out of 100 countries being able to provide quantitative data. Another 15 countries had ordinal-scale data, and 19 countries had nominal-scale data. Our analysis also provided preliminary coarse estimates using the continent level estimates and a forest transition model as a proxy in countries where no data have been available so far. Given the variability and different levels of confidence for these data, the presented results are only based on aggregated data that allow for a pan-tropical assessment of the importance of different drivers, stratified by phases of the forest transition model and by continent.

This study offered a first synthesis of REDD+ driven national-level data reported by countries on forest change, which was a valuable input for the support of global REDD+ policy (e.g. Kissinger et al. 2012). On the national level, however, 
it is of limited value due to the use of coarse and aggregated proxies. Chapter 4 and 5 of this thesis illustrate the importance of spatially-explicit (sub-)national data on proximate drivers, which is currently lacking in most REDD + countries. In addition, within the REDD + context, the national driver data should ultimately be linked to emissions. The increasing use of satellite remote sensing tools for national monitoring will allow for a better national-level tracking of deforestation and forest degradation events and types, and the activities that cause them (Gibbs et al., 2010; Hansen et al., 2010).

\subsubsection{What are land use patterns and related carbon emissions following deforestation, capitalising on available land use and biomass remote sensing data?}

In Chapter 4, we quantified proximate drivers of deforestation from 1990 to 2005, their spatiotemporal dynamics and related carbon losses in South America at continental and national scales using a comprehensive, systematic remote sensing analysis. The 2010 global Remote Sensing Survey of the 2010 FAO Forest Resource Assessment was used as input to determine deforestation areas. To assess proximate drivers, land use following deforestation was assigned by visual interpretation of high-resolution satellite imagery. To estimate gross carbon losses from deforestation, alternative Tier 1 biomass levels per country and eco-zone were used. In Chapter 5 we used newly available remote sensing data sources on biomass and forest cover to assess and analyse carbon emission factors in a spatially explicit manner by including the carbon stock of the land use following deforestation. For this analysis we extended the assessment of land use following deforestation to eight South East Asian countries, and eleven African countries for the 1990 to 2000 period.

Our quantification of land use following deforestation in Chapter 4 and Chapter 5 highlighted that agriculture was the most dominant land use, but the dominance of specific agricultural land uses differed per continent. In South America, pasture was the most common post-deforestation land use, with commercial crop a distant second. In Africa deforestation is often followed by smallholder crop with a smaller role for pasture. In the Asian countries, tree crops are the most dominant agricultural follow-up land use, followed by smallholder crop. The findings for the Amazon region and for South East Asia are in line with previous studies that identified agribusinesses, increasingly producing for international markets (cattle ranching, soybean farming and oil palm plantations), as the main drivers of deforestation since the 1990s (Geist and Lambin, 2002; Rudel et al., 2009; Boucher et al., 2011; Romijn et al., 2013; Stibig et al., 2014). In contrast, deforestation in most of Africa is still 
largely due to small-scale subsistence agriculture (DeFries et al., 2010; Fisher, 2010; Hosonuma et al., 2012). Small-scale subsistence agriculture is also an important factor in deforestation in the Andean region and parts of the Asian region (Vietnam, Cambodia and Lao PDR). Our results also revealed that, especially in Africa and Asia, deforestation is often followed by shrubland with no clear land use. Partly this is due to the limitation of our methodology. Small-scale and dispersed land uses such as subsistence activities (crop, fuelwood collection) and nomadic grazing are not always identifiable by visual interpretation of satellite imagery. Here, our dataset would benefit from more local data and knowledge of land use dynamics, for example from field campaigns or community monitoring. Aside from this, unclear follow-up land use also exposed land use dynamics that are interesting from a policy perspective, such as the misuse of subsidies for establishing palm oil plantations in Indonesia (Romijn et al., 2013). Infrastructure, such as road and urban expansion, contributed little as proximate drivers of forest area loss (Chapter 4 and Chapter 5). This is in contrast to findings from Chapter 2 where these drivers contributed substantially to deforestation. As underlying driver, however, urbanization can contribute significantly to deforestation because it changes consumption patterns and increases the demand for agricultural products (DeFries et al., 2010), while better road infrastructure opens up forest frontiers (Rudel, 2007). This indicates that REDD+ countries do not always separate the direct and underlying effects of drivers in their reporting.

In Chapter 4 we also looked at the temporal dimension of land use patterns following deforestation in South America. Our research showed that the annual rate of deforestation driven by commercial crops doubled in the early 2000s compared to the 1990s. In addition, hotspots of pasture- and crop-driven deforestation moved into higher forest biomass eco-zones in the early 2000s which caused additional carbon losses. On the one hand this shows that gaining insight in spatiotemporal dynamics is essential since drivers of forest loss vary from region to region and change over time (Rudel et al., 2009; Boucher et al., 2011). On the other hand it reveals a major limitation of our dataset which currently only covers a limited time period from 1990 to 2005. This limits the applicability for designing up-to-date REDD+ strategies since the drivers and processes of deforestation might have undergone changes after 2005. Despite the time period limitation, and in view of the paucity of quantitative data on deforestation drivers and related carbon losses, this thesis provides a unique and relevant overview of drivers of deforestation as well as showing that this is achievable with a sample-based time-series approach.

In Chapter 4 we used a simple and conservative approach to estimate carbon losses with mean forest biomass values per eco-zone. In reality, however, there are 
gradations of forest biomass within eco-zones (Saatchi et al., 2011b; Baccini et al., 2012) which might influence the spatial and temporal dynamics of carbon losses from different drivers. In Chapter 5 we explored the integration of our data on land use following deforestation with a newly available 30 meter resolution pan-tropical map of above-ground live woody biomass (Zarin et al., 2016) and a globally consistent 30 meter resolution dataset of tree cover loss (Hansen et al., 2013) to provide more insight into the spatial dynamics of carbon emission factors. We also considered the carbon stock present on the land after deforestation, something that is often not included in studies on forest carbon emissions due to a lack of information on the fate of the land.

Our results in Chapter 5 showed that average forest carbon stocks across an eco-zone do not accurately represent the specific forest areas that have undergone change, which can introduce substantial uncertainties in carbon stock and emission estimates. Deforestation often occurs in forest with lower than average carbon stocks. Our estimates of the carbon stock of live woody vegetation still present after deforestation indicated that not all woody vegetation is cleared, or that regrowth occurs. For example, up to $20 \%$ of the forest carbon stock can remain after forest conversion to smallholder cropland. Forest clearing for mechanised agriculture, associated with commercial crops, typically involves a more thorough removal of biomass than clearing for pasture and small-scale agriculture (Houghton, 2012). Our results do not fully support this for all eco-zones. Whether forest conversion to commercial crop or to pasture has a higher emission factor depends more on the spatial dynamics of both land uses and the initial biomass of the forest. Similarly, emission factors for forest conversion to smallholder crop are high because these conversions happen mostly in high biomass forests. So, carbon emission factors for most land uses are for a large part dependent on the initial forest carbon stock. The percentages of carbon lost seem to be more robust and less dependent on initial forest biomass. Since REDD+ countries are unlikely to have detailed information on the fate and carbon stock of the land following deforestation, we recommend the use of our country or eco-zone estimates of the percentage of carbon lost combined with good quality forest biomass estimates.

Our findings contribute to the understanding of drivers of tropical deforestation and related carbon losses, and are comparable at the national, regional and continental level. In addition, the importance of spatially explicit time-series of land use and biomass data is emphasized for gaining more insight into complex deforestation pathways. Our data can support the development of national REDD+ interventions and forest monitoring systems, and provide valuable input for statistical analysis and modelling of underlying drivers of deforestation. 


\subsection{Reflection and outlook}

The Paris climate agreement on climate change mitigation that was just recently agreed upon requires many countries to improve their greenhouse gas (GHG) emission inventories in the near future. In many developing countries emissions from land use, including from land use change, are the largest contributors to GHG emissions. We cannot make progress on reducing anthropogenic emissions from land use change if we are not able to monitor these land use change emissions and attribute them to human activities. This thesis contributes to the quantification of land use change and drivers of deforestation and related carbon emissions. In this section I provide an outlook for further research and reflect upon remote sensing of land use and carbon losses from tropical deforestation, national forest monitoring for REDD+, the importance of tracking drivers at the international scale, and the importance of considering monitoring for REDD+ in the context of the broader land use sector.

\subsubsection{Remote sensing of land use and carbon losses from tropical defor- estation}

This thesis demonstrates the use of remote sensing datasets in quantifying historical land use following deforestation and related carbon losses. Furthermore, this thesis contributes to the understanding of spatio-temporal dynamics of forest carbon loss, and what drives this loss for the 1990 to 2005 timeframe. Our approach is based on a consistent method using time-series that can be extended to include more recent periods and other tropical countries. However, our method of visual interpretation of land use by a few experts is labour intensive, which puts a limit on incorporating higher spatial (wall-to-wall) and temporal observations to provide more up-to-date and detailed information on drivers of deforestation as well as associated carbon changes.

Advances in remote sensing satellites and sensors, high performance processing and storage platforms create unprecedented opportunities for assessing tropical land use and carbon change in the future. One such advance is the global quantification of year-to-year changes in global forest cover from 2000 to 2012 (Hansen et al., 2013). This dataset is extended on a yearly basis, and will start providing deforestation information in near real-time (Popkin, 2016). A wall-to-wall assessment of land use following deforestation with a similar spatial (30 meter) and temporal (yearly) scale would provide more insight into proximate drivers of deforestation. However, assessing land use/cover based on spectral properties of land surfaces is still challenging, and requires cutting-edge spectral, spatial and/or temporal properties 
of remote sensing sensors. Fortunately, data availability, as well as the spatial, spectral, and temporal resolution of observations are constantly increasing. The new Sentinels satellite missions from the European Space Agency have dedicated sensors for land monitoring at high resolutions. Imagery from the recently launched Sentinel-2A satellite can be used in combination with US's Landsat imagery, which will increase temporal coverage. Multi-temporal (e.g. the use of dense time-series) and multi-sensor methods (e.g. Reiche et al. 2016) for a more automated extraction of land use signals from remote sensing data should be further explored.

The Geo-wiki project has shown that it is possible to improve global land cover maps by combining open access to high resolution satellite imagery from Google Earth with crowd-sourcing into a single web application (Fritz et al., 2012). A similar approach could be tested for providing more up-to-date and detailed information on proximate drivers of land use following deforestation with the use of crowdsourcing for visual interpretation.

Above-ground biomass mapping is also evolving towards global maps with higher spatial resolutions. In this thesis, we capitalised on a newly available $30 \mathrm{~m}$ spatial resolution AGB map (Zarin et al., 2016) that extended the methodology from an earlier coarser resolution $(500 \mathrm{~m}$ ) version (Baccini et al., 2012). Likewise, the NASA Jet Propulsion Laboratory will release an updated higher resolution (100 m) version of their $1 \mathrm{~km}$ AGB map (Saatchi et al., 2011b). These high resolution AGB maps will provide added opportunities to assess carbon emissions from forest change. However, global AGB maps might show notable differences in AGB patterns at national scales (Mitchard et al., 2013). Improved AGB estimates at the local to national level can be achieved by integrating existing AGB maps with additional, country-specific reference datasets (Avitabile et al., 2016). There will be an increase in the temporal resolution of these maps with the launch of the GEDI mission from NASA ${ }^{1}$ and the Earth Explorer Biomass mission from ESA ${ }^{2}$. With time-series of biomass maps the assessment of temporal dynamics of forest carbon losses and associated drivers can be improved.

Our dataset and methodology opens several other interesting avenues for a more comprehensive accounting of biomass emissions from deforestation. In this thesis we have incorporated carbon density of post-clearing land use for the estimation of forest carbon emission factors. Several other steps can be done to complete the estimation of carbon emission factors related to forest conversions. Soil organic

\footnotetext{
${ }^{1}$ http://science.nasa.gov/missions/gedi/

${ }_{2}$ http://www.esa.int/Our_Activities/Observing_the_Earth/The_Living_Planet_Programme

/Earth_Explorers/Future_missions/Biomass
} 
carbon stock change fractions can be linked to specific land use change types (Don et al., 2011). In addition, the information on land use following deforestation can be linked to land use management, the mode of clearing (e.g. fire, mechanised clearing) and fate of the cleared carbon to better estimate carbon emissions from deforestation.

\subsubsection{National forest monitoring for REDD+}

This thesis is motivated by the need for national-level quantitative data on drivers of tropical forest change. We have mainly focused on a comparative assessment of national drivers of deforestation at pan-tropical level. Assessing drivers of forest change and carbon emissions in a spatially explicit way will be a challenge for REDD+ countries. Most countries are still struggling with operational monitoring of forest area change and carbon emissions (Romijn et al., 2015), and often rely on simple methods and default values. The emission factor estimates presented in this thesis can be used as an alternative to the IPCC Tier 1 values. Our assessment of emissions factors, in addition to other studies (e.g. Langner et al. 2014; Baccini et al. 2012) suggests that it is timely to revise the current IPCC Tier 1 values and provide new Tier 1 values based on spatially-explicit biomass data.

Our methodology is suitable for operational (sub-)national monitoring of drivers because we used a low-technology approach (visual interpretation) which uses mostly freely available datasets and imagery (Landsat, Google Earth). In addition, there is no need for intensive (pre-)processing of satellite imagery and the systematic sampling design reduces costs and time for analysis. This all makes our methodology accessible for countries with various levels of technical capacities.

Both the tree cover data (Hansen et al., 2013) and the AGB map (Zarin et al., 2016) are available via Global Forest Watch (www.globalforestwatch.org). Unfortunately, the FAO FRA-2010 RSS (FAO \& JRC, 2012) data is not freely available at the moment. As an alternative, tropical forest cover change data from the TREES-3 project (http://forobs.jrc.ec.europa.eu/trees3/) of the European Joint Research Centre could be used. This dataset is similar to the FAO FRA-2010 RSS (i.e. systematic sampling design, 10 by $10 \mathrm{~km}$ squares), but only covers the tropics and uses a land cover instead of a land use definition. Land cover can be converted to land use by first automatically converting land cover classes to preliminary land use classes. As a second step, human expert interpretation is required to provide the context necessary for the accurate categorization of land use, especially where exceptions to the automated reclassification exist (e.g. temporary 
un-stocked land) (FAO \& JRC, 2012). Since land use following deforestation also needs expert interpretation, these steps can be performed at the same time. At the moment the TREES-3 data covers two periods: 1990 to 2000 and 2000 to 2010. It is unclear whether this period will be extended.

The current one degree sampling scheme is not suited for smaller countries or for subnational analysis, and it needs to be intensified to produce reliable results at the national level (Achard et al., 2010). Intensifying the grid can also be done for specific regions of interests (hot-spots) (Eva et al., 2010). The assessment of land use following deforestation could be improved by using additional data available in a country (e.g. land use maps, statistics, local knowledge) and data from community monitoring. A systematic sampling grid is considered a straightforward and practical way to integrate data from existing national surveys and forest inventories (Eva et al., 2010). The systematic sampling grid can also be used to collect other relevant data such as socio-economic and biodiversity data, which is important for linking to broader development goals and policies.

Monitoring forest in the REDD+ context puts extra emphasis on measurement, reporting and verification of (the change in) anthropogenic forest carbon emissions, and identifying drivers of deforestation and forest degradation. In their current design, forest inventory and monitoring systems are often not relevant for national policy development as they lack basic data on socio-economic issues related to forest change, such as land use, rural and urban population growth and other factors that are linked to forest changes. Incorporating such information will likely make countries gain a deeper understanding of what activities are driving deforestation and how these activities are linked to other (non-forest) sectors. This will allow countries to define and prioritise REDD+ strategies in the context of broader development objectives, such as rural development or low carbon development strategies.

We showed in this thesis that most drivers of deforestation originate outside the forest sector, which indicates that REDD+ interventions should include nonforest sectors such as the agricultural, urban and mining sectors instead of only focusing on forest interventions such as sustainable forest management. An analysis of REDD + readiness documents linking proposed interventions to the quality of driver data reported in these documents yielded that countries with higher quality data on drivers include more non-forest sector interventions (e.g. agricultural intensification) (Salvini et al., 2014). This illustrates that REDD+ countries are struggling with designing effective REDD+ policy interventions, partly due to limited understanding of their deforestation drivers. In addition, it means that data from outside the forestry sector are invaluable for understanding drivers and the impacts 
Table 6.1: Comparing national capacities for forest area change monitoring (Romijn et al., 2012) with the quality of reported data on drivers (Hosonuma et al., 2012) for 45 REDD+ countries.

\begin{tabular}{lrcccc}
\hline & & \multicolumn{2}{c}{ Forest area change monitoring capacity } & \\
\cline { 3 - 5 } & & Low & Medium & High & Total \\
\hline \multirow{3}{*}{$\begin{array}{l}\text { Quality of } \\
\text { driver data }\end{array}$} & Low & 7 & 8 & 3 & 18 \\
& Medium & 3 & 10 & 2 & 15 \\
& High & 2 & 4 & 6 & 12 \\
\cline { 3 - 5 } & Total & 12 & 22 & 11 & 45 \\
\hline
\end{tabular}

of REDD+ policies.

Identifying and assessing drivers at the national level requires resources and efforts additional to the regular estimation and reporting for GHG accounting. Countries should integrate and combine capacity development efforts for monitoring drivers with on-going national forest monitoring for REDD+. In particular countries should, where possible, link monitoring of activity data (i.e. forest area change) with monitoring of drivers. Looking at current country capacities, there is a tendency that countries with higher capacities for forest area change monitoring are able to provide higher quality driver data (Table 6.1). However, there are also cases that deviate from this trend in two ways: 1) where monitoring capacities are lower some countries are still able to provide good driver data - emphasizing that data on drivers are derived from other national efforts (i.e. from other sectors) and that these efforts need to be well coordinated and integrated in REDD+ monitoring and capacity building, and 2) where countries are able to provide good activity data, but still need to expand and integrate the efforts to also identify the drivers; an effort that should be done in an integrated way.

Building a national forest monitoring system, with added requirements of MRV and tracking drivers, is a complex undertaking. A wide variety of spatial and non-spatial observations and measurements coming from different sources, and involving many stakeholders will have to be integrated in an adequate information system to support decision-making and evaluate the effect of interventions. This will require transformational change in terms of national cross-sectoral coordination in many REDD+ countries. In light of this, it would be useful to set up an interdisciplinary research study on institutional capacities linked to REDD+ MRV, similar to the assessment of more technical capacities (Romijn et al., 2012, 2015). This will generate useful insights for capacity building and for guidance on developing national forest monitoring 
and MRV systems for specific national circumstances.

\subsubsection{Underlying drivers of deforestation}

This thesis contributes to increased understanding of regional trends of land use change related to deforestation. Many underlying drivers that influence land use change have an international scope (Geist and Lambin, 2002; Rudel et al., 2009; Boucher et al., 2011) which makes it difficult for countries to track or address them. For example, the global demand for commodities like soya, beef and oil palm is an important driver of the conversion of tropical forests into agricultural land. Understanding proximate drivers, rates and patterns of deforestation is key for linking deforestation and underlying drivers more closely. The quantified national forest losses and carbon emissions per driver that we presented in this thesis can be linked to national statistics, and socio-economic and policy indicators, which can greatly contribute to improving the accuracy of models that link deforestation and underlying drivers. Comparative pan-tropical assessments of proximate drivers of deforestation in combination with underlying drivers will provide more insight into land change issues such as the displacement or 'leakage' of land use (Meyfroidt et al., 2013), carbon emissions from commodity supply chains (Karstensen et al., 2013; Zaks et al., 2009), and the effectiveness of transnational efforts to curb emissions for deforestation.

\subsubsection{Linking with the broader land use sector}

There are several reasons why it is important to take a more holistic look on GHG emissions from the land use sector. Forests, agriculture and other land uses are crucial for the achievement of a wide range of sustainable development goals (SDGs). These SDGs are a new universal set of goals that target, among others, poverty eradication, food security, sustainable management of natural resources and climate change. Competing demands for land, issues of food security, climate change mitigation and adaptation objectives in tropical landscapes cannot be effectively addressed in isolation. These intertwined functions of the tropical landscape have implications for national natural resource and GHG monitoring systems.

Some activities or land uses that result in deforestation can also result in additional GHG emissions after the deforestation event. The most prominent case is agriculture that releases significant amounts of GHG depending on the type of crops or livestock, management type (i.e. irrigation), use of fire, fertilizer use, and soil carbon characteristics (i.e. organic peatland soils). Measuring and monitoring these emissions requires different methods and approaches, and additional capacities 
and resources. But they can also be an opportunity for REDD+ strategies, for example, if a country combines agricultural Nationally Appropriate Mitigation Actions (NAMAs) - to provide a separate financial stream to help change farming practices - with a results-based REDD + programme. In addition, most drivers of deforestation originate outside the forest sector. To track the effectiveness of REDD+, land use information from outside the forest sector needs to be integrated in REDD+ MRV. In addition, when focusing only on land use change happening in relation to deforestation, important indirect land use changes that drive deforestation might be missed (Barona et al., 2010; Arima et al., 2011).

For all the above mentioned reasons, it is important to consider REDD+ MRV and forest monitoring in the context of a broader vision for land use and natural resource monitoring. An integrated forest and land use information system will be more capable of providing policy-relevant information for reaching sustainable development goals, climate change mitigation and adaptation. 


\section{References}

Achard, F., Beuchle, R., Mayaux, P., Stibig, H.J., Bodart, C., Brink, A., Carboni, S., Desclée, B., Donnay, F., Eva, H.D., et al., 2014. Determination of tropical deforestation rates and related carbon losses from 1990 to 2010. Global Change Biology, 20, 2540-2554.

Achard, F., DeFries, R., Eva, H., Hansen, M., Mayaux, P., Stibig, H.J., 2007. Pantropical monitoring of deforestation. Environmental Research Letters, 2, 045022.

Achard, F., Stibig, H.J., Eva, H.D., Lindquist, E.J., 2010. Estimating tropical deforestation from Earth observation data. Carbon Management, 1, 271-287.

Almeida-Filho, R., Shimabukuro, Y.E., Rosenqvist, A., Sánchez, G.A., 2009. Using dualpolarized ALOS PALSAR data for detecting new fronts of deforestation in the Brazilian Amazônia. International Journal of Remote Sensing, 30, 3735-3743.

Angelsen, A., 2008. How Do We Set the Reference Levels for REDD Payments? In A. Angelsen (editor), Moving Ahead with REDD: Issues, Options and Implications. Center for International Forestry Research (CIFOR), Bogor, Indonesia.

Angelsen, A., Brockhaus, M., 2009. Realising REDD+: National strategy and policy options. CIFOR, Bogor, Indonesia.

Arima, E.Y., Richards, P., Walker, R., Caldas, M.M., 2011. Statistical confirmation of indirect land use change in the Brazilian Amazon. Environmental Research Letters, 6, 024010 .

Armenteras, D., Rodríguez, N., Retana, J., Morales, M., 2010. Understanding deforestation in montane and lowland forests of the Colombian Andes. Regional Environmental Change, 11, 693-705.

Asner, G.P., 2009. Tropical forest carbon assessment: integrating satellite and airborne mapping approaches. Environmental Research Letters, 4, 034009.

Asner, G.P., 2011. Painting the world REDD: addressing scientific barriers to monitoring emissions from tropical forests. Environmental Research Letters, 6, 021002. 
Asner, G.P., Clark, J.K., Mascaro, J., Vaudry, R., Chadwick, K.D., Vieilledent, G., Rasamoelina, M., Balaji, A., Kennedy-Bowdoin, T., Maatoug, L., et al., 2012. Human and environmental controls over aboveground carbon storage in Madagascar. Carbon balance and management, $7,2$.

Asner, G.P., Hughes, R.F., Mascaro, J., Uowolo, A.L., Knapp, D.E., Jacobson, J., Kennedy-Bowdoin, T., Clark, J.K., 2011a. High-resolution carbon mapping on the million-hectare Island of Hawaii. Frontiers in Ecology and the Environment, 9, $434-439$.

Asner, G.P., Knapp, D.E., Broadbent, E.N., Oliveira, P.J.C., Keller, M., Silva, J.N., 2005. Selective logging in the Brazilian Amazon. Science, 310, 480-482.

Asner, G.P., Llactayo, W., Tupayachi, R., Luna, E.R., 2013. Elevated rates of gold mining in the Amazon revealed through high-resolution monitoring. Proceedings of the National Academy of Sciences of the United States of America, 110, 1845418459 .

Asner, G.P., Mascaro, J., Muller-Landau, H.C., Vieilledent, G., Vaudry, R., Rasamoelina, M., Hall, J.S., van Breugel, M., 2011b. A universal airborne LiDAR approach for tropical forest carbon mapping. Oecologia, 168, 1147-1160.

Asner, G.P., Powell, G.V.N., Mascaro, J., Knapp, D.E., Clark, J.K., Jacobson, J., Kennedy-Bowdoin, T., Balaji, A., Paez-Acosta, G., Victoria, E., et al., 2010. Highresolution forest carbon stocks and emissions in the Amazon. Proceedings of the National Academy of Sciences of the United States of America, 10\%, 16738-16742.

Avitabile, V., Herold, M., Henry, M., Schmullius, C., 2011. Mapping biomass with remote sensing: a comparison of methods for the case study of Uganda. Carbon balance and management, 6,7 .

Avitabile, V., Herold, M., Heuvelink, G., Lewis, S.L., Phillips, O.L., Asner, G.P., Armston, J., Ashton, P.S., Banin, L., Bayol, N., et al., 2016. An integrated pantropical biomass map using multiple reference datasets. Global change biology, 22.

Baccini, A., Goetz, S.J., Walker, W.S., Laporte, N.T., Sun, M., Sulla-Menashe, D., Hackler, J., Beck, P.S.A., Dubayah, R., Friedl, M.A., et al., 2012. Estimated carbon dioxide emissions from tropical deforestation improved by carbon-density maps. Nature Climate Change, 2, 182-185.

Balzter, H., 2001. Forest mapping and monitoring with interferometric synthetic aperture radar (InSAR). Progress in Physical Geography, 25, 159-177.

Barona, E., Ramankutty, N., Hyman, G., Coomes, O.T., 2010. The role of pasture and soybean in deforestation of the Brazilian Amazon. Environmental Research Letters, 5, 024002. 
Benndorf, R., Federici, S., Forner, C., Pena, N., Rametsteiner, E., Sanz, M.J., Somogyi, Z., 2007. Including land use, land-use change, and forestry in future climate change, agreements: thinking outside the box. Environmental Science 8 Policy, 10, 283-294.

Beuchle, R., Eva, H.D., Stibig, H.J., Bodart, C., Brink, A., Mayaux, P., Johansson, D., Achard, F., Belward, A., 2011. A satellite data set for tropical forest area change assessment. International Journal of Remote Sensing, 32, 7009-7031.

Beuchle, R., Grecchi, R.C., Shimabukuro, Y.E., Seliger, R., Eva, H.D., Sano, E., Achard, F., 2015. Land cover changes in the Brazilian Cerrado and Caatinga biomes from 1990 to 2010 based on a systematic remote sensing sampling approach. Applied Geography, 58, 116-127.

Bontemps, S., Langner, A., Defourny, P., 2011. GLOBCOVER 2009 - Products description and validation report. European Spatial Agency and Université Catholique de Louvain, Frascati, Italy.

Bontemps, S., Langner, A., Defourny, P., 2012. Monitoring forest changes in Borneo on a yearly basis by an object-based change detection algorithm using SPOT- VEGETATION time series. International Journal of Remote Sensing, 33, 4673-4699.

Böttcher, H., Eisbrenner, K., Fritz, S., Kindermann, G., Kraxner, F., McCallum, I., Obersteiner, M., 2009. An assessment of monitoring requirements and costs of 'Reduced Emissions from Deforestation and Degradation'. Carbon balance and management, 4, 7 .

Boucher, D., Elias, P., Lininger, K., May-Tobin, C., Roquemore, S., Saxon, E., 2011. The root of the problem: what's driving tropical deforestation today? Union of Concerned Scientists, Cambridge, MA.

Boucher, D.H., 2011. Brazil's Success in Reducing Deforestation UCS Tropical Forest and Climate Briefing \#8. Union of Concerned Scientists, Cambridge, MA.

Boyd, D.S., Danson, F.M., 2005. Satellite remote sensing of forest resources: three decades of research development. Progress in Physical Geography, 29, 1-26.

Broich, M., Hansen, M.C., Potapov, P., Adusei, B., Lindquist, E., Stehman, S.V., 2011. Time-series analysis of multi-resolution optical imagery for quantifying forest cover loss in Sumatra and Kalimantan, Indonesia. International Journal of Applied Earth Observation and Geoinformation, 13, 277-291.

Bucki, M., Cuypers, D., Mayaux, P., Achard, F., Estreguil, C., Grassi, G., 2012. Assessing REDD+ performance of countries with low monitoring capacities: the matrix approach. Environmental Research Letters, 7, 014031.

Chomitz, K.M., 2007. At Loggerheads?: Agricultural Expansion, Poverty Reduction, 
and Environment in the Tropical Forests. The International Bank for Reconstruction and Development / The World Bank, Washington, DC.

Clark, M.L., Aide, T.M., Grau, H.R., Riner, G., 2010. A scalable approach to mapping annual land cover at $250 \mathrm{~m}$ using MODIS time series data: A case study in the Dry Chaco ecoregion of South America. Remote Sensing of Environment, 114, $2816-2832$.

Clark, M.L., Aide, T.M., Riner, G., 2012. Land change for all municipalities in Latin America and the Caribbean assessed from $250 \mathrm{~m}$ MODIS imagery (2001-2010). Remote Sensing of Environment, 126, 84-103.

Coutinho, A.C., Almeida, C., Venturieri, A., Esquerdo, J.C.D.M., Silva, M., 2013. Uso e cobertura da terra nas áreas desflorestadas da Amazônia Legal: TerraClass 2008. Belém: INPE, Brasília: Embrapa.

da Fonseca, G.A.B., Rodriguez, C.M., Midgley, G., Busch, J., Hannah, L., Mittermeier, R.A., 2007. No forest left behind. PLoS biology, 5, 1645-1646.

Dassot, M., Constant, T., Fournier, M., 2011. The use of terrestrial LiDAR technology in forest science: application fields, benefits and challenges. Annals of Forest Science, 68, 959-974.

De Sy, V., Herold, M., Achard, F., Asner, G.P., Held, A., Kellndorfer, J., Verbesselt, J., 2012. Synergies of multiple remote sensing data sources for REDD+ monitoring. Current Opinion in Environmental Sustainability, 4, 696-706.

De Sy, V., Herold, M., Achard, F., Baccini, A., Carter, S., Clevers, J.G.P.W., Lindquist, E., Pereira, M., Verchot, L., 2016. Estimation of Carbon emission factors from tropical deforestation using remotely-sensed land use and biomass information, to be submitted.

De Sy, V., Herold, M., Achard, F., Beuchle, R., Clevers, J.G.P.W., Lindquist, E., Verchot, L., 2015. Land use patterns and related carbon losses following deforestation in South America. Environmental Research Letters, 10, 124004.

DeFries, R., Achard, F., Brown, S., Herold, M., Murdiyarso, D., Schlamadinger, B., De Souza, C., 2006. Reducing Greenhouse Gas Emissions from Deforestation in Developing Countries: Considerations for Monitoring and Measuring, Report of the Global Terrestrial Observing System (GTOS) number 46. GOFC-GOLD report 26.

DeFries, R., Achard, F., Brown, S., Herold, M., Murdiyarso, D., Schlamadinger, B., de Souza, C., 2007. Earth observations for estimating greenhouse gas emissions from deforestation in developing countries. Environmental Science $\mathcal{E}$ Policy, 10, 385-394. 
DeFries, R.S., Foley, J.A., Asner, G.P., 2004. Land-use choices: balancing human needs and ecosystem function. Frontiers in Ecology and the Environment, 2, 249257.

DeFries, R.S., Houghton, R.a., Hansen, M.C., Field, C.B., Skole, D., Townshend, J., 2002. Carbon emissions from tropical deforestation and regrowth based on satellite observations for the 1980s and 1990s. Proceedings of the National Academy of Sciences of the United States of America, 99, 14256-61.

DeFries, R.S., Rudel, T., Uriarte, M., Hansen, M., 2010. Deforestation driven by urban population growth and agricultural trade in the twenty-first century. Nature Geoscience, 3, 178-181.

Don, A., Schumacher, J., Freibauer, A., 2011. Impact of tropical land-use change on soil organic carbon stocks - a meta-analysis. Global Change Biology, 17, 1658-1670.

Erasmi, S., Twele, A., 2009. Regional land cover mapping in the humid tropics using combined optical and SAR satellite data - a case study from Central Sulawesi, Indonesia. International Journal of Remote Sensing, 30, 2465-2478.

Eva, H., Carboni, S., Achard, F., Stach, N., Durieux, L., Faure, J.F., Mollicone, D., 2010. Monitoring forest areas from continental to territorial levels using a sample of medium spatial resolution satellite imagery. ISPRS Journal of Photogrammetry and Remote Sensing, 65, 191-197.

Eva, H.D., Achard, F., Beuchle, R., de Miranda, E., Carboni, S., Seliger, R., Vollmar, M., Holler, W.A., Oshiro, O.T., Barrena Arroyo, V., et al., 2012. Forest Cover Changes in tropical South and Central America from 1990 to 2005 and related carbon emissions and removals. Remote Sensing, 4, 1369-1391.

FAO, 2001. Global Ecological Zoning for the Global Forest Resources Assessment 2000 (Final Report Working Paper 56). FAO (Food and Agriculture Organization of the United Nations), Rome.

FAO, 2010. Global Forest Resources Assessment 2010 (FAO Forestry Paper 163). FAO (Food and Agriculture Organization of the United Nations), Rome.

FAO, 2011a. State of the World's Forests Report. FAO (Food and Agriculture Organization of the United Nations), Rome.

FAO, 2011b. The 2010 Global Forest Resources Assessment Remote Sensing Survey. Food and Agricultural Organisation (FAO), Rome.

FAO, 2012. State of the World's Forests Report. FAO (Food and Agriculture Organization of the United Nations), Rome.

FAO, 2015. Global Forest Resources Assessment. FAO (Food and Agriculture Organization of the United Nations), Rome. http://fao.org/3/a-i4793e.pdf. 
FAO \& JRC, 2012. Global forest land-use change 1990-2005 (FAO Forestry Paper No. 169). FAO (Food and Agriculture Organization of the United Nations) and JRC (European Commission Joint Research Centre), Rome.

FCPF, 2011. Most Recent R-PP Submissions by Countries to the Worldbank Forest Carbon Partnership Facility (FCPF). http://www. forestcarbonpartnership.org/f cp/node/257.

Fisher, B., 2010. African exception to drivers of deforestation. Nature Geoscience, 3, $375-376$.

Fox, J., Castella, J.C., Ziegler, A.D., 2014. Swidden, rubber and carbon: can REDD+ work for people and the environment in Montane Mainland Southeast Asia? Global Environmental Change, 29, 318-326.

Fritz, S., McCallum, I., Schill, C., Perger, C., See, L., Schepaschenko, D., Van der Velde, M., Kraxner, F., Obersteiner, M., 2012. Geo-Wiki: An online platform for improving global land cover. Environmental Modelling \& Software, 31, 110-123.

Fritz, S., See, L., McCallum, I., You, L., Bun, A., Moltchanova, E., Duerauer, M., Albrecht, F., Schill, C., Perger, C., et al., 2015. Mapping global cropland and field size. Global Change Biology, 21, 1980-1992.

Fry, B.P., 2011. Community forest monitoring in REDD+: the 'M' in MRV? Environmental Science \& Policy, 14, 181-187.

Geist, H., Lambin, E., 2001. What drives tropical deforestation? A meta-analysis of proximate and underlying causes of deforestation based on subnational case study evidence. Land-Use and Land-Cover Change (LUCC) Project, International Geosphere-Biosphere Programme (IGBP), LUCC Report Series: 4.

Geist, H.J., Lambin, E.F., 2002. Proximate causes and underlying driving forces of tropical deforestation. BioScience, 52, 143-150.

Gibbs, B.H.K., Rausch, L., Munger, J., Schelly, I., Morton, D.C., Noojipady, P., Barreto, P., Micol, L., Walker, N.F., Amazon, B., et al., 2015. Brazil's Soy Moratorium. Science, 347, 377-378.

Gibbs, H.K., Brown, S., Niles, J.O., Foley, J.A., 2007. Monitoring and estimating tropical forest carbon stocks: making REDD a reality. Environmental Research Letters, 2, 045023.

Gibbs, H.K., Ruesch, A.S., Achard, F., Clayton, M.K., Holmgren, P., Ramankutty, N., Foley, J.A., 2010. Tropical forests were the primary sources of new agricultural land in the 1980s and 1990s. Proceedings of the National Academy of Sciences of the United States of America, 10\%, 16732-16737.

Giglio, L., Loboda, T., Roy, D.P., Quayle, B., Justice, C.O., 2009. An active-fire based 
burned area mapping algorithm for the modis sensor. Remote Sensing Environment, 113, 408-420.

Giglio, L., Randerson, J.T., van der Werf, G.R., Kasibhatla, P.S., Collatz, G.J., Morton, D.C., DeFries, R.S., 2010. Assessing variability and long-term trends in burned area by merging multiple satellite fire products. Biogeosciences, 7, 11711186.

Goetz, S.J., Baccini, A., Laporte, N.T., Johns, T., Walker, W., Kellndorfer, J., Houghton, R.A., Sun, M., 2009. Mapping and monitoring carbon stocks with satellite observations: a comparison of methods. Carbon balance and management, $4,2$.

GOFC-GOLD, 2011. A sourcebook of methods and procedures for monitoring and reporting anthropogenic greenhouse gas emissions and removals caused by deforestation, gains and losses of carbon stocks in forests remaining forests, and forestation. GOFC-GOLD Project Office, Natural Resources Canada, Alberta, Canada, gofc-gold report version cop 17-1 edition.

GOFC-GOLD, 2014. A sourcebook of methods and procedures for monitoring and reporting anthropogenic greenhouse gas emissions and removals caused by deforestation, gains and losses of carbon stocks in forests remaining forests, and forestation. GOFC-GOLD Land Cover Project Office, Wageningen University, The Netherlands, Alberta, Canada, gofc-gold report version cop 20-1 edition.

Google Earth, 2015. Google Earth, version 7.1.5.1557. http://google.com/earth/index.html. Accessed between January 2013 and March 2014.

Graesser, J., Aide, M.T., Grau, R.H., Ramankutty, N., 2015. Cropland/pastureland dynamics and the slowdown of deforestation in Latin America. Environmental Research Letters, 10, 034017.

Grainger, A., Obersteiner, M., 2011. A framework for structuring the global forest monitoring landscape in the REDD+ era. Environmental Science \& Policy, 14, 127-139.

Grassi, G., Monni, S., Federici, S., Achard, F., D, M., 2008. Applying the conservativeness principle to REDD to deal with the uncertainties of the estimates. Environmental Research Letters, 3, 035005.

Hansen, M.C., Loveland, T.R., 2012. A review of large area monitoring of land cover change using Landsat data. Remote Sensing of Environment, 122, 66-74.

Hansen, M.C., Potapov, P.V., Moore, R., Hancher, M., Turubanova, S.A., Tyukavina, A., 2013. High-resolution global maps of 21st-century forest cover change. Science, 342, 850-853. 
Hansen, M.C., Roy, D.P., Lindquist, E., Adusei, B., Justice, C.O., Altstatt, A., 2008a. A method for integrating MODIS and Landsat data for systematic monitoring of forest cover and change in the Congo Basin. Remote Sensing of Environment, 112, 2495-2513.

Hansen, M.C., Stehman, S.V., Potapov, P.V., 2010. Quantification of global gross forest cover loss. Proceedings of the National Academy of Sciences of the United States of America, 10\%, 8650-8655.

Hansen, M.C., Stehman, S.V., Potapov, P.V., Arunarwati, B., Stolle, F., Pittman, K., 2009. Quantifying changes in the rates of forest clearing in Indonesia from 1990 to 2005 using remotely sensed data sets. Environmental Research Letters, 4, 034001.

Hansen, M.C., Stehman, S.V., Potapov, P.V., Loveland, T.R., Townshend, J.R.G., DeFries, R.S., Pittman, K.W., Arunarwati, B., Stolle, F., Steininger, M.K., et al., 2008b. Humid tropical forest clearing from 2000 to 2005 quantified by using multitemporal and multiresolution remotely sensed data. Proceedings of the National Academy of Sciences of the United States of America, 105, 9439-9444.

Harris, N., Brown, S., Hagen, S., Saatchi, S., Pertova, S., Salas, W., Hansen, M.C., Potapov, P., Lotch, A., 2012. Baseline map of carbon emissions from deforestation in tropical regions. Science, 336, 1573-1576.

Herold, M., Angelsen, A., Verchot, L., Wijaya, A., Ainembabazi, J.H., 2012. A stepwise framework for developing REDD+ reference levels. In A. Angelsen, M. Brockhaus, W.D. Sunderlin, L.V. Verchot (editors), Analysing REDD+: Challenges and choices. Center for International Forestry Research (CIFOR), Bogor, Indonesia. http://www . cifor.org/publications/pdf_files/Books/BAngelsen1201.pdf.

Herold, M., Johns, T., 2007. Linking requirements with capabilities for deforestation monitoring in the context of the UNFCCC-REDD process. Environmental Research Letters, 2, 045025.

Herold, M., Román-Cuesta, R.M., Mollicone, D., Hirata, Y., Van Laake, P., Asner, G.P., Souza, C., Skutsch, M., Avitabile, V., Macdicken, K., 2011. Options for monitoring and estimating historical carbon emissions from forest degradation in the context of REDD+. Carbon balance and management, 6, 13.

Herold, M., Skutsch, M., 2011. Monitoring, reporting and verification for national REDD + programmes: two proposals. Environmental Research Letters, 6, 014002.

Hosonuma, N., Herold, M., De Sy, V., De Fries, R.S., Brockhaus, M., Verchot, L., Angelsen, A., Romijn, E., 2012. An assessment of deforestation and forest degradation drivers in developing countries. Environmental Research Letters, 7, 044009.

Houghton, R.A., 2005. Aboveground Forest Biomass and the Global Carbon Balance. Global Change Biology, 11, 945-958. 
Houghton, R.A., 2012. Carbon emissions and the drivers of deforestation and forest degradation in the tropics. Current Opinion in Environmental Sustainability, 4, 597-603.

Huang, C., Goward, S.N., Masek, J.G., Thomas, N., Zhu, Z., Vogelmann, J.E., 2010. An automated approach for reconstructing recent forest disturbance history using dense Landsat time series stacks. Remote Sensing of Environment, 114, 183-198.

Huettner, M., Leemans, R., Kok, K., Ebeling, J., 2009. A comparison of baseline methodologies for 'Reducing Emissions from Deforestation and Degradation'. Carbon balance and management, 4, 4 .

Ichoku, C., Kaufman, Y.J., 2005. A method to derive smoke emission rates from MODIS fire radiative energy measurements. IEEE Transactions on Geoscience and Remote Sensing, 43, 2636-2649.

IPCC, 2006. Guidelines for National Greenhouse Gas Inventories. IGES, Japan.

IPCC, 2013. Climate Change 2013: The Physical Science Basis. Contribution of Working Group I to the Fifth Assessment Report of the Intergovernmental Panel on Climate Change. Cambridge University Press, Cambridge.

Jiang, L., Kogan, F.N., Guo, W., Tarpley, J.D., Mitchell, K.E., Ek, M.B., Tian, Y., Zheng, W., Zou, C.Z., Ramsay, B.H., 2010. Real-time weekly global green vegetation fraction derived from advanced very high resolution radiometer-based NOAA operational global vegetation index (GVI) system. Journal of Geophysical Research, 115, D11114.

Justice, C.O., Giglio, L., Korontzi, S., Owens, J., Morisette, J.T., Roy, D., Descloitres, J., Alleaume, S., Petitcolin, F., Kaufman, Y., 2002. The MODIS fire products. Remote Sensing of Environment, 83, 244-262.

Kaimowitz, D., Angelsen, A., 1998. Economic Models of Tropical Deforestation: A Review. Center for International Forestry Research (CIFOR), Bogor, Indonesia.

Karstensen, J., Peters, G.P., Andrew, R.M., 2013. Attribution of CO2 emissions from Brazilian deforestation to consumers between 1990 and 2010. Environmental Research Letters, 8, 024005.

Kauppi, P.E., Ausubel, J.H., Fang, J., Mather, A.S., Sedjo, R.A., Waggoner, P.E., 2006. Returning forests analyzed with the forest identity. Proceedings of the $\mathrm{Na}$ tional Academy of Sciences of the United States of America, 103, 17574-17579.

Keenan, R.J., Reams, G.A., Achard, F., de Freitas, J.V., Grainger, A., Lindquist, E., 2015. Dynamics of global forest area : Results from the FAO Global Forest Resources Assessment 2015. Forest Ecology and Management, 352, 9-20.

Kennedy, R.E., Yang, Z., Cohen, W.B., 2010. Detecting trends in forest disturbance 
and recovery using yearly Landsat time series: 1. LandTrendr - Temporal segmentation algorithms. Remote Sensing of Environment, 114, 2897-2910.

Kissinger, G., Herold, M., De Sy, V., 2012. Drivers of deforestation and forest degradation: a synthesis report for REDD+ policy makers. Lexeme Consulting, Vancouver, Canada.

Koch, B., 2010. Status and future of laser scanning, synthetic aperture radar and hyperspectral remote sensing data for forest biomass assessment. ISPRS Journal of Photogrammetry and Remote Sensing, 65, 581-590.

Kuemmerle, T., Erb, K., Meyfroidt, P., Müller, D., Verburg, P.H., Estel, S., Haberl, H., Hostert, P., Jepsen, M.R., Kastner, T., et al., 2013. Challenges and opportunities in mapping land use intensity globally. Current Opinion in Environmental Sustainability, 5, 484-493.

Lambin, E.F., 1999. Monitoring forest degradation in tropical regions by remote sensing: some methodological issues. Global ecology and biogeography, 8, 191-198.

Lambin, E.F., Meyfroidt, P., 2010. Land use transitions : Socio-ecological feedback versus socio-economic change. Land Use Policy, 27, 108-118.

Langner, A., Achard, F., Grassi, G., 2014. Can recent pan-tropical biomass maps be used to derive alternative Tier 1 values for reporting REDD+ activities under UNFCCC? Environmental Research Letters, 9, 124008.

Larrazábal, A., McCall, M.K., Mwampamba, T.H., Skutsch, M., 2012. The role of community carbon monitoring for REDD+: a review of experiences. Current Opinion in Environmental Sustainability, 4, 707-716.

Law, E.A., Thomas, S., Meijaard, E., Dargusch, P.J., Wilson, K.A., 2012. A modular framework for management of complexity in international forest-carbon policy. Nature Climate Change, 2, 155-160.

Lehmann, E.A., Caccetta, P.A., Zhou, Z.S., McNeill, S.J., Wu, X., Mitchell, A.L., 2012. Joint Processing of Landsat and ALOS-PALSAR Data for Forest Mapping and Monitoring. IEEE Transactions on Geoscience and Remote Sensing, 50, 55-67.

Lentile, L.B., Holden, Z.A., Smith, A.M.S., Falkowski, M.J., Hudak, A.T., Morgan, P., Lewis, S.A., Gessler, P.E., Benson, N.C., 2006. Remote sensing techniques to assess active fire characteristics and post-fire effects. International Journal of Wildland Fire, 15, 319-345.

Lucas, R., Armston, J., 2007. ALOS PALSAR for Characterizing Wooded Savannas in Northern Australia. IEEE International Geoscience and Remote Sensing Symposium, IGARSS 2007, 3610-3613.

Macedo, M.N., DeFries, R.S., Morton, D.C., Stickler, C.M., Galford, G.L., 
Shimabukuro, Y.E., 2012. Decoupling of deforestation and soy production in the southern Amazon during the late 2000s. Proceedings of the National Academy of Sciences of the United States of America, 109, 1341-1346.

Malingreau, J.P., Eva, H.D., de Miranda, E.E., 2012. Brazilian Amazon: A significant five year drop in deforestation rates but figures are on the rise again. Ambio, 41, 309-314.

Maniatis, D., Mollicone, D., 2010. Options for sampling and stratification for national forest inventories to implement REDD+ under the UNFCCC. Carbon balance and management, 5, 1-14.

Mascaro, J., Detto, M., Asner, G.P., Muller-Landau, H.C., 2011. Evaluating uncertainty in mapping forest carbon with airborne LiDAR. Remote Sensing of Environment, 115, 3770-3774.

Mather, A.S., 1992. The Forest Transition. Area, 24, 367-379.

Matricardi, E.A.T., Skole, D.L., Cochrane, M.A., Qi, J., Chomentowski, W., 2005. Monitoring Selective Logging in Tropical Evergreen Forests Using Landsat: Multitemporal Regional Analyses in Mato Grosso, Brazil. Earth Interactions, 9, 1-24.

Matricardi, E.A.T., Skole, D.L., Pedlowski, M.A., Chomentowski, W., Fernandes, L.C., 2010. Assessment of tropical forest degradation by selective logging and fire using Landsat imagery. Remote Sensing of Environment, 114, 1117-1129.

Matthews, R., Swallow, B., Milne, E., Minang, P., Bakam, I., Brewer, M., Muhammed, S., Poggio, L., Glenk, K., Fiorini, S., et al., 2010. Development and application of methodologies for reduced emissions from deforestation and forest degradation $(R E D D+)$ - Phase I. Final report for project ceosa 0803, department of energy and climate change (decc), Macaulay Land Use Research Institute, World Agroforestry Centre, Aberdeen, Nairobi.

Mayaux, P., Bartholomé, E., Fritz, S., Belward, A., 2004. A new land-cover map of Africa for the year 2000. Journal of Biogeography, 31, 861-877.

Mertz, O., 2009. Trends in shifting cultivation and the REDD mechanism. Current Opinion in Environmental Sustainability, 1, 156-160.

Meyfroidt, P., Lambin, E.F., Erb, K.H., Hertel, T.W., 2013. Globalization of land use: distant drivers of land change and geographic displacement of land use. Current Opinion in Environmental Sustainability, 5, 438-444.

Mitchard, E.T., Saatchi, S.S., Baccini, A., Asner, G.P., Goetz, S.J., Harris, N.L., Brown, S., 2013. Uncertainty in the spatial distribution of tropical forest biomass: a comparison of pan-tropical maps. Carbon Balance Management, 8, 10.

Mollicone, D., Achard, F., Federici, S., Eva, H.D., Grassi, G., Belward, A., Raes, 
F., Seufert, G., Stibig, H.J., Matteucci, G., et al., 2007. An incentive mechanism for reducing emissions from conversion of intact and non-intact forests. Climatic Change, 83, 477-493.

Morton, D.C., DeFries, R.S., Shimabukuro, Y.E., Anderson, L.O., Arai, E., del Bon Espirito-Santo, F., Freitas, R., Morisette, J., 2006. Cropland expansion changes deforestation dynamics in the southern Brazilian Amazon. Proceedings of the National Academy of Sciences of the United States of America, 103, 14637-14641.

Morton, D.C., DeFries, R.S., Shimabukuro, Y.E., Anderson, L.O., Del Bon EspíritoSanto, F., Hansen, M., Carroll, M., 2005. Rapid Assessment of Annual Deforestation in the Brazilian Amazon Using MODIS Data. Earth Interactions, 9, 1-22.

Müller, R., Larrea-Alcázar, D.M., Cuéllar, S., Espinoza, S., 2014. Causas directas de la deforestación reciente (2000-2010) y modelado de dos escenarios futuros en las tierras bajas de Bolivia. Ecología en Bolivia, 49, 20-34.

Müller, R., Müller, D., Schierhorn, F., Gerold, G., Pacheco, P., 2012. Proximate causes of deforestation in the Bolivian lowlands: an analysis of spatial dynamics. Regional Environmental Change, 12, 445-459.

Munsi, M., Areendran, G., Joshi, P.K., 2012. Modeling spatio-temporal change patterns of forest cover: a case study from the Himalayan foothills (India). Regional Environmental Change, 12, 619-632.

Mustard, J.F., DeFries, R.S., Fisher, T., Moran, E., 2004. Land-use and land-cover change pathways and impacts. In Land change science. Springer, 411-429.

Nepstad, D.C., Stickler, C.M., Almeida, O.T., 2006. Globalization of the Amazon Soy and Beef Industries: Opportunities for Conservation. Conservation Biology, 20, 1595-1603.

Obersteiner, M., Huettner, M., Kraxner, F., Mccallum, I., Aoki, K., Böttcher, H., Fritz, S., Gusti, M., Havlik, P., Kindermann, G., et al., 2009. On fair , effective and efficient REDD mechanism design. Carbon Balance and Management, 4, 11.

Pacheco, P., Poccard-Chapuis, R., 2012. The Complex Evolution of Cattle Ranching Development Amid Market Integration and Policy Shifts in the Brazilian Amazon. Annals of the Association of American Geographers, 102, 1366-1390.

Penman, J., Gytarsky, M., Hiraishi, T., Krug, T., Kruger, D., Pipatti, R., Buendia, L., Miwa, K., Ngara, T., 2003. Good Practice Guidance for Land Use, LandUse Change and Forestry. Intergovernmental Panel on Climate Change (IPCC), Kanagawa, Japan.

Pistorius, T., 2012. From RED to REDD+: The evolution of a forest-based mitigation approach for developing countries. Current Opinion in Environmental Sustainabil- 
ity, 4, 638-645.

Plummer, S., Arino, O., Fierens, F., Borstlap, G., Chen, J., Dedieu, G., Ranera, F., Simon, M., 2005. THE GLOBCARBON INITIATIVE: Multi-sensor estimation of global biophysical products for global terrestrial carbon studies. In Proceedings of the MERIS (A)ATSR Workshop 2005 (ESA SP-597); 26-30 September, ESRIN Frascati, Italy.

Popkin, G., 2016. Satellite alerts track deforestation in real time. Nature, 530, 392.

Potapov, P., Yaroshenko, A., Turubanova, S., Dubinin, M., Laestadius, L., Thies, C., Aksenov, D., Egorov, A., Yesipova, Y., Glushkov, I., et al., 2008. Mapping the world 's intact forest landscapes by remote sensing. Ecology and Society, 13, 51.

Potapov, P.V., Turubanova, S.A., Hansen, M.C., Adusei, B., Broich, M., Altstatt, A., Mane, L., Justice, C.O., 2012. Quantifying forest cover loss in Democratic Republic of the Congo, 2000-2010, with Landsat ETM+ data. Remote Sensing of Environment, 122, 106-116.

Powell, S.L., Pflugmacher, D., Kirschbaum, A.A., Kim, Y., Cohen, W.B., 2007. Moderate resolution remote sensing alternatives: a review of Landsat-like sensors and their applications. Journal of applied remote sensing, 1, 012506.

Rademaekers, K., Eichler, L., Berg, J., Obersteiner, M., Havlik, P., 2010. Study on the evolution of some deforestation drivers and their potential impacts on the costs of an avoiding deforestation scheme. ECORYS and IIASA, Rotterdam, Netherlands.

Rahman, M.M., Sumantyo, J.T.S., 2010. Mapping tropical forest cover and deforestation using synthetic aperture radar (SAR) images. Applied Geomatics, 2, 113-121.

Ramankutty, N., Gibbs, H.K., Achard, F., DeFries, R., Foley, J.A., Houghton, R.A., 2007. Challenges to estimating carbon emissions from tropical deforestation. Global change biology, 13, 51-66.

Reiche, J., Lucas, R., Mitchell, A.L., Verbesselt, J., Hoekman, D.H., Haarpaintner, J., Kellndorfer, J.M., Rosenqvist, A., Lehmann, E.A., Woodcock, C.E., et al., 2016. Combining satellite data for better tropical forest monitoring. Nature Climate Change, 6, 120-122.

Romijn, E., Ainembabazi, J.H., Wijaya, A., Herold, M., Angelsen, A., Verchot, L., Murdiyarso, D., 2013. Exploring different forest definitions and their impact on developing REDD+ reference emission levels: A case study for Indonesia. Environmental Science \&5 Policy, 33, 246-259.

Romijn, E., Herold, M., Kooistra, L., Murdiyarso, D., Verchot, L., 2012. Assessing capacities of non-Annex I countries for national forest monitoring in the context of REDD+. Environmental Science \& Policy, 19-20, 33-48. 
Romijn, E., Lantican, C.B., Herold, M., Lindquist, E., Ochieng, R., Wijaya, A., Murdiyarso, D., Verchot, L., 2015. Assessing change in national forest monitoring capacities of 99 tropical countries. Forest Ecology and Management, 352, 109-123.

Rudel, T.K., 2007. Changing agents of deforestation: From state-initiated to enterprise driven processes, 1970-2000. Land Use Policy, 24, 35-41.

Rudel, T.K., Coomes, O.T., Moran, E., Achard, F., Angelsen, A., Xu, J., Lambin, E., 2005. Forest transitions: towards a global understanding of land use change. Global Environmental Change, 15, 23-31.

Rudel, T.K., DeFries, R., Asner, G.P., Laurance, W.F., 2009. Changing drivers of deforestation and new opportunities for conservation. Conservation biology, 23, 1396-1405.

Rudorff, B.F.T., Adami, M., Aguilar, D.A., Moreira, M.A., Mello, M.P., Fabiani, L., Amaral, D.F., Pires, B.M., 2011. The soy moratorium in the amazon biome monitored by remote sensing images. Remote Sensing of Environment, 3, 185-202.

Ryan, C.M., Hill, T., Woollen, E., Ghee, C., Mitchard, E., Cassells, G., Grace, J., Woodhouse, I.H., Williams, M., 2012. Quantifying small-scale deforestation and forest degradation in African woodlands using radar imagery. Global Change Biology, 18, 243-257.

Saatchi, S., Marlier, M., Chazdon, R.L., Clark, D.B., Russell, A.E., 2011a. Impact of spatial variability of tropical forest structure on radar estimation of aboveground biomass. Remote Sensing of Environment, 115, 2836-2849.

Saatchi, S.S., Harris, N.L., Brown, S., Lefsky, M., Mitchard, E.T.A., Salas, W., Zutta, B.R., Buermann, W., Lewis, S.L., Hagen, S., et al., 2011b. Benchmark map of forest carbon stocks in tropical regions across three continents. Proceedings of the National Academy of Sciences of the United States of America, 108, 9899-9904.

Salvini, G., Herold, M., De Sy, V., Kissinger, G., Brockhaus, M., Skutsch, M., 2014. How countries link REDD + interventions to drivers in their readiness plans: implications for monitoring systems. Environmental Research Letters, 9, 074004.

Sánchez-Azofeifa, G.A., Castro-Esau, K.L., Kurz, W.A., Joyce, A., 2009. Monitoring carbon stocks in the tropics and the remote sensing operational limitations: from local to regional projects. Ecological applications : a publication of the Ecological Society of America, 19, 480-494.

Särndal, C.E., Swensson, B., Wretman, J., 1992. Model Assisted Survey Sampling. Springer, New York.

Schultz, M.G., Heil, A., Hoelzemann, J.J., Spessa, A., Thonicke, K., Goldammer, J.G., Held, A.C., Pereira, J.M.C., van het Bolscher, M., 2008. Global wildland fire 
emissions from 1960 to 2000. Global Biogeochemical Cycles, 22, 1-17.

Shearman, P.L., Ash, J., Mackey, B., Bryan, J.E., Lokes, B., 2009. Forest conversion and degradation in Papua New Guinea 1972-2002. Biotropica, 41, 379-390.

Shimabukuro, Y.E., Duarte, V., Anderson, L.O., Valeriano, D.M., Arai, E., de Freitas, R., Rudorff, B., Moreira, M., 2006. Near real time detection of deforestation in the Brazilian Amazon using MODIS imagery. Ambiente e Agua, 1, 37-47.

Simon, M., Plummer, S., Fierens, F., Hoelzemann, J.J., Arino, O., 2004. Burnt area detection at global scale using ATSR-2 : The GLOBSCAR products and their qualification. Journal of Geophysical Research, 109, 1-16.

Skutsch, M., Torres, A.B., Mwampamba, T., Ghilardi, A., Herold, M., 2011. Dealing with locally-driven degradation ; a quick start option under REDD +. Carbon Balance and Management, 6, 16.

Smith, A., Wooster, M., 2005. Remote classification of head and backfire types from MODIS fire radiative power and smoke plume observations. International Journal of Wildland Fire, 14, 249-254.

Souza, C.M., Roberts, D.A., Cochrane, M.A., 2005a. Combining spectral and spatial information to map canopy damage from selective logging and forest fires. Remote Sensing of Environment, 98, 329-343.

Souza, C.M.J., Roberts, D.A., Monteiro, A.L., 2005b. Multitemporal Analysis of Degraded Forests in the Southern Brazilian Amazon. Earth Interactions, 9, 1-24.

Stach, N., Salvado, A., Petit, M., Faure, J.F., Durieux, L., Corbane, C., Joubert, P., Lasselin, D., Deshayes, M., 2009. Land use monitoring by remote sensing in tropical forest areas in support of the Kyoto Protocol : the case of French Guiana. International Journal of Remote Sensing, 30, 5133-5149.

Stibig, H.J., Achard, F., Carboni, S., Raši, R., Miettinen, J., et al., 2014. Change in tropical forest cover of Southeast Asia from 1990 to 2010. Biogeosciences, 11, $247-258$.

Swenson, J.J., Carter, C.E., Domec, J.C., Delgado, C.I., 2011. Gold mining in the Peruvian Amazon: global prices, deforestation, and mercury imports. PloS one, 6, e18875.

Trisasongko, B.H., 2010. The Use of Polarimetric SAR Data for Forest Disturbance Monitoring. Sensing and Imaging: An International Journal, 11, 1-13.

Tyukavina, A., Baccini, A., Hansen, M.C., Potapov, P.V., Stehman, S.V., Houghton, R.A., Krylov, A.M., Turubanova, S., Goetz, S.J., 2015. Aboveground carbon loss in natural and managed tropical forests from 2000 to 2012. Environmental Research Letters, 10, 074002. 
UNFCCC, 2009a. Cost of implementing methodologies and monitoring systems relating to estimates of emissions from deforestation and forest degradation, the assessment of carbon stocks and GHG emissions from changes in forest cover, and the enhancement of forest carbon stocks. UNFCCC Secretary, Bonn, Germany.

UNFCCC, 2009b. Methodological guidance for activities relating to reducing emissions from deforestation and forest degradation and the role of conservation, sustainable management of forests and enhancement of forest carbon stocks in developing countries. Decision CP. 4/15, UNFCCC.

UNFCCC, 2010. Outcome of the work of the ad hoc working group on long-term cooperative action under the convention-policy approaches and positive incentives on issues relating to reducing emissions from deforestation and forest degradation in developing countries: and and the role of conservation, sustainable management of forests and enhancement of forest carbon stocks in developing countries. Decision CP. $1 / 16$, UNFCCC.

UNFCCC, 2011. Guidance on systems for providing information on how safeguards are addressed and respected and modalities relating to forest reference emission levels as referred to in decision 1/CP.16. Decision CP. 12/17, UNFCCC.

UNFCCC, 2014. Conference of the Parties, Report of the Conference of the Parties on its 19th session (Warsaw, 11-23 November 2013) Addendum, part two: action taken by the Conference of the Parties at its nineteenth session, contents, decisions adopted by COP19, on addressing the drivers of deforestation and forest degradation. FCCC/CP/2013/10/Add.1 Decision 15/CP.19, UNFCCC.

van der Werf, G.R., Morton, D.C., DeFries, R.S., Giglio, L., Randerson, J.T., Collatz, G.J., Kasibhatla, P.S., 2009. Estimates of fire emissions from an active deforestation region in the southern Amazon based on satellite data and biogeochemical modelling. Biogeosciences, 6, 235-249.

van der Werf, G.R., Randerson, J.T., Giglio, L., Collatz, G.J., Mu, M., Kasibhatla, P.S., Morton, D.C., DeFries, R.S., Jin, Y., van Leeuwen, T.T., 2010. Global fire emissions and the contribution of deforestation, savanna, forest, agricultural, and peat fires (1997-2009). Atmospheric Chemistry and Physics, 10, 11707-11735.

Velasco Gomez, M.D., Beuchle, R., Shimabukuro, Y., Grecchi, R., Simonetti, D., Eva, H.D., Achard, F., 2015. A long-term perspective on deforestation rates in the Brazilian Amazon. ISPRS - International Archives of the Photogrammetry, Remote Sensing and Spatial Information Sciences, XL-7/W3, 539-544.

Verbesselt, J., Hyndman, R., Newnham, G., Culvenor, D., 2010. Detecting trend and seasonal changes in satellite image time series. Remote Sensing of Environment, $114,106-115$. 
Verbesselt, J., Zeileis, A., Herold, M., 2012. Near Real-Time Disturbance Detection Using Satellite Image Time Series : Drought Detection in Somalia. Remote Sensing of Environment, 123, 98-108.

Visseren-Hamakers, I.J., Gupta, A., Herold, M., Peña-Claros, M., Vijge, M.J., 2012. Will REDD+ work? The need for interdisciplinary research to address key challenges. Current Opinion in Environmental Sustainability, 4, 590-596.

Walker, W.S., Stickler, C.M., Kellndorfer, J.M., Kirsch, K.M., Nepstad, D.C., 2010. Large-Area Classification and Mapping of Forest and Land Cover in the Brazilian Amazon : A Comparative Analysis of ALOS / PALSAR and Landsat Data Sources. IEEE Journal of selected topics in applied earth observations and remote sensing, 3, 594-604.

Wulder, M.a., White, J.C., Gillis, M.D., Walsworth, N., Hansen, M.C., Potapov, P., 2010. Multiscale satellite and spatial information and analysis framework in support of a large-area forest monitoring and inventory update. Environmental monitoring and assessment, 170, 417-433.

Wulder, M.A., White, J.C., Masek, J.G., Dwyer, J., Roy, D.P., 2011. Continuity of Landsat observations: Short term considerations. Remote Sensing of Environment, $115,747-751$.

Xu, W., Wooster, M.J., Roberts, G., Freeborn, P., 2010. New GOES imager algorithms for cloud and active fire detection and fire radiative power assessment across North, South and Central America. Remote Sensing of Environment, 114, 1876-1895.

Zaks, D., Barford, C., Ramankutty, N., Foley, J., 2009. Producer and consumer responsibility for greenhouse gas emissions from agricultural productiona perspective from the Brazilian Amazon. Environmental Research Letters, 4, 044010.

Zarin, D.J., Harris, N.L., Baccini, A., Aksenov, D., Hansen, M.C., Ramos, C.A., Azevedo, T., Margono, B.A., Alencar, A.C., Gabris, C., et al., 2016. Can carbon emissions from tropical deforestation drop by $50 \%$ in five years? Global change biology, 22, 1336-1347. 



\section{Summary}

The new Paris Agreement, approved by 195 countries under the auspice of the United Nations Framework Convention on Climate Change (UNFCCC), calls for limiting global warming to "well below" $2^{\circ}$ Celsius. An important part of the climate agreement relates to reducing emissions from deforestation and forest degradation, and enhancing carbon stocks (REDD+) in non-Annex I (mostly developing) countries. Over the last decades the growing demand for food, fibre and fuel has accelerated the pace of forest loss. In consequence, tropical deforestation and forest degradation are responsible for a large portion of global carbon emissions to the atmosphere, and destroy an important global carbon sink that is critical in future climate change mitigation.

Within the REDD+ framework, participating countries are given incentives to develop national strategies and implementation plans that reduce emissions and enhance sinks from forests and to invest in low carbon development pathways. For REDD+ activities to be effective, accurate and robust methodologies to estimate emissions from deforestation and forest degradation are crucial. Remote sensing is an essential REDD+ observation tool, and in combination with ground measurements it provides an objective, practical and cost-effective solution for developing and maintaining REDD+ monitoring systems. The remote sensing monitoring objective for REDD+ is not only to map deforestation but also to support policy formulation and implementation. Identifying and addressing drivers and activities causing forest carbon change is crucial in this respect. Monitoring drivers (e.g. deforestation by agricultural expansion, fuelwood extraction etc.) for REDD+ puts an emphasis on monitoring and tracking post-deforestation land use activities. Despite the importance of identifying and addressing drivers, quantitative information on these drivers, and the related carbon emissions, is scarce at the national level.

Most tropical developing countries have a limited capacity for monitoring forest area change and carbon stocks. There is progress being made regarding several 
gaps (e.g. data, remote sensing methodologies, capacity building) and approaches are being put forward to manage the challenges associated with monitoring tropical forests for REDD+. However, many gaps still remain and knowledge about and experience with various remote sensing data sources and methods for forest monitoring for REDD+ is scattered among researchers and practitioners. This thesis explores the role of remote sensing for monitoring tropical forests for REDD+ in general, and for assessing land use and related carbon emissions linked to drivers of tropical deforestation in particular.

Chapter 2 reviews the availability, potential and limitations of remote sensing data sources with a focus on different forest information products and synergies among various approaches and evolving technologies. This study shows that although remote sensing technologies provide significant opportunities to support forest monitoring objectives, their operational usefulness is constrained by a lack of consistent and continuous coverage, data availability, and appropriate methodologies for national-scale use and available capacities in developing countries. Coordinated international efforts, regional cooperation and continued research efforts are essential to further develop national approaches and capacities to fully explore and use the potential remote sensing has to offer for REDD+ forest monitoring.

Chapter 3 provides an assessment of proximate drivers of deforestation and forest degradation by synthesizing empirical data reported by countries as part of their REDD+ readiness activities, national communications and scientific literature. The availability and quality of national data on deforestation and forest degradation drivers varied, with only 12 out of 100 countries being able to provide quantitative data. Given the variability and different levels of confidence for these data, we present a pan-tropical assessment of the importance of different drivers by phases of the forest transition model and by continent, based on aggregated national data. Commercial agriculture is the most important driver of deforestation, followed by subsistence agriculture. Timber extraction and logging drives most of the degradation, followed by fuelwood collection and charcoal production, uncontrolled fire and livestock grazing. This study provides the first comprehensive and comparative assessment of drivers on the national level and highlights the current limitations and data gaps regarding national data on drivers of deforestation and forest degradation.

Chapter 4 explores how proximate drivers of deforestation and related carbon losses can be quantified in a systematic, spatially explicit manner, based on remote sensing time series. This study quantifies land use patterns and related carbon losses following deforestation in South America between 1990 and 2005 at continental and national scales using a comprehensive, systematic remote sensing analysis. 
Deforestation areas were derived from the 2010 global remote sensing survey of the FAO Forest Resource Assessment. To assess proximate drivers, land use following deforestation was determined by visual interpretation of high-resolution satellite imagery. Gross carbon losses from deforestation were estimated using Tier 1 biomass levels per country and eco-zone combined with the deforested area. In Brazil, Argentina, Paraguay and Bolivia large ranches and commercial crop agriculture were the main drivers of deforestation and carbon losses. In the Andean countries (Peru, Colombia and Venezuela) smallholder and mixed agriculture were important drivers of deforestation. In addition, hotspots of pasture- and crop-driven deforestation were found to move into higher forest biomass eco-zones in the early 2000s causing additional carbon losses. This insight emphasizes the importance of spatial and temporal information on drivers of deforestation in designing effective REDD+ interventions.

Chapter 5 capitalised on newly available remote sensing information on land use following deforestation (Chapter 4), above-ground live biomass density and tree cover at similar spatial resolutions. This chapter explores how to combine these datasets to improve carbon emission factor estimates by using spatially and temporally consistent high resolution remote sensing datasets, and by incorporating the carbon stock of the land use following deforestation. We extended the quantification of land use following deforestation to 27 countries across the pan-tropics. This revealed that in South America, pasture was the most common post-deforestation land use (74\%), with commercial crop (11\%) a distant second. In Africa deforestation is often followed by smallholder crop (57\%) with a smaller role for pasture (12\%). In the Asian countries, tree crops are the most dominant agricultural follow-up land use (32\%), followed by smallholder crop (23\%). Our approach yields considerable progress towards better quantification of carbon fluxes from deforestation, and gives added insight into their link to human activities. In addition, the resulting emission factor estimates on the eco-zone and national level can be used as input for REDD+ forest monitoring.

This research conducted in this $\mathrm{PhD}$ contributes to the understanding of the role of remote sensing in forest monitoring for REDD + and in the assessment of drivers of deforestation. In addition, this thesis contributes to the improvement of spatial and temporal quantification of land use and related carbon emissions linked to drivers of tropical deforestation. The results and insights described herein are valuable for ongoing REDD+ forest monitoring efforts and capacity development as REDD+ moves closer to becoming an operational mitigation mechanism. 



\section{Acknowledgements}

Many people contributed to the successful completion of my $\mathrm{PhD}$ thesis and I would like to express my gratitude to all of them.

First of all, I would like to express my gratitude to my promotor Martin Herold for the opportunity to undertake this PhD. Thank you for your guidance and support, for always providing new ideas and inspiration, and for the help with shaping those ideas into scientific papers. Many thanks as well for the chances you provided to interact with and learn from other scientists, policy makers and specialists.

Second I would like to thank my co-promotors. My gratitude goes to my daily supervisor Jan Clevers for his invaluable eye for detail and scientific expertise which contributed greatly to the successful competition of this PhD. Knowing that I could always knock on your door with small and big questions, was not only useful but also gave me peace of mind. I would also like to thank Lammert Kooistra for his guidance in the first years of my $\mathrm{PhD}$. Your guidance in proposal writing, conceptualising research ideas and surviving a $\mathrm{PhD}$ in general were very much appreciated. Many thanks as well to my co-promotor Lou Verchot for his interesting research insights and valuable feedback.

A big thanks goes out to Mathieu, Loic, Arun, Nandika, Maria, Sarah, Johannes, Peter, Astrid, Alvaro, Giullia, Simon, Eliakim, Michi and all the other past and present PhDs of the department for providing such a pleasurable and positive working environment. Many thanks to my $\mathrm{PhD}$ colleagues Sarah and Maria for bearing with me during the development of the driver methodology, and for staring at many deforested patches. I would also like to thank my other colleagues: Valerio, Jan V., Arnold, Harm, Aldo, John, Sytze, Ron, Arend, Brice, Jessica, Kathleen, Juha, Rosa, Erika, Lukasz, Antoinette and Truus.

Special thanks go to my paranymphs Ben and Richard for their friendship 
and support. Ben, it was a pleasure being your officemate. Thank you for all your practical help and for being a sounding board. Richard, our walks around the lake were always a source of inspiration and relaxation for me. And thanks for providing the soundtrack of my $\mathrm{PhD}$.

Life in the Netherlands has been an adventure filled with wonderful people. I am especially grateful to Karin, Gunnar, Annika, Thomas, Renske and Harry for making Wageningen into a mind-altering, crazy and cosy place with just enough rules to control the fun. Thanks to Simone for providing me with a "thuis" the first moment I set foot in Wageningen. Thanks as well to Stephanie for her "joie de vivre" and friendship. You have all helped me discover myself and have enriched my life tremendously.

Many thanks to Jan and Ann for making this possible, for believing in me and supporting me in this second career. One of the things that kept me (mostly) sane during this $\mathrm{PhD}$ is your life motto "work to live, not live to work" with a touch of "no pain, no gain". Having parents such as you, knowing that you are there for me is a wonderful feeling and has provided me with a secure base to explore the world from. Many thanks as well to my brother and sisters, Pieter-Jan, Katrien and Pauline, and the rest of the clan. Pauline, thank you for making the thesis cover!

Sid, thank you very much for supporting me through this $\mathrm{PhD}$ in so many ways. One of the many things I love about you is your modesty so I will not embarrass you with many flowery words here but just say this: you (post)rock! 


\section{List of publications}

\section{Peer-reviewed journal publications}

De Sy, V., Herold, M., Achard, F., Beuchle, R., Clevers, J.G.P.W., Lindquist, E., Verchot, L., 2015. Land use patterns and related carbon losses following deforestation in South America. Environmental Research Letters, 10, 124004

Salvini, G., Herold, M., De Sy, V., Kissinger, G., Brockhaus, M., Skutsch, M., 2014. How countries link REDD+ interventions to drivers in their readiness plans: implications for monitoring systems. Environmental Research Letters, 9, 074004

Pratihast, A.K., Herold, M., De Sy, V., Murdiyarso, D., Skutsch. M., 2013. Linking community-based and national REDD+ monitoring: A review of the potential. Carbon Management, 4, 91-104

De Sy, V., Schoorl, J.M., Keesstra, S.D., Jones, K.E., Claessens, L., 2013. Landslide model performance in a high resolution small-scale landscape. Geomorphology, 190, 73-81

De Sy, V., Herold, M., Achard, F., Asner, G.P., Held, A., Kellndorfer, J., Verbesselt, J., 2012. Synergies of multiple remote sensing data sources for REDD+ monitoring. Current Opinion in Environmental Sustainability, 4, 696-706

Hosonuma, N., Herold, M., De Sy, V., De Fries, R.S., Brockhaus, M., Verchot, L., Angelsen, A., Romijn, E., 2012. An assessment of deforestation and forest degradation drivers in developing countries. Environmental Research Letters, \%, 044009 


\section{Other publications}

Kissinger, G., Herold, M., De Sy, V., 2012. Drivers of deforestation and forest degradation: a synthesis report for REDD+ policy makers. Lexeme Consulting, Vancouver, Canada

Mora, B., Herold, M., De Sy, V., Wijaya, A., Verchot, L., Penman, J. (eds), 2012. Capacity development in national forest monitoring: Experiences and progress for $R E D D+$. CIFOR, Bogor, Indonesia

De Sy, V., Herold, M., Wijaya, A., Verchot, L.V., Lindquist, E., Achard, F., 2013. Multiple remote sensing data sources for REDD+ monitoring. In Living Planet Symposium, 9-13 September 2013, Edinburgh, UK

De Sy, V., Herold, M., 2014. Monitoring drivers for REDD+: status and options. In 2nd GLP open Science Meeting, 19-21 March 2014, Berlin, Germany

De Sy, V., Herold, M., Achard, F., Beuchle, R., Besnard, S., Clevers, J., Lindquist, E., Verchot, L., Wijaya, A, 2015. Drivers of deforestation in REDD+ countries: Results from a pan-tropical remote sensing analysis. In Our common Future Under Climate Change conference, 7-10 July, Paris, France 


\section{Short biography}

Veronique De Sy was born in Mol, Belgium on 28 April, 1980. She grew up in Heusden-Zolder where she followed secondary school at the Sint-Fransicus college.

Veronique completed her Master of Science in Rehabilitation Sciences and Physiotherapy at Ghent University in 2002, and went on to work as a physiotherapist in private practices and hospitals in Langdorp and Ghent.

In 2004 she started a Bachelor of Science in International Land and Water Management at Wageningen University. In this BSc program she successfully completed an internship in the Philippines, working with a local NGO "Binhi Sang Kauswagan" to study the adoption of Soil and Water Conservation technology in small upland communities.

Veronique completed her Master of Science in International Land and Water Management at Wageningen University in 2010. Her major MSc thesis was about "Spatial modelling of windbreak effects on wind erosion in South Patagonia, Argentina". Veronique spend some time of her master studies as a student-assistant where she developed an interactive database to integrate physical-hydrological and political-social research data of the Sustainable Land \& Water Management course in Spain of the Land Degradation and Development Group and the Irrigation and Water Engineering Group. Later she joined the Land Degradation and Development Group as a Junior Researcher.

In 2011 Veronique joined the Laboratory of Geo-Information Science and Remote Sensing of Wageningen University as a $\mathrm{PhD}$ candidate. Her $\mathrm{PhD}$ thesis is entitled: "Remote sensing of land use and carbon losses following tropical deforestation". Her PhD was part of the "Global comparative study on REDD+" of the Center for International Forestry Research (CIFOR) and explored the role of remote sensing for monitoring tropical forests for REDD+ in general, and for assessing 
land use and related carbon emissions linked to drivers of tropical deforestation in particular.

Veronique's current research interests are related to the drivers and spatial dynamics of land use (change) processes in the context of the sustainable development goals such as food security, sustainable management of natural resources and climate change. 


\section{PE\&RC Training and Education Statement}

With the training and education activities listed below the $\mathrm{PhD}$ candidate has complied with the requirements set by the C.T. de Wit Graduate School for Production Ecology and Resource Conservation (PE\&RC) which comprises of a minimum total of $32 \operatorname{ECTS}$ (= 22 weeks of activities)

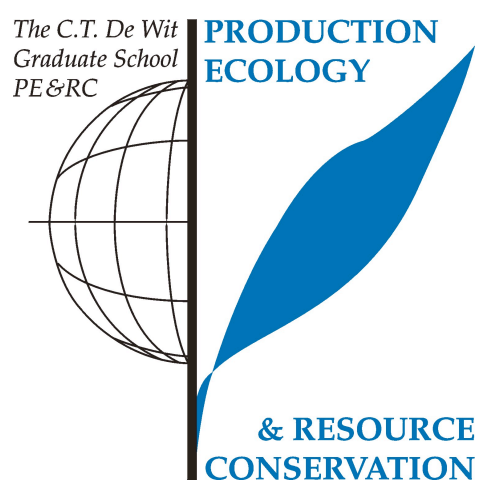

Review of literature (6 ECTS)

- Synergies of multiple remote sensing data sources for REDD+ monitoring

Writing of project proposal (4.5 ECTS)

- Monitoring tropical forests for REDD+: a comparative assessment

Post-graduate courses (3.6 ECTS)

- Introduction to R for statistical analysis; PE\&RC (2012)

- REDD+ Science and governance: opportunities and challenges; REDD@WUR, PE\&RC (2012)

- Geostatistics; PE\&RC (2013)

Laboratory training and working visits (4.5 ECTS)

- REDD+ and drivers of deforestation and forest degradation; CIFOR, Bogor, Indonesia (2013) 
Invited review of (unpublished) journal manuscript (2 ECTS)

- ECOSUST: lessons learned from the first generation of REDD+ activities (2012)

- Journal of Environmental Management: spatial scale and the forest transition model (2015)

Competence strengthening / skills courses (1.8 ECTS)

- Competence assessment; WGS (2012)

- Techniques for writing and presenting a scientific paper; WGS (2014)

- Pump your career; NWO (2015)

- Last stretch of PhD: PE\&RC (2015)

PE\&RC Annual meetings, seminars and the PE\&RC weekend (1.2 ECTS)

- PE\&RC PhD Weekend (2012)

- PE\&RC Day (2014)

Discussion groups / local seminars / other scientific meetings (5 ECTS)

- Remote sensing thematic group meeting (2011-2015)

- Climate change \& soil-water-atmosphere interactions (2012-2014)

- REDD Discussion group (2012-2015)

- UNFCCC Subsidiary Body for Scientific and Technological Advice (SBSTA); Bonne, Germany (2012-2015))

International symposia, workshops and conferences (11.9 ECTS)

- REDD+ Science + Governance symposium; Wageningen, the Netherlands (2012)

- GOFC-GOLD/CIFOR workshop: stepwise approaches for national forest monitoring and REDD+ MRV capacity development; Wageningen, the Netherlands (2012)

- ESA Living planet symposium; Edinburgh, United Kingdom (2013)

- REDD+ Exchange; Oslo, Norway (2013)

- UNFCCC COP 20 side event: assessing the potential for community monitoring in REDD+; Lima, Peru (2014)

- Global landscape forum (CIFOR); Lima, Peru (2014)

- 36th International Symposium on Remote Sensing of Environment (ISRSE); Berlin, Germany (2015)

- Our common future under climate change; Paris, France (2015)

- Global landscape forum (CIFOR); Paris, France (2015) 


\section{Supervision of MSc students (3 ECTS)}

- Simon Besnard: Pan-tropical analysis of deforestation drivers using global land cover products and the role of deforestation drivers in global gross carbon emissions for 1990-2000-2005 time period (2015) 



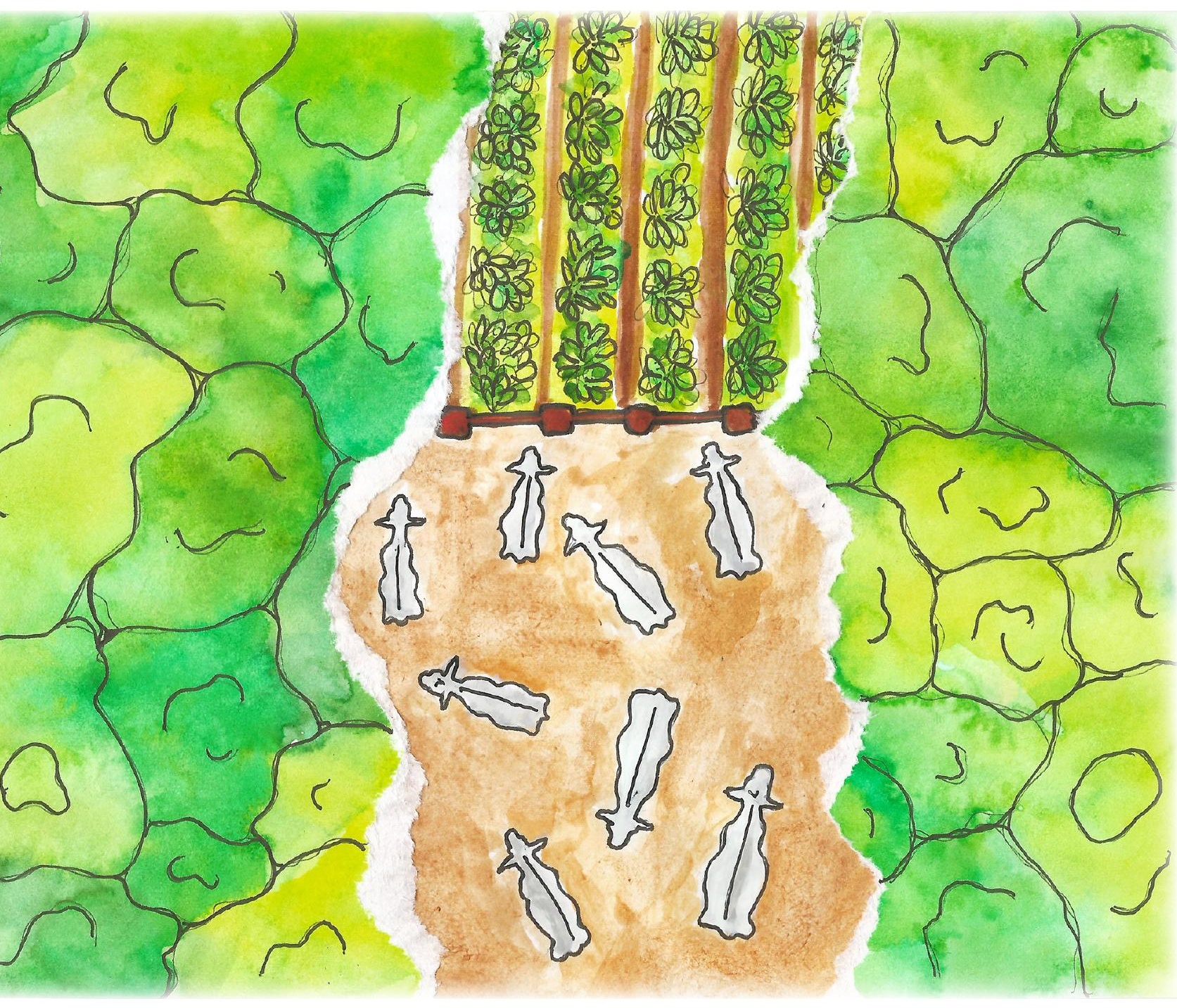

